\title{
Sexuality and Intellectual Disability : Implications for sex education
}

Citation for published version (APA):

Schaafsma, D. (2013). Sexuality and Intellectual Disability : Implications for sex education. [Doctoral Thesis, Maastricht University]. Datawyse / Universitaire Pers Maastricht. https://doi.org/10.26481/dis.20131010ds

Document status and date:

Published: 01/01/2013

DOI:

$10.26481 /$ dis.20131010ds

Document Version:

Publisher's PDF, also known as Version of record

\section{Please check the document version of this publication:}

- A submitted manuscript is the version of the article upon submission and before peer-review. There can be important differences between the submitted version and the official published version of record.

People interested in the research are advised to contact the author for the final version of the publication, or visit the DOI to the publisher's website.

- The final author version and the galley proof are versions of the publication after peer review.

- The final published version features the final layout of the paper including the volume, issue and page numbers.

Link to publication

\footnotetext{
General rights rights.

- You may freely distribute the URL identifying the publication in the public portal. please follow below link for the End User Agreement:

www.umlib.nl/taverne-license

Take down policy

If you believe that this document breaches copyright please contact us at:

repository@maastrichtuniversity.nl

providing details and we will investigate your claim.
}

Copyright and moral rights for the publications made accessible in the public portal are retained by the authors and/or other copyright owners and it is a condition of accessing publications that users recognise and abide by the legal requirements associated with these

- Users may download and print one copy of any publication from the public portal for the purpose of private study or research.

- You may not further distribute the material or use it for any profit-making activity or commercial gain

If the publication is distributed under the terms of Article $25 \mathrm{fa}$ of the Dutch Copyright Act, indicated by the "Taverne" license above, 


\title{
Sexuality and Intellectual Disability
}

\author{
Implications for sex education
}




\section{COLOPHON}

The research presented in this dissertation was conducted at the Gouverneur Kremers Centrum (GKC) Maastricht University. The project was carried out in collaboration with, and with the financial support of Lunet zorg.
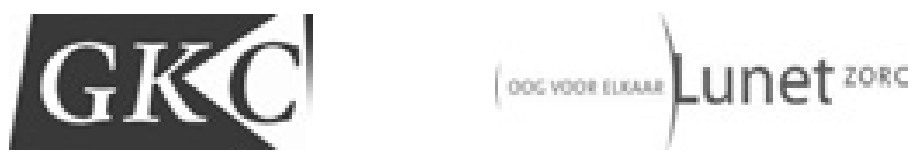

Cover design: Jornie Rinia \& Dilana Schaafsma (based on artwork by Marlies, p. 6)

Layout: Dilana Schaafsma

Artwork: Artclub Maasveld: Jo, Marlies, Ria, Jet, Isabel, Romij, Mia, Vivian \& WS

Illustrations: Remko Rinia

Production: Datawyse | Universitaire Pers Maastricht

ISBN: 9789461592491

\section{(C) 2013 Dilana Schaafsma, Maastricht}

All rights reserved. No parts of this thesis may be reproduced or transmitted in any form or by any means, electronic or mechanical, including photocopy, recording or any other information storage or retrieval system, without permission in writing from the author, or, when appropriate, from the publishers holding the copyright of the published articles. 


\title{
Sexuality and Intellectual Disability
}

\author{
Implications for sex education
}

\section{PROEFSCHRIFT}

ter verkrijging van de graad van doctor aan de Universiteit Maastricht, op gezag van de Rector Magnificus, Prof. dr. L.L.G. Soete, volgens het besluit van het College van Decanen, in het openbaar te verdedigen op 10 oktober 2013 om 10 uur.

$$
\text { door }
$$

Dilana Schaafsma

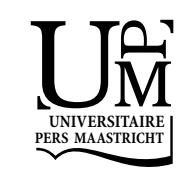




\section{Promotores:}

Prof. dr. L.M.G. Curfs

Prof. dr. G. Kok

\section{Beoordelingscommissie:}

Prof. dr. R.A.C. Ruiter (voorzitter)

Prof. dr. J.J.D.M. van Lankveld (Open Universiteit)

Prof. dr. H.H.W. van den Borne

Dr. L. Löfgren-Mårtenson (Malmö University)

Dr. M.A. Maaskant 


\section{Table of contents}

$\begin{array}{lll}\text { Chapter } 1 \text { General Introduction } & 7\end{array}$

Chapter 2 Exploring the development of existing sex education 17 programs for people with intellectual disabilities: An Intervention Mapping approach

Chapter 3 Identifying the important determinants of teaching sex education to people with intellectual disabilities: A crosssectional survey among paid care staff

Chapter 4 People with intellectual disabilities about sexuality: important implications for the development of sex education

Chapter 5 Identifying effective methods for teaching sex education to people with intellectual disabilities: a systematic review

Chapter 6 General Discussion

References 125

Summary

Samenvatting 137

Eenvoudige samenvatting

Dankwoord 157

Curriculum Vitae 


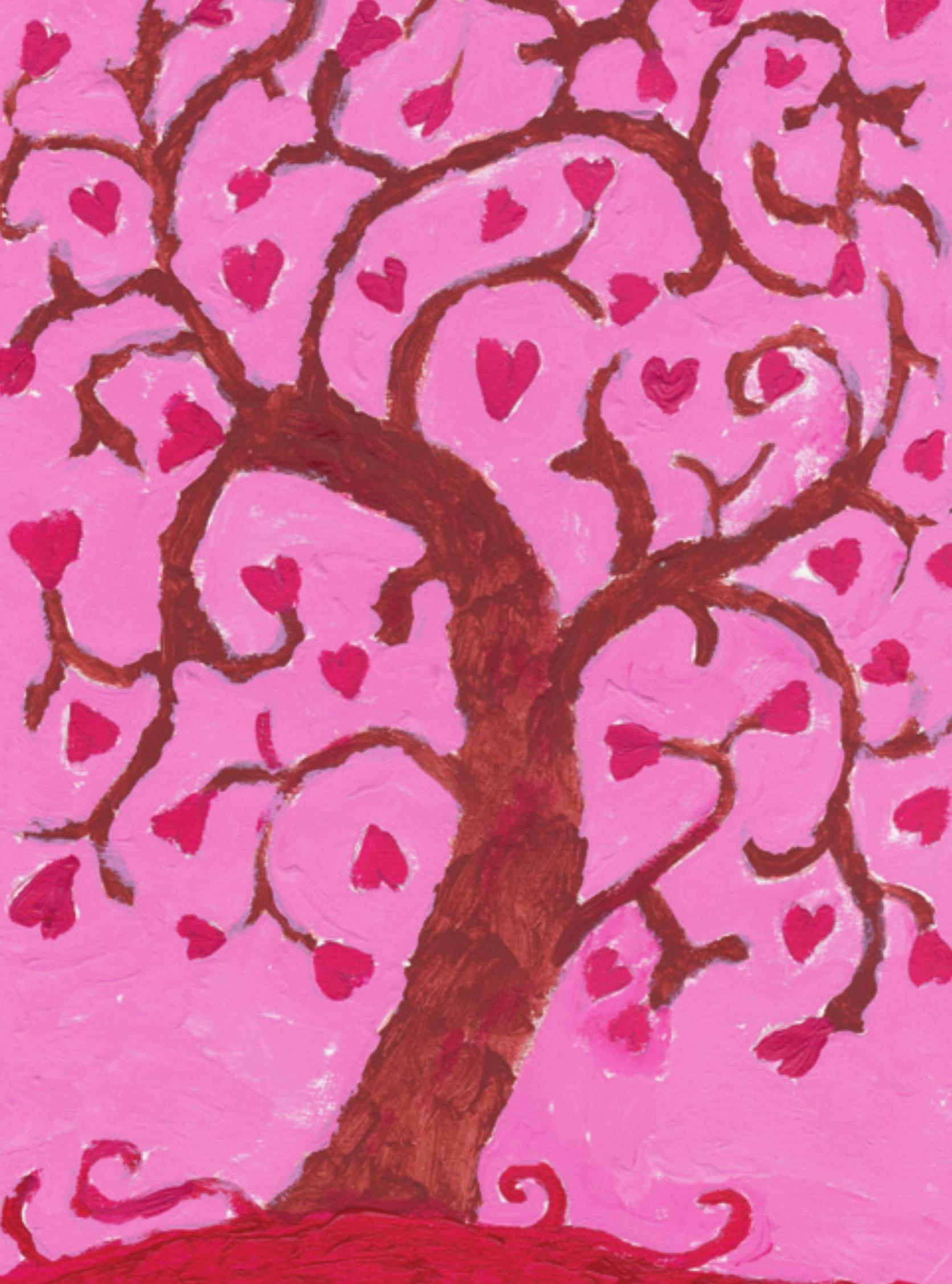


Chapter 1:

General Introduction 


\section{General introduction}

This chapter describes the importance of sex education for people with intellectual disabilities by providing a summary of the most common issues concerning their sexual health.

\section{Sexual health of people with intellectual disabilities}

"Sexual Health is a state of physical, emotional, mental and social well-being in relation to sexuality; it is not merely the absence of disease, dysfunction or infirmity. Sexual health requires a positive and respectful approach to sexuality and sexual relationships, as well as the possibility of having pleasurable and safe sexual experiences, free of coercion, discrimination and violence. For sexual health to be attained and maintained, the sexual rights of all persons must be respected, protected and fulfilled" (WHO, 2006). This means that all persons, including people with intellectual disabilities have the right to lead a sexually healthy and sexually fulfilling life. Moreover, people with intellectual disabilities ${ }^{1}$ also express the need and desire to form relationships, have sexual contacts and attain sexual knowledge (Kelly et al., 2009; Konstantareas \& Lunsky, 1997; McCabe, 1999a; Siebelink et al., 2006) and are in that respect not different from non-disabled people.

\section{Issues concerning the sexual health of people with intellectual disabilities}

The situation regarding the sexual health of people with intellectual disabilities is far from ideal at this moment ${ }^{2}$. People with intellectual disabilities regularly report incidences of sexual abuse (Eastgate et al., 2011; McCarthy, 1996; Stoffelen et al., 2013; Yacoub \& Hall, 2009) and have been shown to run a greater risk for being sexually abused than their non-disabled peers; which can be up to three times as high (Reiter et al., 2007; Van Berlo et al., 2011; Rapport commissie Samson, 2012). The perpetrators are usually people in their environment: peers, staff members or family members (Lesseliers, 1999; Van Berlo et al., 2011). People with intellectual disabilities who have experienced sexual abuse more often suffer from mental health problems such as depression and anxiety symptoms, than people with intellectual disabilities who did not have such experiences (Sequeira et al., 2003).

Additionally, the sexual experiences that are not related to sexual abuse, such as intercourse, seem to be limited compared to their non-disabled peers (Leutar \&

\footnotetext{
1 Intellectual disability is characterized by significant limitations both in intellectual functioning and adaptive behaviors as expressed in conceptual, social, and practical adaptive skills. This disability originates before age 18 .

2 The group of people with an intellectual disability that is referred to in this dissertation mainly consists of people with a mild intellectual disability (IQ level between 50 and 70).
} 
Mihokovic, 2007; McCabe, 1999a; Siebelink et al., 2006). They do report to have experiences with friendship, kissing, cuddling and holding hands (Leutar \& Mihokovic, 2007; Siebelink et al., 2006). Other sexual expressions are not allowed by parents (Lesseliers, 1999) or discouraged by relatives or staff members (LöfgrenMårtenson, 2004).

Moreover, specific issues regarding women have been identified. For example, many women with intellectual disabilities do not seem to associate sex with something pleasurable (Bernert \& Ogletree, 2013; Fitzgerald \& Withers, 2011; McCarthy, 1999; Shandra \& Chowdhury, 2012) and tend to play a rather passive role in sex (Fitzgerald \& Withers, 2011; McCarthy, 1999). Women are also most likely to experience feelings of guilt and depression after sex (Shandra \& Chowdhury, 2012). This might explain why these women do not see themselves as sexual beings, despite having sexual experiences (Fitzgerald \& Withers, 2011), and think sex is only for procreation (Bernert \& Ogletree, 2013).

The problems do not only exist in the area of sexual experiences; people with intellectual disabilities also experience difficulties in finding, forming and maintaining relationships, both friendships as sexual relationships (Abbott \& Burns, 2007; Abbott \& Howarth, 2007). The inability to form healthy and enjoyable relationships has a negative impact on their sexual health.

\section{Individual level}

A number of factors, described in the literature, contribute to the problems regarding the sexual health of people with intellectual diabilities. These factors can be found on both the individual and the environmental level. First of all, having an intellectual disability signifies limitations in both intellectual functioning and in adaptive behavior such as conceptual, social and practical adaptive skills (Schalock et al., 2012; Schalock et al., 2010). This negatively influences attainability of knowledge and skills that are beneficial for sexual health. It is therefore not surprising that people with intellectual disabilities show low levels of knowledge regarding sexuality-related topics such as masturbation, pregnancy, safe sex, reproduction and same-sex relationships (Healy et al., 2009; Kelly et al., 2009; Lesseliers, 1999; Leutar \& Mihokovic, 2007; McCabe, 1999a; McCarthy, 2009; Murphy \& O'Callaghan, 2004) compared tot non-disabled people (McCabe et al., 1999b), and demonstrate low levels of social, behavioral and decision-making skills (EgemoHelm et al., 2007; Hayashi et al., 2011; Khemka et al., 2005; Miltenberger, 1999). Low levels of knowledge impede the recognition of sexual abuse situations, safe sex practices or the development of positive attitudes towards sexuality. A review by Bruder and Kroese (2005) showed that knowledge alone does not change behavior, the necessary skills to perform the correct behavior are also important.

Regarding the topic of homosexuality, it seems that not only knowledge on the topic is limited, but the attitudes towards homosexuality also tend to be negative 
(Konstantareas \& Lunsky, 1997; Leutar \& Mihokovic, 2007; Murphy \& O'Callaghan, 2004; Siebelink et al., 2006; Stoffelen et al., 2013). This might explain why people with intellectual disabilities, who are homosexual, experience loneliness, isolation and negative reactions regarding their sexuality (Abbott \& Burns, 2007; Stoffelen et al., 2013).

\section{Environmental level}

The intellectual disability alone does not explain the low levels of sexual knowledge and skills. Many of the problems that greatly influence the sexual health of people with intellectual disabilities are situated in their environment. One of these factors might be the absence or low frequency of sex education. Research shows that people with intellectual disabilities receive less sex education (Levy \& Packman, 2004; McCabe et al., 1999b; Murphy \& O'Callaghan, 2004) or find it difficult to remember whether they have received sex education (Löfgren-Mårtenson, 2011). So why do they receive less sex education, while it is known that they have problems understanding and attaining knowledge and possess low levels of conceptual, social and practical adaptive skills? Even though attitudes towards the sexuality of people with intellectual are becoming more positive (Christian et al., 2001; Cuskelly \& Bryde, 2004; Cuskelly \& Gilmore, 2007; Lafferty et al., 2012; Rohleder \& Swartz, 2009) sexuality is still a topic of taboo (Bernert \& Ogletree, 2013; LöfgrenMårtenson, 2004; McCabe, 1999a; Rohleder \& Swartz, 2010); which might explain why family members and staff members, who provide support to people with intellectual disabilities, do not initiate conversation about the subject (Abbott \& Howarth, 2007; Kok et al., 2009) or are unprepared to deal with sexual issues (HowardBarr et al., 2005). Some do not feel comfortable to talk about sexuality, because they do not know how to start the conversation; an important factor is lack of training (Lafferty et al., 2012). Moreover, staff and family members primarily encourage friendship instead of sexual relationships (Healy et al., 2009; Kelly et al., 2009; Löfgren-Mårtenson, 2004) or staff members feel a pressure to limit the sexual expression of their clients (Lafferty et al., 2012). Additionally, parents or staff members might be reluctant to teach sex education because they want to protect people with intellectual disabilities because they are vulnerable, (Lafferty et al., 2012) and might hold beliefs such as that teaching sex education might actually cause harm or lead to unwanted sexual behavior (Rohleder, 2010). This might explain the fact that when sex education is taught, it is usually taught reactively in response to problems, rather than as a tool to prevent problems and proactively support people with intellectual disabilities (Abbott \& Burns, 2007; Abbott \& Howarth, 2007).

Parents and staff members also influence the sexual experiences of people with intellectual disabilities. Their experiences are limited due to lack of privacy given by staff or family members (Evans et al., 2009; Healy et al., 2009). Where 
sexual experiences are normally private, they often become public, due to the large involvement of staff and family members, but also due to a lack of private space (Löfgren-Mårtenson, 2004). For example, in a study by Lesseliers (1999) it was shown that couples were never left alone and therefore unable to experiment sexually. Moreover, caregivers also tend to judge the quality and sexual expressions within the relationship of the person with intellectual disabilities (LöfgrenMårtenson, 2004). Additionally, it was found in both Belgium and Sweden that most staff members are usually female and they tend to enforce more restrictive rules regarding sexual expressions (Lesseliers, 1999; Löfgren-Mårtenson, 2004).

In conclusion, caregivers, both parents as staff members, have a great impact on the sexual experiences of and provision of sex education to people with intellectual disabilities. It would therefore make sense, when trying to improve the sexual health of people with intellectual disabilities, to focus on both the individual as the environmental level.

\section{Intervention Mapping}

The sexual knowledge, attitudes towards sexuality, and sexuality-related skills of people with intellectual disabilities can be improved by providing them proper sex education. Moreover, a high quality sex education program should also focus on positively changing environmental factors (Kok et al., 2008) such as the knowledge, attitudes and skills of educators regarding sex education or the policy on sexuality. Important is that such a program is developed systematically using a theory- and evidence-base. Programs which are developed using a theory- and evidence base are more likely to be effective than programs who do not use a theory- and evidence-base. Intervention Mapping is a protocol that can be used for developing a program in a systematic way using theory and evidence in the process (Bartholomew et al., 2011). The protocol consists of six steps (Figure 1): 1) needs assessment, 2) specifying program outcomes, 3) selecting theory- and evidence-based intervention methods and practical applications, 4) designing and organizing the program, 5) specifying adoption and implementation plans, and 6) generating an evaluation plan. These steps are not necessarily taken sequentially, but program developers will usually go back and forth throughout the development process.

In the first step, the needs assessment, the problem for which a program should be developed, is analyzed. In this step, program developers explore the groups involved in or impacted by the problem, the behaviors related to the problem, environmental factors influencing the problem (Kok et al., 2008), and the relevant psycho-social determinants. This information is obtained by reviewing the literature on the topic and combining this with additional qualitative and/ or quantitative research to fill in the gaps. A qualitative technique that is being explored for eliciting responses in our particular target population, people with intel- 
lectual disabilities, is the Nominal Group technique (Tuffrey-Wijne et al., 2007). After the analyses have been carried out, adequate decisions can be made for prioritizing behaviors, environmental conditions, and their determinants for change.

\begin{tabular}{|c|c|c|}
\hline & $\begin{array}{l}\text { Step } 1 \\
\text { Needs assessment }\end{array}$ & $\begin{array}{l}\text { - Establish a participatory planning group } \\
\text { - Conduct the needs assessment } \\
\text { - Asses community capacity } \\
\text { - Specify program goals for health and quality of life }\end{array}$ \\
\hline & $\begin{array}{l}\text { Step } 2 \\
\text { Matrices }\end{array}$ & $\begin{array}{l}\text { - State outcomes for behavior and environmental change } \\
\text { - State performance objectives } \\
\text { - Select important and changeable determinants } \\
\text { - Create a matrix of change objectives }\end{array}$ \\
\hline & $\begin{array}{l}\text { Step } 3 \\
\text { Theory-based } \\
\text { intervention } \\
\text { methods and } \\
\text { practical applications }\end{array}$ & $\begin{array}{l}\text { - Generate program ideas with the planning group } \\
\text { - Identify theoretical methods } \\
\text { - Choose program methods } \\
\text { - Select or design practical applications } \\
\text { - Ensure that applications address change objectives }\end{array}$ \\
\hline \multirow{3}{*}{ Evaluation } & $\begin{array}{l}\text { Step } 4 \\
\text { Intervention program }\end{array}$ & $\begin{array}{l}\text { - Consult with intended participants and implementers } \\
\text { - Create program themes, scope, sequence, and materials list } \\
\text { - Prepare design documents } \\
\text { - Review available program materials } \\
\text { - Draft program materials and protocols } \\
\text { - Pretest program materials and protocols } \\
\text { - Produce materials and protocols }\end{array}$ \\
\hline & $\begin{array}{l}\text { Step } 5 \\
\text { Adoption and } \\
\text { Implementation }\end{array}$ & $\begin{array}{l}\text { - Identify potential adopters and implementers } \\
\text { - Reevaluate the planning group } \\
\text { - State program use outcomes and performance objectives } \\
\text { - Specify determinants for adoption and implementation } \\
\text { - Create a matrix of change objectives } \\
\text { - Select methods and practical applications } \\
\text { - Design interventions for adoption and implementation }\end{array}$ \\
\hline & $\begin{array}{l}\text { Step } 6 \\
\text { Evaluation Plan }\end{array}$ & $\begin{array}{l}\text { - Review the program logic model } \\
\text { - Write effect evaluation questions } \\
\text { - Write evaluation questions for changes in the determinants } \\
\text { - Write process evaluation questions } \\
\text { - Develop indicators and measures } \\
\text { - specify evaluation design }\end{array}$ \\
\hline
\end{tabular}

Figure 1. An overview of the Intervention Mapping protocol (Bartholomew et al., 2011).

In the second step, program developers determine the expected behavioral and environmental outcomes of the program, which are based on theory, evidence 
and input from relevant groups, such as members of the target population and implementers. When formulating these program outcomes, it is important to state what the target group needs to learn and do as a result of the program. Also in this step, change objectives are formulated. These change objectives link the determinants that need to be changed to specific and realistic performance objectives for the desired behavioral and environmental outcomes (i.e. the goals of the program).

In the third step, program developers select theory- and evidence-based methods that can be used to change the psycho-social determinants of the behaviors that were identified in the first step and converted into objectives in the second step. These methods are only effective under certain circumstances, called parameters for use. The parameters for use must be met in order for the method to be effective. The methods subsequently need to be translated into practical applications, which are actual materials and activities that fit the specific target group and the context of the program. It is important to involve program implementers and members of the target group in the selection of the theoretical methods and practical applications.

In the fourth step, all of the components that have been developed are integrated to make one coherent program. Plans are made for pilot-testing and the production of materials. Again, it is imperative that members of the target group are involved in the development and testing of the materials.

In the fifth step, the program is implemented. This fifth step starts as soon as it is clear who the implementers of the program will be; which will most likely be during the needs assessment. It is necessary in this step to determine how the program can be efficiently realized on a larger scale. Involvement of the intended program implementers and implementation decision-makers (e.g. agents involved in policy-making) is crucial in this process, as they can offer insight regarding not only how program implementers can be motivated to carry out the program, but also what kind of support is needed during the implementation process.

The final step of Intervention Mapping entails developing an evaluation plan. This involves assessing whether the measurable objectives, stated in the second step, have been met. The evaluation plan is anticipated from the beginning of the development process.

\section{Dissertation outline}

The studies that have been conducted in this PhD project were aimed at gathering scientific evidence for improving future development of sex education programs for people with intellectual disabilities, using Intervention Mapping (Bartholomew et al., 2011) as a guideline.

Chapter 2 describes a study that was conducted to identify existing sex education programs geared towards people with intellectual disabilities in the Netherlands. The goal was to utilize what is learned from these programs in the future 
development of sex education materials. The program developers of five sex education programs were interviewed, using Intervention Mapping as a guideline. This is an important first step to take before developing new program materials, because it would be wasteful to ignore existing knowledge.

Chapter 3 describes a cross-sectional survey conducted among 163 paid care staff members, who work for an organization specialized in the care for people with intellectual disabilities. This study was conducted, because paid care staff members might be suitable for providing sex education to people with intellectual disabilities. However, previous studies describe a number of barriers regarding sex education taught by paid care staff. It was therefore important to find out if they are a suitable population to teach sex education by identifying factors that influence whether staff members teach sex education to their clients with intellectual disabilities or not.

Chapter 4 presents the views of twenty people with intellectual disabilities on sexuality-related topics such as sex education, homosexuality, relationships, sex, parenthood, social media, negative experiences and support. This study was conducted because up until now people with intellectual disabilities have not been involved in the development of sex education materials. Consequently, the views of people with intellectual disabilities have not been examined in the context of sex education.

Chapter 5 presents the findings of a review that has been conducted to identify effective methods for teaching sex education to people with intellectual disabilities. Many existing sex education programs lack a theory- and evidence-base, making it very important for future development of sex education programs to identify which theoretical methods are effective in teaching sex education.

Finally, chapter 6 summarizes and discusses the major findings of the four studies. Moreover, it discusses the implications for future research, sex education program development and professionals working in the field of intellectual disabilities. 



\section{Chapter 2:}

Exploring the development of existing sex education programs for people with intellectual disabilities: An Intervention Mapping approach

Schaafsma, D., Stoffelen, J. M. T., Kok, G., \& Curfs, L. M. G. (2013). Exploring the development of existing sex education programs for people with intellectual disabilities: an Intervention Mapping approach. Journal of Applied Research in Intellectual Disabilities, 26, 157-166. doi:10.11 11/jar.12017 


\section{Abstract}

Background People with intellectual disabilities face barriers that affect their sexual health. Sex education programs have been developed by professionals working in the field of intellectual disabilities with the aim to overcome these barriers. The aim of this study was to explore the development of these programs.

Methods Sex education programs geared to people with intellectual disabilities were examined in the context of the Intervention Mapping protocol. Data were obtained via interviews with the program developers.

Results All programs lack specific program outcomes, do not have a theoretical basis, did not involve members of relevant groups in the development process, and lack systematic evaluation.

Conclusions Based on our findings and the literature, we conclude that these programs are unlikely to be effective. Future programs should be developed using a more systematic and theory- and evidence-based approach. 


\section{Introduction}

In the past two decades more knowledge has become available on how to develop better health promotion programs. This influences how we develop sex education programs nowadays. We now know that providing people only with information will not make them change their behavior. Behavior is also influenced by other determinants, like our attitude towards the behavior, our confidence about performing the behavior (self-efficacy), and how the behavior is perceived by others (social norms) (Kirby \& Laris, 2009; Schaalma et al., 2004).

People with intellectual disabilities, face challenges in the area of sexuality that might differ from the challenges their non-disabled peers face. For example, people with intellectual disabilities tend to be less informed about sexuality, have fewer sexual experiences, have more negative attitudes toward sexual activities, and have more experience with sexual abuse, often as victims, than those without intellectual disabilities (McCabe, 1999a; Murphy \& O'Callaghan, 2004; Servais, 2006). These problems affect their sexual health and, consequently, their quality of life. Studies have shown that sex education can influence important determinants, such as social or behavioral skills (Egemo-Helm et al., 2007; Hayashi et al., 2011; Miltenberger, 1999), decision making skills (Khemka et al., 2005) and knowledge (Lindsay et al., 1992; McDermott et al., 1999) in a positive way.

The aim of our study was to explore the development of existing sex education programs. Sex education programs have been developed by professionals who work in the field of intellectual disability to provide paid care staff and parents a tool for improving the sexual health of people with intellectual disabilities. Little is known regarding how these sex education programs are developed and how effective they are. Interviews were held with the developers of the programs. Intervention Mapping (Bartholomew et al., 2011) was used as a guideline.

Intervention Mapping provides a systematic framework to the development of theory- and evidence-based programs (Bartholomew et al., 2011). Intervention Mapping describes the process of program development in six steps: 1) needs assessment, 2) specifying program outcomes, 3) selecting theory- and evidencebased intervention methods and practical applications, 4) designing and organizing the program, 5) specifying adoption and implementation plans, and 6) generating an evaluation plan.

In the first step, the needs assessment, the problem for which a program should be developed is analyzed. In this step, program developers explore the groups involved or impacted by the problem, the behaviors related to the problem, environmental factors influencing the problem, and the relevant psycho-social determinants of the problem. This information can be obtained by doing qualitative and/ or quantitative research. A qualitative technique that is being explored for eliciting responses in our particular target population, people with intellectual disabilities, is the Nominal Group technique (Tuffrey-Wijne et al., 2007). After the 
analyses have been carried out, adequate decisions can be made for prioritizing behaviors, expected outcomes, environmental conditions, and their determinants for change.

In the second step, program developers determine the expected outcomes of the program, which are based on theory, evidence and input from relevant groups, like members of the target population and implementers. When formulating these program outcomes, it is important to state what the target group needs to learn and do as a result of the intervention. Also in this step, change objectives are formulated. These change objectives link the determinants that need to be changed to specific and realistic performance objectives for the desired behavioral and environmental outcomes.

In the third step, program developers select theory- and evidence-based methods that can be used to change the psycho-social determinants of the behaviors that were identified in the first step and converted into outcomes in the second step. All conditions for the method must be met in order for it to be effective. The methods subsequently need to be translated into practical applications, which are actual materials and activities that fit the specific target group and the context of the intervention. It is important to involve program implementers and members of the target group in the selection of the theoretical methods and practical applications.

In the fourth step, all of the components that have been developed are put together to make one coherent program. Plans are made for pilot-testing and the production of materials. Again, it is imperative that members of the target group are involved in the development and testing of the materials.

In the fifth step, the program is implemented. This fifth step starts as soon as it is clear who the implementers of the program will be. It is necessary, in this step, to determine how the program can be efficiently realized on a larger scale. Involvement of the intended program implementers and implementation decisionmakers (e.g. agents involved in policy-making) is thus crucial in this process, as these people can offer insight regarding not only how program implementers can be motivated to carry out the intervention but also what kind of support is needed during the implementation process.

The final step of Intervention Mapping entails developing an evaluation plan. This involves assessing if the measurable outcomes stated in the second step have been met.

The adaptation of the Intervention Mapping protocol, which was used for this study, can be found in Table 1. 
Table 1. Adaptation of the Intervention Mapping process for the interviews.
Needs assessment
1. Give a description of the problem or problem behavior.
2. Which factors influence the problem?
3. Give a description of the target group(s) of the program

\section{Program outcomes}

1. Which behaviors and environmental conditions need to be changed in order to improve quality of life.

2. Were the changes formulated in terms of outcomes? And what are the outcomes?

3. While formulating the outcomes, have changeable factors been taken into account?

\section{Theory- and evidence-based methods and practical applications}

1. Were members of the target group involved in the development of theoretical methods and practical applications?

2. Which theoretical methods have been used and why?

\section{Program development}

1. Were members of the target group consulted about the design of the program?

2. Were the outcomes incorporated in the program? And in what way?

3. Were the materials tested before implementation?

\section{Implementation}

1. Were the program implementers and implementation decision makers involved?

2. Were potential barriers identified and taken into account? (e.g. policy, motivation, planning, education level, etc.)

\section{Evaluation}

1. Has the program been evaluated?

2. Which measurement instruments have been used?

\section{Materials and Methods}

\section{Selected sex education programs}

The sex education programs were selected if they were about sex education, targeted people with intellectual disabilities, and were currently in use in the Netherlands. We excluded programs that only focused on providing sex education in school settings and programs that focused primarily on preventing sexual abuse. A number of sources were used to retrieve information about existing sex education programs, namely the Internet, sexologists, and other professionals working with people with intellectual disabilities. In total, five sex education programs were selected for this study (Table 2).

\section{Sample}

Eleven program developers of five different sex education programs were interviewed. Two program developers of one program were interviewed separately resulting in a total of six interviews (on average $\pm 60 \mathrm{~min}$.). 
Table 2. Overview of the sex education programs described in this article.

\begin{tabular}{|c|c|c|c|c|c|}
\hline Number & Content & Receiver $^{1}$ & Giver & $\begin{array}{l}\text { Group/ } \\
\text { Individual }\end{array}$ & $\begin{array}{l}\text { Course } \\
\text { available }\end{array}$ \\
\hline 1 & $\begin{array}{l}\text { - Manual/ Workbook } \\
\text { - Four DVD’s } \\
\text { - Four story books }\end{array}$ & Mild (adults) & $\begin{array}{l}\text { Paid care staff } \\
\text { Parents }\end{array}$ & Both & No \\
\hline 2 & $\begin{array}{l}\text { - Manual } \\
\text { - Workbook } \\
\text { - Stickers }\end{array}$ & $\begin{array}{l}\text { Mild/Moderate } \\
\text { (>12 years) }\end{array}$ & $\begin{array}{l}\text { Paid care staff } \\
\text { Parents }\end{array}$ & Individual & Yes \\
\hline 3 & $\begin{array}{l}\text { - Manual } \\
\text { - CD }\end{array}$ & Mild & $\begin{array}{l}\text { Paid care staff } \\
\text { Parents }\end{array}$ & Both & Yes \\
\hline 4 & $\begin{array}{l}\text { Box: } \\
\text { - Manual } \\
\text { - Set of photographs } \\
\text { - Drawings } \\
\text { - Puzzles } \\
\text { - Set of icons }\end{array}$ & Moderate $^{2}$ & $\begin{array}{l}\text { Paid care staff } \\
\text { Parents }\end{array}$ & Individual & No \\
\hline 5 & $\begin{array}{l}\text { Box: } \\
\text { - Manual } \\
\text { - Sheets with 3D images }\end{array}$ & Mild & $\begin{array}{l}\text { Paid care staff } \\
\text { Parents }\end{array}$ & Both & Yes \\
\hline
\end{tabular}

${ }_{1}^{1}$ Level of intellectual disability (Mild: IQ 50-70; Moderate: IQ 35-50)

2 People who are supposedly not able to form a relationship

The number of people interviewed in a single interview ranged from 1 to 4 people and included a psychologist, behavioral experts, a communication expert, sexologists, and program designers. Two interviewers carried out all interviews. The program developers were approached individually by e-mail and all agreed to participate in the study.

\section{Procedure and interview topics}

In all interviews, one of the two interviewers functioned as the primary interviewer. Five of six interviews were held in a formal setting, either at the university or the institution where the participant worked. The other interview was conducted at a participant's residence. The interviews were semi-structured. Topics were derived from Intervention Mapping and were as follows: the needs assessment, the program outcomes, the theoretical methods and applications, the program development, the implementation, and the evaluation (Table 1). The participants received an overview of the topics prior to the interview so that they could prepare in advance.

\section{Data processing and analysis}

The interviews were recorded with a digital voice recorder and then transcribed. To check for and correct any missing or incorrect information, the completed tran- 
scripts were sent to the program developers for feedback. Once approved, the transcripts were imported into a software program for qualitative data analysis (NVivo 8). A coding scheme derived from the topics discussed during the interviews was employed. A second researcher then validated this coding by topic. Discrepancies between the first and second researcher were resolved through discussion and consensus. Once the topic codes were agreed upon, content was further assigned to categories that were later also validated by the second researcher. Then, the list with scores per category was sent to the program developers for verification. Of the six interviews, four were returned with feedback. The feedback was subsequently incorporated in the existing list of categories and then compiled to make up the final list of categories.

\section{Results}

Based on the data received from the interviews we divided the information about the needs assessment into two topics, problem description and determinants, and information about the theoretical methods and practical applications into theories, and theoretical methods and practical applications. Therefore, the results section consists of eight topics: problem description, determinants, program outcomes, theories, theoretical methods and practical applications, program development, implementation, and evaluation.

\section{Problem description}

During the interviews we found that program developers had trouble describing the health-related problems that were the reason for developing the program. This suggests that identifying the problem and its related factors might not be a significant part of the development process. It was mentioned that sexual abuse was a large issue within the group of people with intellectual disabilities as well as sexual problems and other problem behavior, such as sexually inappropriate behavior (Table 3). However, no specific health problems were described by the program developers.

With respect to environmental factors, it was mentioned that on the interpersonal level there was a lack of confidence in the environment to talk about sexuality and that there is a taboo on talking about sexuality. On the organizational level, lack of adequate material and lack of privacy/room were stated as problems. 
Table 3. Description of problem as stated by program developers.

\begin{tabular}{llllll}
\hline & 1 & 2 & 3 & 4 & $5^{3}$ \\
\hline Individual level & & & & & \\
Sexual abuse & $\mathrm{x}$ & $\mathrm{x}$ & - & - & - \\
Sexual Problems & - & - & - & $\mathrm{x}$ & - \\
$\begin{array}{l}\text { Other problem behavior (e.g. } \\
\text { inappropriate behavior) }\end{array}$ & - & $\mathrm{x}$ & - & $\mathrm{x}$ & - \\
$\begin{array}{l}\text { Interpersonal level } \\
\text { Taboo (in environment) }\end{array}$ & $\mathrm{x}$ & - & - & - & - \\
Lack of confidence (by staff) & $\mathrm{x}$ & - & $\mathrm{x}$ & $\mathrm{x}$ & - \\
Organizational level & & & & & \\
Lack of adequate material & $\mathrm{x}$ & - & - & $\mathrm{x}$ & - \\
Lack of privacy/ room & - & $\mathrm{x}$ & $\mathrm{x}$ & - & - \\
\hline
\end{tabular}

\section{Determinants}

When the program developers were asked to give a description of the problem, they generally gave a description of determinants influencing the problem at the individual level (Table 4). These can be divided into two types of determinants, unchangeable and changeable. Unchangeable determinants were, for example, low IQ level and low social-emotional level. And a changeable determinant was, for example, lack of knowledge concerning topics related to sexuality.

The program developers of two programs mentioned determinants on the interpersonal level, such as dependence of client on caregivers, beliefs about sexuality, and Internet access to pornography. The program developers of two other programs mentioned a determinant on the organizational level, namely the absence of policy.

\section{Program outcomes}

The outcomes described by the program developers all focus on the individual level (Table 5). Knowledge (4), tailoring (4) and empowerment (5) were the outcomes most mentioned. Knowledge stands for increasing the knowledge of people with intellectual disabilities in different areas of sexuality. With tailoring developers meant that each program had to be adjusted according to the clients' needs and wishes. Empowerment was described as teaching someone to make his or her own decisions. Teaching skills were only mentioned by the program developers of one program and so was enjoying sexuality. No outcomes on interpersonal or organizational levels were stated.

\footnotetext{
${ }^{3}$ Numbers refer to the programs in Table 1.
} 
Table 4. Description of determinants influencing the problem as stated by the program developers.

\begin{tabular}{llllll}
\hline & 1 & 2 & 3 & 4 & 5 \\
\hline Individual level & & & & & \\
Low IQ level & $\mathrm{x}$ & $\mathrm{x}$ & $\mathrm{x}$ & $\mathrm{x}$ & $\mathrm{x}$ \\
Low social-emotional level & - & $\mathrm{x}$ & $\mathrm{x}$ & $\mathrm{x}$ & - \\
Autism & - & $\mathrm{x}$ & - & - & $\mathrm{x}$ \\
Lack of sexual knowledge & $\mathrm{x}$ & $\mathrm{x}$ & $\mathrm{x}$ & $\mathrm{x}$ & $\mathrm{x}$ \\
Lack of social skills & - & $\mathrm{x}$ & $\mathrm{x}$ & - & - \\
Negative attitude & - & $\mathrm{x}$ & - & - & $\mathrm{x}$ \\
(towards their sexuality) & - & & & & \\
Vulnerable to sexual abuse & - & $\mathrm{x}$ & - & - & - \\
Interpersonal level & - & & & & - \\
Dependence client & - & $\mathrm{x}$ & - & - & - \\
Vision (on sexuality) & - & $\mathrm{x}$ & $\mathrm{x}$ & - & - \\
Internet (access to pornography) & & & & - & $\mathrm{x}$ \\
Organizational level & - & - & - & $\mathrm{x}$ & \\
Policy (absence of) & & &
\end{tabular}

Table 5. Description of program outcomes as stated by the program developers.

\begin{tabular}{llllll}
\hline & 1 & 2 & 3 & 4 & 5 \\
\hline Individual level & - & - & - & - & - \\
Knowledge & $\mathrm{x}$ & $\mathrm{x}$ & $\mathrm{x}$ & - & $\mathrm{x}$ \\
Teaching skills & - & - & $\mathrm{x}$ & - & - \\
Tailoring & $\mathrm{x}$ & - & $\mathrm{x}$ & $\mathrm{x}$ & $\mathrm{x}$ \\
Empowerment & $\mathrm{x}$ & $\mathrm{x}$ & $\mathrm{x}$ & $\mathrm{x}$ & $\mathrm{x}$ \\
Enjoying sexuality & - & - & - & - & $\mathrm{x}$ \\
\hline
\end{tabular}

\section{Theories}

Program developers were asked to describe which theories were incorporated into the program. The program developers of one program mentioned applying communication models to identify a person's communication level and the program developers of another program use the hermeneutic circle as a way to get a complete overview of a persons' history, social-emotional level, cognitive level, etc. No theories on influencing behavior or psycho-social determinants were pointed out.

\section{Theoretical methods and practical applications}

Program developers gave descriptions of practical applications they incorporated into the program and the underlying theoretical methods of these strategies were separately identified by two researchers. It was not checked if all the conditions, governing effective use of the method, were met. This section presents the theo- 
retical methods that were identified in several categories derived from Bartholomew et al. (2011)(Table 6). In the category 'basic methods at the individual level' tailoring was reported by all the program developers. Other methods used were persuasive communication (2), participation (2), active learning (2), individualization (2), modeling (1), facilitation (1), and reinforcement (1). In the 'increase knowledge' category images were mentioned by all program developers. Other methods to increase knowledge were increasing memory and understanding (2), providing cues (2), and discussion (1). In the third category 'change skills' guided practice was the most often used method (4). Other methods were goal setting (3), setting graded tasks (2), and planning coping responses (1). In the two remaining categories 'changing social influence' (1) was mentioned as a method to change self-awareness and 'social comparison' (1) was mentioned as a method to change social influence.

\section{Program development}

The program developers of one program consulted implementers, in this case paid care staff, during the development of the program. When it comes to testing the materials the program developers of one program showed the raw material to clients and paid care staff in different parts of the country. The program developers of a second program have shown visual materials to their clients and enlarged the material after receiving feedback that the size was too small. And the program developers of a third program showed their clients drawings and found that photographs were clearer to them than drawings. Furthermore, program developers indicated that people should be cautious when dealing with a client who has a history of or is currently experiencing sexual abuse.

\section{Implementation}

None of the program developers mentioned involvement of the implementation decision makers to plan implementation, while only a few barriers for implementation were indicated. First, program developers of one program mentioned that the professional caregivers' lack of confidence and norms could be of influence. Program developers of a second program mentioned time as a barrier, meaning it takes time to get familiar with the materials and methods of the program. Finally, it was mentioned that retrenchment and lack of time given by the institution could be of influence. No clear explanations were given on how to overcome these barriers. 


\section{Evaluation}

All interviewees mentioned that there was never an evaluation study conducted of their program. 


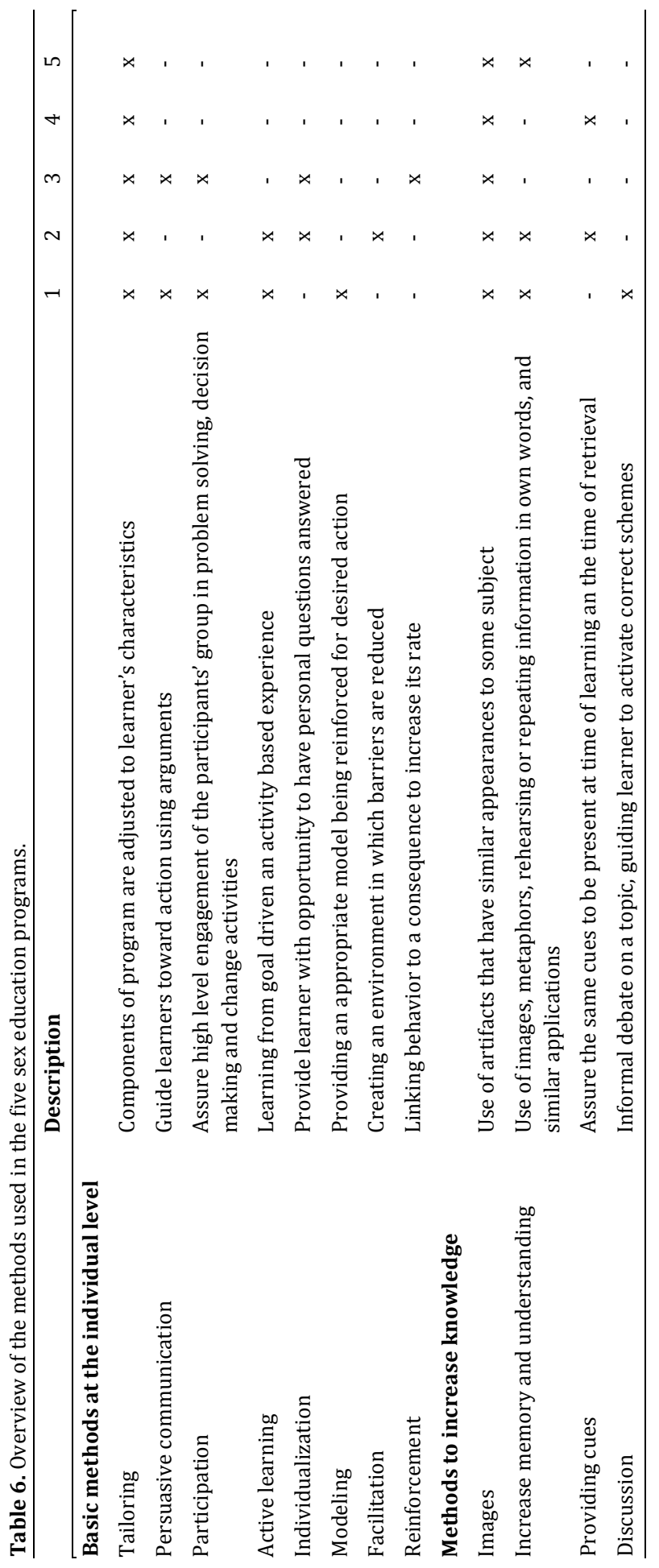




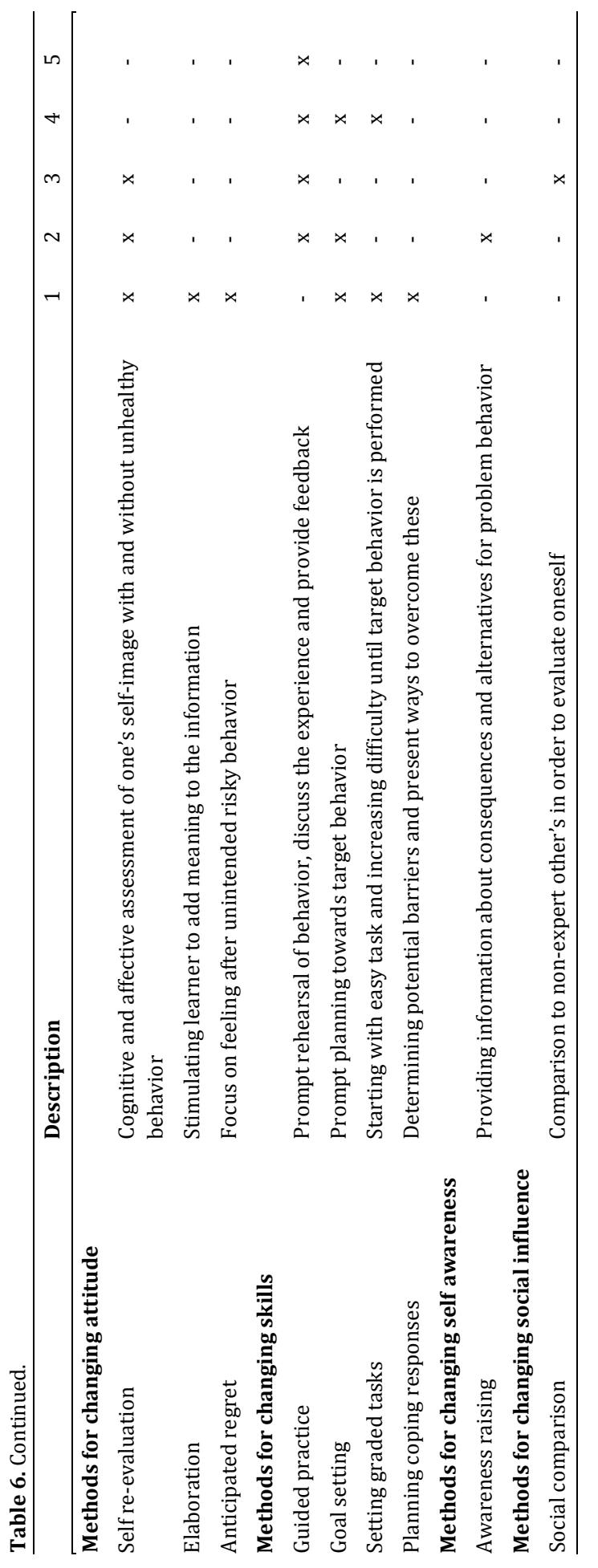




\section{Discussion}

The purpose of this study was to assess the development of sex education programs for people with intellectual disabilities, using existing sex education programs from the Netherlands as an example. The program developers who were interviewed all share the same passion to improve the sexual lives of those with intellectual disabilities and were therefore highly motivated to participate in this study. The programs described in this study are all practice based. An adaptation of the Intervention Mapping steps was used as a guideline to describe the process and to identify blank spaces and potential for improvement.

Sex education for people with intellectual disabilities may be improved in five areas. The first area is the needs assessment. Description of the problem was usually in terms of determinants instead of focusing on the health problem in terms of behavior. The determinants that were identified were predominantly on the individual level focusing on the cognitive factor, social emotional factors and amount of knowledge. Two programs mentioned determinants on the interpersonal level and two other programs mentioned determinants on the organizational level. It is clear that the problems that exist in the area of sexuality of people with intellectual disabilities have to be identified and made more explicit on behavioral level. Only then is it possible to find the related determinants on the individual and environmental levels, which are important for developing an effective program.

The second area of interest concerns the outcomes stated by the programs. The ones mentioned most were knowledge, tailoring the program to the person's need, and emancipation. Two of these outcomes, knowledge and tailoring, are represented in methods that were used; however, it was unclear how the outcome of emancipation was reflected in the methods. From the needs assessment and the outcomes stated it becomes clear that these programs are only aimed at the target group, people with intellectual disabilities. The question remains whether the outcomes stated by the program developers are specific and measurable enough. These requirements are important, because a useful evaluation study cannot be conducted if they are not met. Moreover, one should also take environmental outcomes, directed to implementers and implementation decision makers, into consideration.

The third area concerns the theoretical basis of the programs. The practical applications that are used are generally chosen based on previous positive experiences and the methods in general lack a theoretical basis, which has a large impact on the effectiveness of the program since non theory- and evidence-based programs are not as effective as theory- and evidence-based programs (Albarracín et al., 2005; Bos et al., 2008; de Bruin et al., 2010; Mullen et al., 1985; Peters et al., 2009; van Achterberg et al., 2010; van Empelen et al., 2003). The theoretical models mentioned were mostly applied for identifying a persons' level of IQ, socialemotional level or communication level. 
The fourth area concerns the involvement of the target groups, program implementers and implementation decision makers. The involvement of these groups during the developmental process was minimal. One program mentioned involvement of implementers (paid care staff), but the involvement was minimal; no involvement was mentioned of implementation decision makers. Also, the involvement of the target group (people with intellectual disabilities) was limited to testing materials in two occasions. This lack of involvement is very concerning. Involvement of the target group is very important for the content and development of materials and involvement of implementers is very important for recognizing potential barriers for implementation. Finally, implementation decision makers are very important when it comes to policy; it is next to impossible to implement a sex education program without good management support (Mendel et al., 2008).

The fifth area concerns the evaluation of the programs. None of the programs have been evaluated; which is not uncommon (Kok et al., 2009). As a consequence, there are no data on the effectiveness of these programs.

A comparable study that has been conducted by Godin et al., (2007), in which they assessed community-based interventions on HIV/STD prevention, found similar results: lack of a proper needs assessment, no specific goals described, lack of theoretical basis and absence of evaluation studies. However, they did not include the involvement of relevant groups in the development process in their assessment tool.

In summary, it is clear that program developers are very committed and have put a lot of time and effort into making these programs, but when we look at the development process of these programs we can conclude that based on our findings and on literature that the programs will most likely not be effective. Even more so, due to the lack of measurable outcomes it will be impossible to do a useful evaluation study (Rossi \& Freeman, 1993; pp. 218). Furthermore, we'd like to note that even though we know from the literature that different problems exist in the area of sexuality (McCabe, 1999a; Murphy \& O'Callaghan, 2004; Servais, 2006) we found it remarkable that problems, such as people with intellectual disabilities having fewer sexual experiences, having negative attitudes towards sexual activities and having experiences of sexual abuse, were not as frequently mentioned as was to be expected beforehand.

\section{Limitations}

There are some limitations to this study that should be taken into consideration. The first is that results reflect what is said during the interview by the program developers and it does not reflect the actual content of the sex education program. Therefore, it might be possible that they have forgotten to mention important issues due to their lack of knowledge about the Intervention Mapping process. We did try to solve this problem by giving the program developers an opportunity to 
provide feedback on two occasions. Furthermore, the practical applications that were mentioned were scored by two researchers and put in different categories of methods. It was not checked if all the conditions for using the method were effectively met.

Finally, it must be taken into account that Intervention Mapping itself has its limitations. It is a protocol and not a method for developing interventions. The quality of the interventions that are developed according to the Intervention Mapping process, heavily depend on knowledge that is already out there, and time and money for doing extra research, if that proves to be necessary. Knowledge on the problem behavior and its determinants is the foundation of a good intervention (Bartholomew et al., 2011). When this knowledge is incomplete, it can be expected that this has consequences for the effectiveness of the intervention. The advantage of systematically developing interventions and writing down the process of development, is that it increases the likelihood that interventions can be successfully adapted to other settings, knowledge on what is effective can be more easily identified and shared, and aspects of the intervention that turn out not to be effective, can be identified and adjusted accordingly.

\section{Recommendations}

For the development of sex education programs, it is very important to do a proper needs assessment and get a clear idea of the problem and the impact it has on the sexual health of people with intellectual disabilities and identify the psycho-social determinants of the behaviors related to this problem. Usually, these can be found on different ecological levels, such as the individual level, interpersonal, and organizational levels (Kok et al., 2008).

Additionally, the interviews make clear that the focus predominantly lies on the target group, namely people with intellectual disabilities who are receiving sex education. However, other groups should be taken into account as well, such as the program implementers, paid care staff who give sex education, implementation decision makers, and environmental agents who develop policy.

Furthermore, as mentioned in the introduction, theory- and evidence-based programs produce larger effects than non theory- and evidence-based programs. It would therefore be useful to develop sex education programs for people with intellectual disabilities that are theory- and evidence-based instead of only practicebased, such as the current programs.

Moreover, it is crucial to involve members of the target groups and program implementers in the different stages of development, because it adds to the effectiveness of the program and increases the chance of a program to be successfully implemented. In addition, to understand what parts of the program are effective and what parts need to be improved an adequate evaluation plan is necessary. However, in order to conduct a proper evaluation it is essential to have measurable 
outcomes in a well implemented program (Rossi \& Freeman, 1993; pp. 218), which are well described (van der Knaap et al., 2008). It is therefore preferred to have a systematic and theory- and evidence-based approach when developing a sex education program.

Finally, assessment of intervention programs by independent professionals working in the field of intervention development is important to assure the quality of these programs (Brug et al., 2010). This study shows that an adaptation of the Intervention Mapping steps can be a useful tool to asses the development process of sex education programs.

Summarizing, future research is needed to provide more information on what problems are affecting the sexual health of people with intellectual disabilities and a more systematical and theory- and evidence-based approach, such as Intervention Mapping, should be applied in the development of future sex education programs for people with intellectual disabilities. 


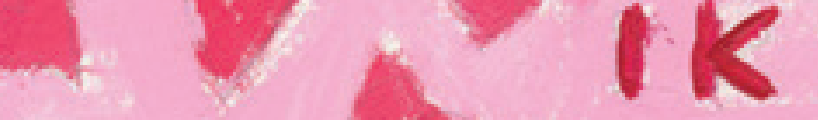

C C HEB a je

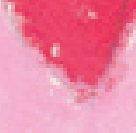

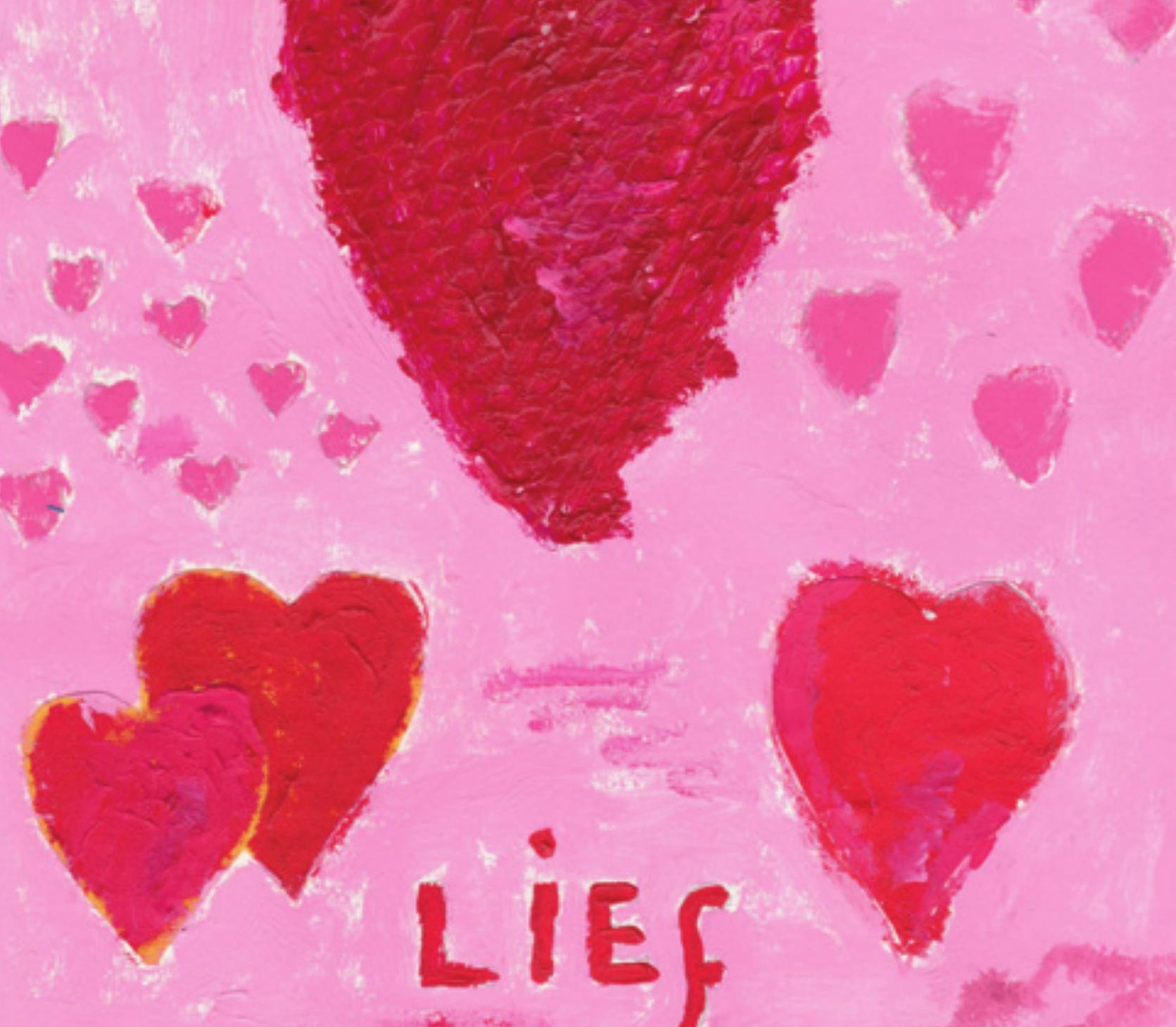




\section{Chapter 3:}

\section{Identifying the important determinants of teaching sex}

education to people with intellectual disabilities: A crosssectional survey among paid care staff 


\section{Abstract}

Background Sex education programmes have been developed with paid care staff as sex educators. However, no information is available about whether these programmes are being delivered.

Method The aim of this study was to investigate whether paid care staff working in an organization, specialized in the care for people with mild to moderate intellectual disabilities, teach sex education or not. An online questionnaire was therefore constructed to assess the important determinants.

Results Of the 163 staff members, 39\% provided sex education. Results show that it is mainly provided reactively. The main determinant is the perceived social norm towards teaching sex education.

Conclusions If we want paid care staff to teach sex education reactively, then we need to focus on changing the perceived social norm. However, if we want them to teach sex education proactively, a new needs assessment should to be conducted in order to identify the important determinants to motivate and enable them to provide proactive sex education. 


\section{Introduction}

Intellectual disability is characterized by significant limitations both in intellectual functioning and in adaptive behaviour as expressed in conceptual, social, and practical adaptive skills (Luckasson \& Schalock et al., 2013; Schalock et al., 2010; Schalock et al., 2012; Schalock \& Luckasson, 2013). Regardless of this impairment in intellectual functioning, people with intellectual disabilities have sexual needs and desires, like anyone else. In several studies, individual with intellectual disabilities have expressed a desire to have an intimate relationship, to marry and to have children (Healy et al., 2009; Kelly et al., 2009). However, due to their disability, they encounter more barriers in the area of sexuality and are more vulnerable to sexual abuse than people without disabilities. People with intellectual disabilities have been found to have insufficient or incorrect knowledge about subjects like masturbation, pregnancy, safe sex, reproduction and same-sex relationships (Healy et al., 2009; Kelly et al., 2009; Leutar \& Mihokovic, 2007; McCarthy, 2009; Murphy \& O'Callaghan, 2004). Furthermore, they experience a lack of privacy (e.g. people are more likely to enter their room without knocking), receive restrictive rules concerning intimate relationships or experience people expressing disapproval towards them about having an intimate relationship (Healy et al., 2009; Kelly et al., 2009). Finally, people with intellectual disabilities often report having experiences with sexual abuse (Eastgate et al., 2011; McCarthy, 1996; Stoffelen et al., 2012; Yacoub \& Hall, 2009). These problems affect the sexual health of people with intellectual disabilities and consequently, their quality of life.

Sex education programmes have been developed in order to improve the sexual health of people with intellectual disabilities. Sexual health is defined by the World Health Organization (2006) as: "a state of physical, emotional, mental and social well-being in relation to sexuality; it is not merely the absence of disease, dysfunction or infirmity. Sexual health requires a positive and respectful approach to sexuality and sexual relationships, as well as the possibility of having pleasurable and safe sexual experiences, free of coercion, discrimination and violence. For sexual health to be attained and maintained, the sexual rights of all persons must be respected, protected and fulfilled". Sex education programmes in the Netherlands are, in most cases, designed to be delivered by paid care staff (Schaafsma et al., 2012). However, there is no evidence supporting the idea that paid care staff are willing and feel able to successfully deliver sex education to people with intellectual disabilities. In order to find out whether paid care staff members are willing and feel able to provide sex education, it is important to know what kind of determinants influence the provision of sex education by paid care staff. 


\section{Theory of Planned Behavior/ Reasoned Action approach}

The Theory of Planned Behavior and its more recent version, the Reasoned Action Approach (Fishbein \& Ajzen, 2009), are social cognitive theories that describe the influence of changeable cognitive determinants on human behavior and can help us explain why paid care staff members do or do not teach sex education. Among these determinants, the intention to perform the desired behavior is the most important predictor of future behavior. However, the intention to perform the desired behavior is, in turn, determined by the attitude towards the behavior, the perceived social norms regarding the behavior, and the perceived self-efficacy (similar to perceived behavioral control and perceived competence) in terms of performing the desired behavior. Attitude refers the person's overall evaluation of the desired behavior change and includes both the positive and negative consequences of the behavior. Two types of attitude have been identified in the literature. The instrumental attitude is based on an evaluation of the advantageous or disadvantageous outcomes of a certain behavior. Experiential attitude, on the other hand, is an affective evaluation of the outcomes of a certain behavior (e.g. this behavior feels comfortable or uncomfortable) (p. 75). Perceived social norms refer to the person's beliefs about whether important people, for example colleagues, approve of the desired behavior or not. Two types of social norms are distinguished. An injunctive social norm refers to a person's perception of what behavior is approved of or disapproved of by a specific group of people within a specific context. A descriptive social norm refers to a person's perception of what behavior is commonly exerted by a specific group of people within a specific context (p. 129). Perceived behavioral control, similar to perceived self-efficacy, refers to the person's perceived ability to perform the desired behavior (p. 64).

These social cognitive models of behavior thus imply that paid care staff members will be willing to provide sex education if they demonstrate 1 ) a positive attitude towards providing sex education, 2) perceive social support and approval from important others in the work context, including colleagues, managers and clients' parents, and 3) feel confident and capable of providing the intended sex education.

\section{Potential barriers}

However, previous studies show that this is not always the case. Concerning attitudes, older staff members seem to have more conservative attitudes towards the sexuality of their clients than younger staff members (Abbott \& Howarth, 2007; Evans et al., 2009; Gilmore \& Chambers, 2010; Meaney-Tavares \& Gavidia-Payne, 2012), but the general attitude of staff is more liberal and in general positive, compared to the attitude of family members (Bazzo et al., 2007; Evans et al., 2009; Gilmore \& Chambers, 2010). 
Regarding self-efficacy, several studies show that staff members report a lack of experience in dealing with sexuality (Abbott \& Howarth, 2007) and also lack training in this area (Abbott \& Burns, 2007; Evans et al., 2009; Grieveo et al., 2007).

When it comes to the perceived social norm, some staff members express concerns about the reactions of other staff members or parents if they would talk about sexuality (Abbott \& Howarth, 2007), indicating a negative perceived social norm.

Furthermore, sex education programmes are designed to be delivered proactively (Schaafsma et al., 2012). This means that sex education is should be provided before a person is sexually active, so that he or she has the knowledge, cognitions and skills needed to make decisions that have a positive effect on ones sexual health. When a person lacks the right knowledge, cognitions or skills, problems may arise that have a negative impact on the sexual health of people with intellectual disabilities. For example, they may be more vulnerable to sexual abuse, due to a lack of skills needed to identify abusive situations (Murphy \& O'Callaghan, 2004). Previous studies, however, show that staff in general act reactively, thus teach sex education reactively, (Abbott \& Burns, 2007; Abbott \& Howarth, 2007) and respond idiosyncratically (Evans et al., 2009) to situations concerning sexuality issues, which is cause for concern.

Next to cognitive determinants, environmental determinants can also play an important role. Environmental determinants can form barriers to performing the desired behaviour. For example, policies on sexuality within organizations are often inadequate or there are simply not present (Abbott \& Howarth, 2007), or staff may be unfamiliar with the policy (Cuskelly \& Bryde, 2004) or unsure about how to implement the policy (Grieveo et al., 2007). Some staff members even worry about being prosecuted if they would discuss sexuality with their client (Grieveo et al., 2007). A lack of policy or ambiguities about the organization's policy may be a possible barrier to teaching sex education, even when staff members express a positive intention.

\section{Present study}

The present study investigated the differences between paid care staff members who teach sex education to people with intellectual disabilities and paid care staff members who do not teach sex education, while both these groups are responsible for the sexual health of their clients, according to the guidelines of the organization. They were compared on a number of determinants, such as self-efficacy, attitude and social norms regarding sex education, derived from earlier studies and relevant theoretical perspectives. The goal was to identify important predictors and possible barriers for teaching sex education to people with intellectual disabilities. 


\section{Methods}

\section{Ethical procedures}

Approval was given by the Ethical Committee of the Faculty of Psychology and Neuroscience at Maastricht University. Preceding the online questionnaire participants were provided with information about the true goals of the study. They were also informed that participation was anonymous and that they could discontinue their participation at any given moment.

\section{Participants and procedure}

For this study we used a convenience sample. The organization where the study was conducted is a research partner. This organization is specialized in the care of people with intellectual disabilities. In the Netherlands, organizations such as this one accommodate a large portion of the population of people with intellectual disabilities and are therefore important providers of sexual health care. In 2008 the number of people that requested these organizations for extra support was 147.000 (Ras et al., 2010).

All paid care staff members were sent a link to an online questionnaire $(\mathrm{N}=$ 1475). A total of 630 paid care staff members completed the questionnaire, resulting in a response rate of $43 \%$. This number was reached two weeks after the questionnaire was put online, with a reminder sent after one week. For the analyses, 163 of the 630 paid care staff members were included. This group only included people who are directly responsible for the well-being of the client. They provide inpatient care to people with a moderate or mild intellectual disabilities, do not work exclusively with children under the age of 12 , and do not work at an activity centre (part of the organisation that provides activities for clients during the day). According to the guidelines of the organization, the selected sample is responsible for the sexual health of their clients, and therefore most eligible to provide sex education. This means that the staff members that have been excluded work, for example, with the elderly or with children, have clients that do not live within the facilities of the organization or work with clients who have a severe or profound intellectual disability.

\section{Measures}

Except for age, behaviour, presence of sex education materials and descriptive social norm, constructs were measured using a 5-point scale item, where 1 is totally disagree and 5 is totally agree. Items for intention, self-efficacy, attitude and social norms were constructed using the guidelines provided by Fishbein and Ajzen (2009). In accordance with these guidelines, the content of the questions 
(Table 1) was derived from the results of qualitative research; in this case ten interviews conducted among a representative sample of paid care staff members (Appendix A). Pearson correlation is used for scales with two items. Omega total $(\omega t)$ is used to indicate the reliability of scales with more than two items (Revelle \& Zinbarg, 2009) instead of the widely used Cronbach's alpha, because Cronbach's alpha has been shown to be, in many cases, a gross underestimate of reliability. Moreover, Cronbach's alpha is used in many papers as a measure for internal consistency, but is unrelated to the internal structure of a test (Sijtsma, 2009). A paper by Revelle and Zinbarg (2009) reveals that $\omega t$ is a better estimate of reliability than Cronbach's alpha or other estimates such as the greatest lower bound.

The content of the questionnaire was checked by two health psychologists and a sexologist working in the field of intellectual disabilities. Additionally, five paid care staff members checked the content for feasibility and understandability and adjustment were made accordingly.

\section{Analysis}

The correlation between intention to teach sex education and past behavior in terms of teaching sex education was calculated in order to examine the predictive value of intention on past behavior. Next, bivariate correlations were determined for the study variables and for intention. A multiple regression analysis, using blockwise entry, was conducted to discover the unique contribution of the study variables to the explanation of intention as well as the total amount of variance explained in intention. Psychosocial determinants, derived from the Reasoned Action Approach (Fishbein \& Ajzen, 2009) were entered first. Second, modifiable determinants, derived from the interviews, with a high correlation with intention were added. And finally, client behavior, which is a measure of experience with matters in the area of sexuality, was added. Furthermore, independent sample ttests were carried out to identify differences on individual constructs and single items between staff members who teach sex education and those who do not. Finally, a cross-tabulation was performed to identify a possible relationship between the presence of sex education materials and the behavior (practice) of teaching sex education.

\section{Results}

\section{Sample description}

The sample ( $\mathrm{N}=163)$ was $85 \%$ female and $15 \%$ male, with a mean age of 37.63 (SD $=10.87$, range $=22-63$ ). Years of working experience ranged from 1-42 years, with a mean of $14.48(\mathrm{SD}=9.96)$. 


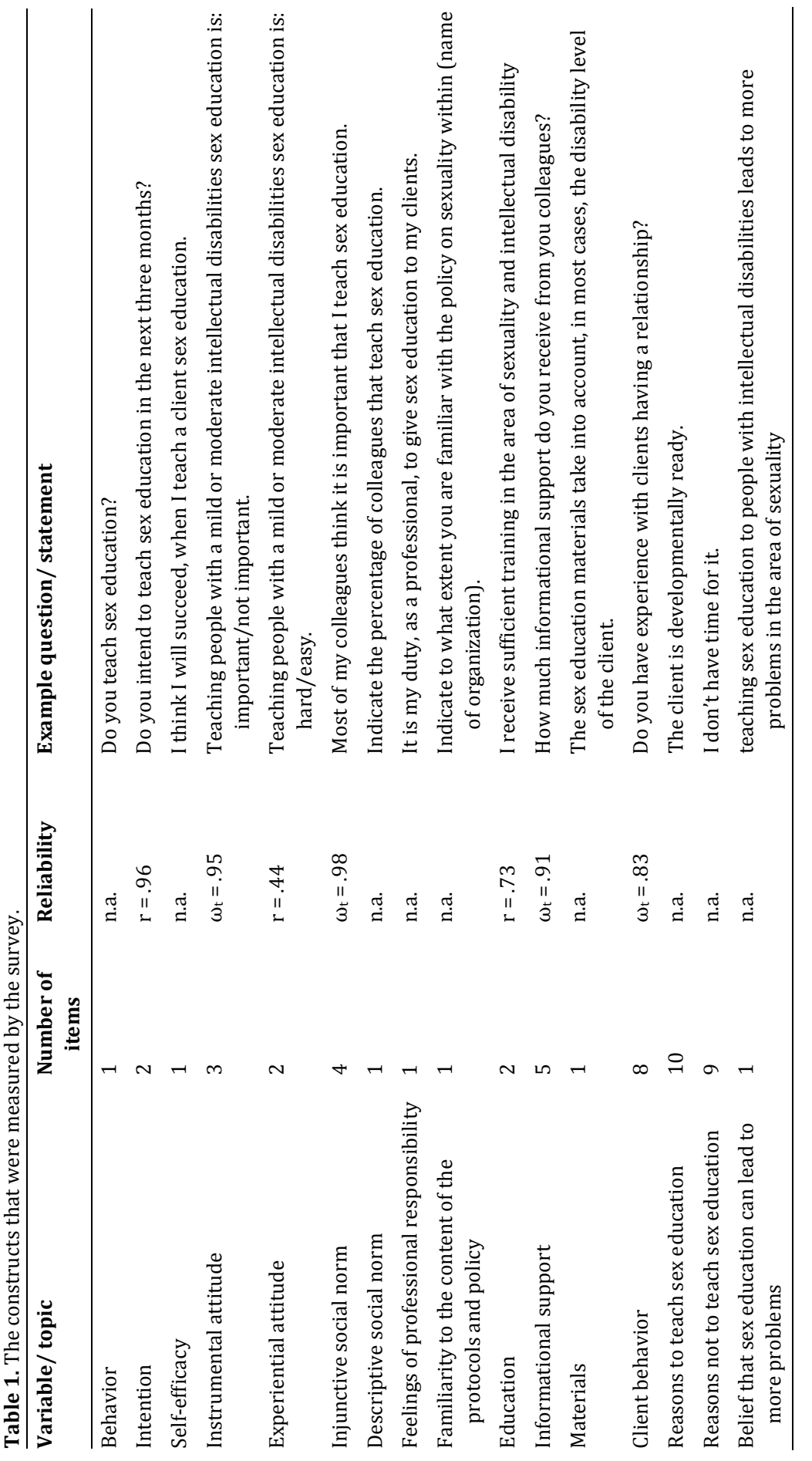


The percentage of people who work 11-20 hours is 15\%, 21-30 hours is $50 \%$ and $31-40$ hours is $35 \%$. Concerning highest education, $1 \%$ finished high school, $52 \%$ completed intermediate vocational training, $42 \%$ higher vocational education, $3 \%$ university and $3 \%$ filled in "other".

\section{Current behavior and intention}

Of the 163 staff members, $39 \%(\mathrm{~N}=64)$ indicated to teach sex education and $61 \%$ $(\mathrm{N}=99)$ staff members indicated not to teach sex education at the moment of filling out the questionnaire. Intention had a mean of $2.28(\mathrm{SD}=1.46)$ with a minimum of 1 and a maximum of 5 . A strong positive correlation was found between the intention to teach sex education and the past behavior of teaching sex education, $r(163)=.75$. Scores on intention to teach sex education were higher for staff members that teach sex education $(\mathrm{M}=3.63, \mathrm{SD}=1.27)$ than for the staff members who do not teach sex education $(\mathrm{M}=1.41, \mathrm{SD}=.73), \mathrm{t}(90)=12.71, \mathrm{p}<.01, \mathrm{~d}=2.28$.

\section{Correlations of study variables}

Age showed a low positive correlation with both instrumental and experiential attitude. Client behavior, responsibility, injunctive social norms and descriptive social norms showed a medium to high positive correlation with intention. Selfefficacy, instrumental attitude, experiential attitude, policy and education showed a low to medium positive correlation with intention. Age and informational support did not correlate with intention (Table 2).

Table 3 shows a multiple regression analysis of paid care staff members' intention to teach sex education in the next three months. A model with self-efficacy, instrumental attitude, experiential attitude, injunctive social norms and descriptive social norms explained $42 \%\left(\mathrm{R}^{2}=.42\right)$ of the variance in intention $(\mathrm{F}(5,157)=$ $22.97, \mathrm{p}=<.01)$. Adding responsibility, policy, education and informational increased the explained variance with $2 \%\left(\mathrm{R}^{2}=.44\right),(\mathrm{F}(9,153)=1.30, \mathrm{p}=.27)$. Adding client behavior increased the explained variance with another $7 \%$ to $\mathrm{R}^{2}=.51$, $F(10,152)=20.21, p=<.01$. In the final regression model unique significant contributions were found for injunctive social norm, descriptive norm, responsibility, and client behavior. 


\section{Chapter 3}

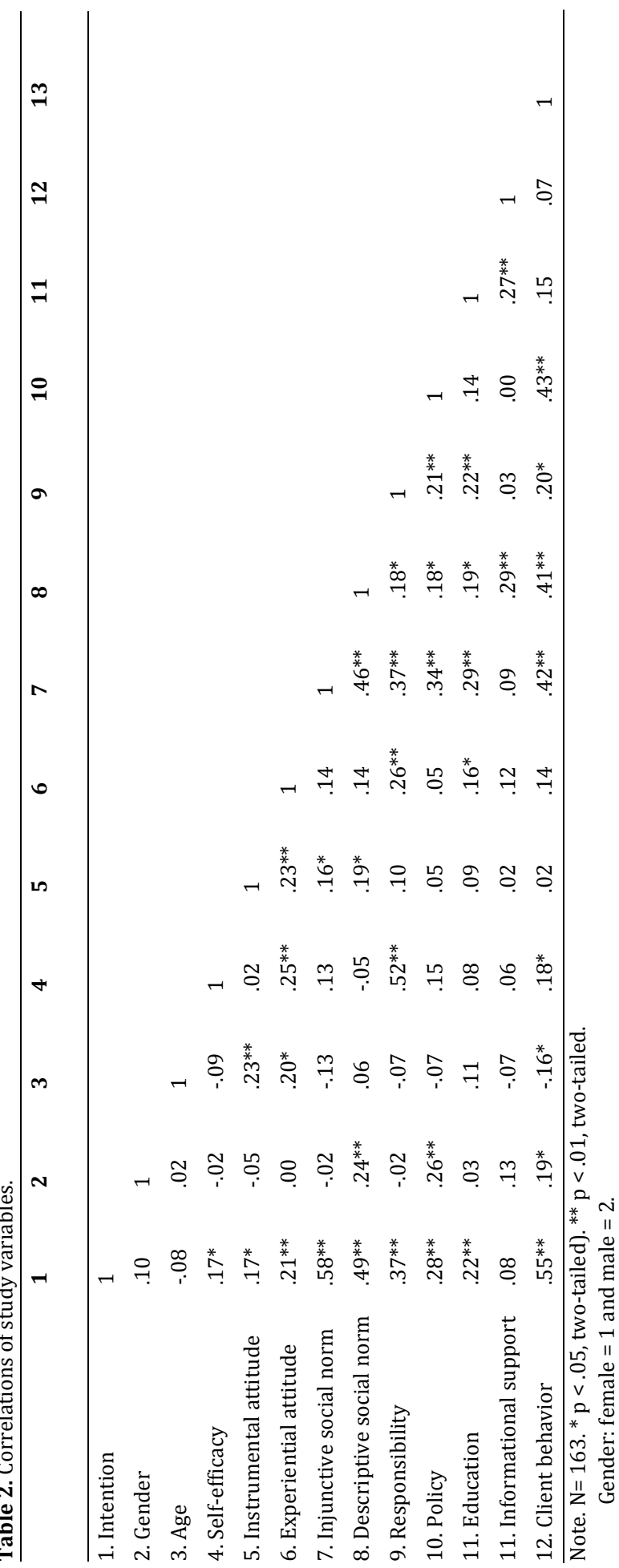




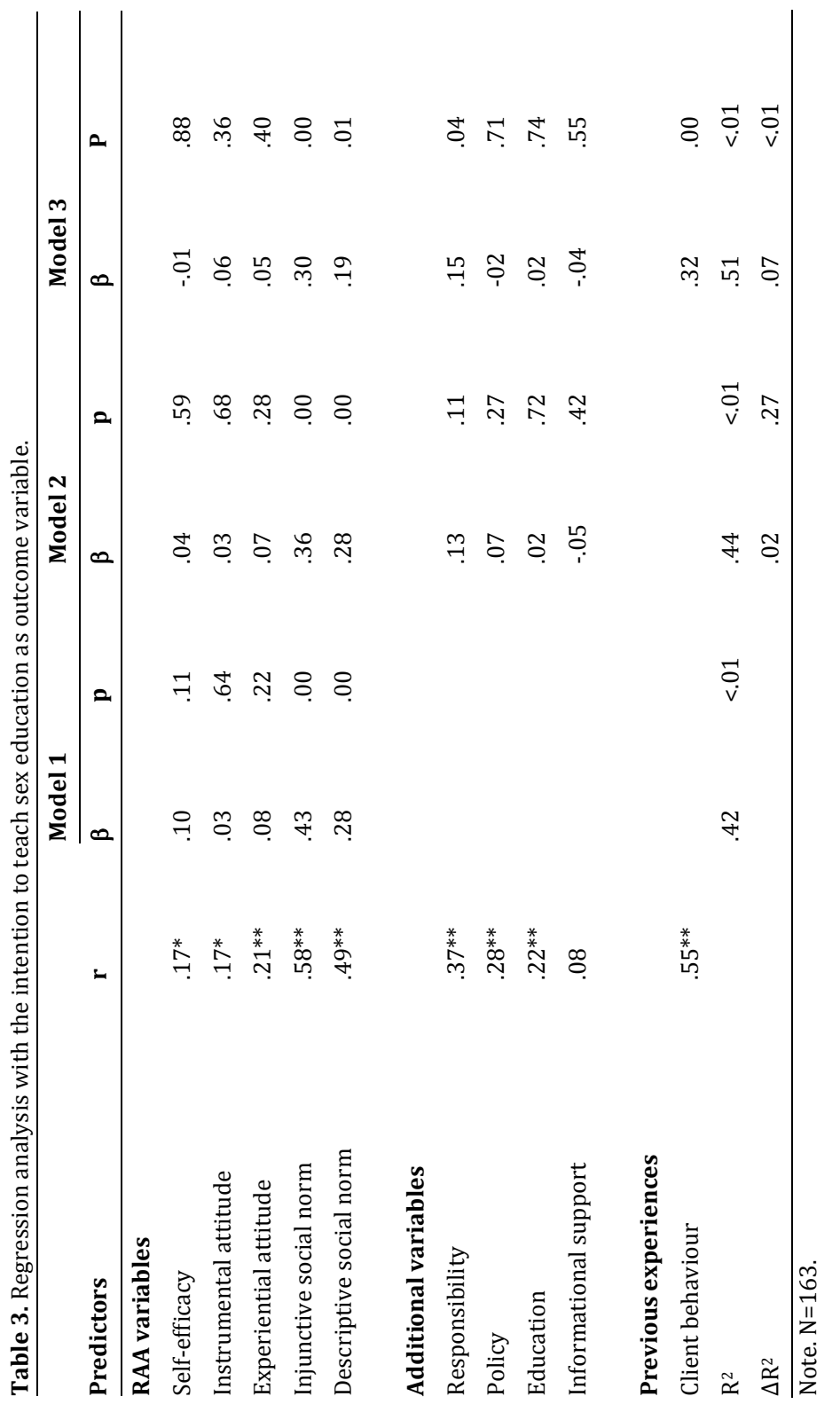




\section{Staff members who teach sex education vs. staff members who do not}

With regard to the study variables, staff members who indicated that they did teach sex education at the moment of filling out the questionnaire were compared to staff members who did not teach sex education. Staff members who did teach sex education reported higher intentions to teach sex education, rated their environment as being more positive towards teaching sex education (injunctive social

Table 4. Comparison of staff members who teach sex education versus those who do not on study variables.

\begin{tabular}{|c|c|c|c|c|c|c|c|c|}
\hline \multirow[b]{3}{*}{ Determinant + Beliefs } & \multicolumn{4}{|c|}{ Teaching sex education } & \multirow[b]{3}{*}{ df } & \multirow[b]{3}{*}{$\mathbf{T}$} & \multirow[b]{3}{*}{$\mathbf{p}$} & \multirow[b]{3}{*}{$\mathrm{d}^{4}$} \\
\hline & No & & Yes & & & & & \\
\hline & $\mathbf{M}$ & SD & $\mathbf{M}$ & SD & & & & \\
\hline Intention & 1.41 & .73 & 3.63 & 1.27 & 90 & -12.71 & $<.01$ & 2.28 \\
\hline Self-efficacy & 3.87 & .72 & 4.08 & .67 & 161 & -1.85 & .06 & .30 \\
\hline Injunctive social norm & 2.28 & 1.17 & 3.87 & .73 & 121 & -9.40 & $<.01$ & 1.60 \\
\hline Colleagues & $\begin{array}{l}2.12 \\
(N=58)\end{array}$ & 1.11 & $\begin{array}{l}3.93 \\
(N=42)\end{array}$ & .81 & 98 & -9.43 & $<.01$ & 1.83 \\
\hline Manager & $\begin{array}{l}2.25 \\
(\mathrm{~N}=59)\end{array}$ & 1.20 & $\begin{array}{l}3.98 \\
(\mathrm{~N}=46)\end{array}$ & .83 & 102 & -8.33 & $<.01$ & .165 \\
\hline Parents of clients & $\begin{array}{l}1.82 \\
(\mathrm{~N}=62)\end{array}$ & 1.02 & $\begin{array}{l}3.39 \\
(\mathrm{~N}=33)\end{array}$ & .97 & 93 & -7.30 & $<.01$ & 1.58 \\
\hline Descriptive social norm & 14.40 & 20.99 & 40.64 & 28.71 & 106 & -6.30 & $<.01$ & 1.08 \\
\hline Instrumental attitude & 4.59 & .60 & 4.73 & .54 & 145 & -1.50 & .14 & .24 \\
\hline Useful & 4.57 & .67 & 4.73 & .51 & 157 & -1.81 & .07 & .28 \\
\hline Important & 4.61 & .62 & 4.72 & .65 & 161 & -1.11 & .27 & .18 \\
\hline Good & 4.61 & .62 & 4.73 & .65 & 161 & -1.27 & .21 & .20 \\
\hline $\begin{array}{l}\text { Experiential } \\
\text { attitude }\end{array}$ & 3.25 & .57 & 3.61 & .72 & 161 & -3.55 & $<.01$ & .57 \\
\hline Easy & 3.11 & .81 & 3.55 & .89 & 125 & -3.17 & $<.01$ & .52 \\
\hline Pleasant & 3.38 & .62 & 3.67 & .74 & 161 & -2.69 & $<.01$ & .43 \\
\hline Responsibility & 3.63 & .93 & 4.17 & .73 & 155 & -4.19 & $<.01$ & .64 \\
\hline Policy & 2.75 & .94 & 3.31 & 1.05 & 161 & -3.57 & $<.01$ & .57 \\
\hline Education & 2.76 & .90 & 3.27 & 1.08 & 161 & -3.29 & $<.01$ & .53 \\
\hline Informational support & 3.57 & .80 & 3.70 & .69 & 160 & -1.06 & .29 & .17 \\
\hline Client behavior & 2.02 & .60 & 2.69 & .53 & 161 & -7.32 & $<.01$ & 1.18 \\
\hline
\end{tabular}

Note. No-group $\mathrm{N}=99$ and Yes-group $\mathrm{N}=64$, unless otherwise indicated. Scores are based on a 1 to 5 scale, except for descriptive social norm, which is depicted in percentages. For details on client behavior see Table 5 .

${ }^{4}$ Cohen's d effect size: $0.2-0.3$ is small, $0.3-0.5$ is medium, and above 0.5 is large. 
norm), indicated a higher percentage of colleagues that teach sex education (descriptive social norm), showed a more positive experiential attitude, reported higher feelings of responsibility for teaching sex education, were more satisfied with the education they received in the area of sexuality and more frequently reported having materials available for teaching sex education in their working environment (Table 4). It was noticeable that high scores for instrumental attitude and self-efficacy were found in both groups and did not differ significantly between the two groups.

\section{Client behavior}

Several sexuality-related matters were presented (Table 5), and paid care staff members were asked to indicate to what extent they had experience with these matters. The data are presented for the group that teaches sex education and the group who does not. Staff members reported having most experience with clients who have a relationship, clients who have problems within their relationship, and clients who exhibit sexually inappropriate behavior. Staff members, who teach sex education, reported having more experience on all items than staff members who do not teach sex education, except for the item "client has masturbation related problems".

Table 5. Differences in experiences between staff members who teach sex education and those who do not on client behavior items.

\begin{tabular}{|c|c|c|c|c|c|c|c|c|}
\hline \multirow[b]{3}{*}{ Experiences } & \multicolumn{4}{|c|}{ Teaching sex education } & \multirow[b]{3}{*}{ df } & \multirow[b]{3}{*}{$\mathbf{T}$} & \multirow[b]{3}{*}{$\mathbf{p}$} & \multirow[b]{3}{*}{ d } \\
\hline & \multicolumn{2}{|l|}{ No } & \multicolumn{2}{|l|}{ Yes } & & & & \\
\hline & $\mathbf{M}$ & SD & $\mathbf{M}$ & SD & & & & \\
\hline The client has a relationship & 2.56 & 1.34 & 3.45 & 1.15 & 148 & -4.55 & $<.01$ & .71 \\
\hline The client has sexuality-related questions & 2.14 & .92 & 2.98 & .85 & 142 & -6.02 & $<.01$ & .95 \\
\hline The client has relationship problems & 2.20 & 1.20 & 3.30 & .99 & 152 & -6.36 & $<.01$ & .98 \\
\hline The client wants a child & 1.37 & .71 & 2.13 & 1.02 & 102 & -5.16 & $<.01$ & .89 \\
\hline $\begin{array}{l}\text { The client exhibits sexually inappropriate } \\
\text { behavior }\end{array}$ & 2.29 & .96 & 2.83 & .92 & 161 & -3.53 & $<.01$ & .57 \\
\hline The client has been sexually abused & 2.22 & 1.14 & 2.70 & 1.12 & 161 & -2.65 & $<.01$ & .43 \\
\hline The client has sexually abused a person & 1.44 & .88 & 1.89 & .86 & 161 & -3.19 & $<.01$ & .51 \\
\hline $\begin{array}{l}\text { The client has masturbation related } \\
\text { problems }\end{array}$ & 1.92 & 1.00 & 2.23 & 1.04 & 161 & -1.94 & $>.05$ & .31 \\
\hline
\end{tabular}

Note. No-group N=99 and Yes-group N=64.

\section{Reasons for teaching sex education}

No differences in reasons to teach sex education were found between paid care staff members who teach sex education and those who do not. The highest scores were given to "the client has sexuality-related questions" and "the client is exhibit- 
ing sexually inappropriate behavior". The lowest score was given to "the client is developmentally ready" (Table 6).

Table 6. Means and standard deviations of reasons for teaching sex education.

\begin{tabular}{lll}
\hline Reasons & M & SD \\
\hline The client is developmentally ready & 3.67 & 1.13 \\
The client starts a relationship & 4.07 & 1.24 \\
The client has a relationship & 4.06 & 1.23 \\
The client has sexuality-related questions & 4.31 & 1.13 \\
The client has problems within the relationship & 3.98 & 1.24 \\
The client wants a child & 4.11 & 1.41 \\
The client is exhibiting sexually inappropriate behavior & 4.20 & 1.28 \\
The client has experienced sexual abuse & 3.74 & 1.47 \\
The client has sexually abused a person & 3.85 & 1.55 \\
The client has masturbation related questions & 4.02 & 1.33 \\
\hline
\end{tabular}

\section{Reasons for not teaching sex education}

As with reasons for teaching sex education, a list of reasons for not teaching sex education was also given. Staff members who indicated that they did not teach sex education, were asked to rate to what extent the reason given would be a reason not to teach sex education, with a score of 1 being not a reason and 5 being a really important reason (see table 7). The highest scores were given to "my clients are not sexually active" and "my clients don't want to be educated" and "I don't have the skills". The lowest scores were given to "I don't have a quiet environment to teach in" and "I don't have time for it".

Table 7. Means and standard deviations of reasons for not teaching sex education.

\begin{tabular}{lll}
\hline Reasons & M & SD \\
\hline I don't have time for it & 1.73 & 1.32 \\
I don't have a quiet environment to teach in & 1.65 & 1.31 \\
It's not my responsibility/ task & 2.13 & 1.78 \\
My clients are not sexually active & 3.88 & 1.95 \\
I find it unpleasant to do & 2.03 & 1.34 \\
I am too close to my client for teaching that & 1.84 & 1.43 \\
I don't have the right materials & 2.36 & 1.74 \\
I don't have the knowledge and/or skills for it & 2.58 & 1.65 \\
My clients don't want to be educated & 3.66 & 1.93 \\
\hline
\end{tabular}

Note. $\mathrm{N}=99$.

Additionally, the whole group was given the statement: teaching sex education to people with intellectual disabilities leads to more problems in the area of sexuality 
(1 - strongly disagree, 5 - strongly agree). Both the group that teaches sex education $(M=1.86, S D=0.81)$ and the group who does not $(M=1.99, S D=0.75)$ disagreed with this statement $(\mathrm{t}(161)=1.05, \mathrm{p}=.30, \mathrm{~d}=-0.17)$.

\section{Sex education materials}

An association between the presence of sex education materials and the behavior (practice) of providing sex education was found. A Chi-square test was performed on the presence of material (Yes/No) and the behavior of providing sex education (yes/no). In the group of staff members who teach sex education, a larger portion of staff members indicate that materials are present in their working environment (78\%) than in the group where staff members indicate that they do not teach sex education (58\%), $\chi^{2}(1, \mathrm{~N}=163)=7.28, \mathrm{p}<.01$.

Of the 64 staff members who teach sex education, $64 \%(\mathrm{~N}=41)$ have used sex education materials and $36 \%(\mathrm{~N}=23)$ have never used materials to teach sex education. The staff members that make use of sex education materials are on average positive about how the materials take into account the disability level of the person with intellectual disabilities $(\mathrm{M}=3.61, \mathrm{SD}=0.86)$.

\section{Policy}

In the Netherlands, the general policies of organizations that specialize in the care for people with intellectual disabilities are aimed towards improving the sexual health of their clients.

Of all staff members ( $\mathrm{N}=163), 99 \%$ know that policy concerning the sexuality of their clients exists within the organization; $95 \%$ also know where they can find this policy. When asked whether they are familiar with the content of the policy, $40 \%$ indicated that they know nothing to a little of the content of the policy, $38 \%$ indicated that they know most or the entire content of the policy, and $22 \%$ fell somewhere in the middle.

\section{Discussion}

In previous studies, barriers have been identified that may affect the provision of sex education by paid care staff to people with intellectual disabilities (Abbott \& Burns, 2007; Abbott \& Howarth, 2007; Bazzo et al., 2007; Cuskelly \& Bryde, 2004; Evans et al., 2009; Gilmore \& Chambers, 2010; Grieveo et al., 2007; Healy et al., 2009). In this study we tried to establish which determinants are important predictors of the intention of paid care staff to provide sex education to their clients with intellectual disabilities and whether these results are similar to the results of previous studies. 
The number of participants $(\mathrm{N}=630)$ who filled out the questionnaire was $43 \%$. It was possible to filter out a specific group that is directly responsible for the sexual well-being of the client in order to get more clear data about their behavior with regard to providing sex education and the influence of certain determinants on this behavior. However, a few issues concerning the survey have to be taken into consideration when interpreting the results. The survey did not provide a description of what is meant by sex education. A description was not given for the reason that this could then have influenced the scores on items and consequently skewed the results. The answers are therefore totally based on what the individual staff members consider constitute sex education, which can differ from one person to another. Furthermore, we do not have data from $57 \%$ of the population that received the link to the survey. Therefore we can not rule out a potential response bias. Finally, since the survey was done within one organization, the population might not be representative of the rest of the Netherlands.

Of the 163 paid care staff members that were included in the analyses, 39\% indicated that they do teach sex education. These numbers were expected to be higher, since the group of staff members that were included in the analyses are fully responsible for the well-being, and therefore sexual health, of their clients, who are young adults or adults with a moderate to mild intellectual disability. Furthermore, in accordance with previous studies (Abbott \& Burns, 2007; Abbott \& Howarth, 2007), the results imply that when sex education is provided, it is taught in response to problems, rather than as a tool to prevent problems or proactively support people with intellectual disabilities (Young et al., 2012). This was reflected in the reasons for teaching sex education that were given the highest rates: "the client has sexuality-related questions" and "the client exhibits sexually inappropriate behavior". The reason that received the lowest score was "the client is developmentally ready", which should be the foremost reason to teach sex education. Also, the results of the regression analyses show that client behavior is an important predictor for the intention to teach sex education, meaning that the more experience staff members have with sexuality-related issues concerning their clients, the more inclined they are to teach sex education. This is contradictory to the reason why most sex education programs are developed, namely as a preventive tool to increase the chances of having a sexual healthy life (Schaafsma et al., 2013). Teaching sex education reactively can impede the individual from having pleasurable and safe sexual experiences.

The intention to teach sex education was found to be positively associated with the behavior of teaching sex education. The influence of several determinants on the intention to teach sex education were tested, as described by the Reasoned Action Approach (Fishbein \& Ajzen, 2009). Self-efficacy, instrumental attitude, experiential attitude, injunctive social norm and descriptive social norm were found to be correlated with the intention to teach sex education. Injunctive social norm produced the highest correlation with intention, a pattern that was also 
found in the regression analysis, where injunctive social norms were found to be the most important predictor for the intention to teach sex education. No differences were found in self-efficacy and instrumental attitude between staff members who teach sex education and those who do not. It is therefore not expected that, in this case, these determinants form a barrier to the teaching of sex education. This is due to the fact that both groups gave high scores on both determinants. Interestingly, this contradicts some findings from other studies that have been conducted in other countries, where conservative attitudes towards sexuality (Abbott \& Howarth, 2007; Evans et al., 2009; Gilmore \& Chambers, 2010; Meaney-Tavares \& Gavidia-Payne, 2012) and lack of training concerning sexuality-related issues (Abbott \& Burns, 2007; Evans et al., 2009; Grieveo et al., 2007), which has a negative effect on self-efficacy, have been identified as being the most important correlates.

Additionally, age was shown to have a small positive correlation with both instrumental and experiential attitude, meaning that older staff members seem to have a more positive attitude towards sex education. This is contrary to what has been reported by previous studies (Abbott \& Burns, 2007; Abbott \& Howarth, 2007; Evans et al., 2009; Gilmore \& Chambers, 2010).

Another determinant that proved to be an important predictor was client behavior. The more experience paid care staff has with sexuality-related issues concerning their clients, the higher their intention to teach sex education will be. Additionally, we found that paid care staff members who teach sex education to their clients have a higher intention to do so in the near future. They also think that colleagues, managers and parents of their clients' find it more important that they teach sex education and indicate that a higher percentage of their colleagues teach sex education. They also find it easier and more pleasant to teach sex education, feel more responsible for teaching sex education and are more informed about the contents of the protocols and policy on sexuality. Finally, they give higher scores on client behavior, are more satisfied about the education they receive and are more likely to indicate that they have sex education materials at their disposal.

The question, however, remains in which direction does the causal relationship goes? Does teaching sex education cause these differences? Or do these differences make staff members more inclined to teach sex education? As mentioned above, the injunctive social norm seems to be an important predictor in terms of the intention to teach sex education reactively, since attitudes toward the behavior seem to be very positive, and perceived skills in terms of teaching sex education seem to be high. Increasing injunctive social norms, should, logically, lead to an increased provision of reactive sex education. However, self-efficacy and attitudes might be different for proactive sex education. When this form of sex education is preferable for an organization, a new needs assessment should be conducted to identify the determinants of this specific behavior. Additionally, one might also want to investigate what proactive sex education entails and what kind of measures need to be taken to facilitate this form of sex education. 
One possible explanation for paid care staff providing sex education reactively is potentially ambivalent attitudes toward teaching sex education. Rohleder (2010) reports that educators in his study acknowledged that people with intellectual disabilities should be allowed to lead fully sexual lives, however he also described paid care staff's anxiety in being afraid that sex education might lead to potentially dangerous behaviors. Contrary to this study, the participants in our study indicated that they did not think teaching sex education would cause more problems. Still, this might be a socially desirable answer and not a reflection of how they really feel. Another explanation for teaching sex education reactively might be that staff members just don't talk with their clients about sexuality that often (Kok et al., 2009). Not talking about the subject might lead to late detection of sexual issues or sexual health needs of the client.

To try and identify possible barriers, staff members who do not teach sex education were given reasons for not teaching sex education and asked to rate to what extent these reasons apply to their situation. Interestingly, no environmental constraints or time constraints appeared to be a major issue, but the reasons with the highest rates were: "my clients are not sexually active", "my clients do not want to be sexually educated", and "I don't have the knowledge and/or skills for it". That clients are not sexually active should never be a reason not to teach sex education, since it still makes them vulnerable to sexual abuse. That clients do not want to be educated would indeed present a big issue, however, this might also still be an easy excuse for not teaching sex education. If clients do not want to be educated, research should focus on the reasons why. A combination of interviews with staff and interviews with their clients could shed some light on this issue. The third reason contradicts the scores on self-efficacy, which were high. It could be that the reason "not having the right knowledge and/or skills" relates to proactive sex education and the self-efficacy scores to reactive sex education.

The presence of sex education material in the working environment was also examined. Seventy-eight percent of the staff members who teach sex education indicated that sex education materials are present in the working environment. Only $64 \%$ of them actually used materials, so we assume that $36 \%$ of the sex education happens verbally. This is unexpected, because we know that the usage of graphic materials is very important when communicating with people with intellectual disabilities. The question is why these staff members don't use any graphic materials? Do they not feel comfortable using these materials? Or are the right materials not available to them? It would be interesting to investigate these reasons in more detail. Furthermore, of the staff members who do not teach sex education, only 58\% indicated that materials are present. Even though lack of the right materials does not seem to be an important reason for not teaching sex education, not having materials in the working environment might impede the provision of sex education. Also, not having the materials might strengthen the notion that 
teaching sex education is not important, and that might have an impact on the ruling injunctive social norm.

Finally, the extent to which staff members were aware of policy was examined. Some studies revealed a lack of policy or clear guidelines on how to deal with the sexuality of clients within the working environment (Abbott \& Howarth, 2007; Löfgren-Mårtenson, 2004) which can lead to misinterpretations of sexual behavior, but can also instigate idiosyncratic responses to similar situations. Differences in response may lead to differences in quality of care. This study showed that although most staff members knew that there was policy on sexuality, and knew where to find it, only $38 \%$ indicated to have knowledge of the majority or entire content of the policy. This could suggest implementation problems of the policy within the organization.

In conclusion, if organizations want to increase the number of people with intellectual disabilities that receive sex education, some things need to be taken into consideration. First of all, an organization needs to establish whether staff members currently teach sex education reactively or proactively. In this study we found that injunctive social norms are an important predictor of reactive sex education. However, the determinants of proactive sex education can be different and therefore the approach to changing them will differ. A new needs assessment should be conducted in order to identify the relevant determinants of that behavior (Bartholomew et al., 2011). Second, organizations should not only look at personal determinants, such as attitude, self-efficacy and perceived social norm, but also at environmental influences, such as policy. Knowing where to find policy on sexuality is not the same as knowing what the policy entails. Implementation of policy is as important as the development of policy aimed at influencing the sexual health of people with intellectual disabilities in a positive way.

Finally, in order to truly have a positive impact on the sexual lives of people with intellectual disabilities, it is not only necessary to have people, such as paid care staff members, to teach sex education, but it is also important to have a good quality sex education program. A good quality sex education program has a theoryand evidence-base and has been systematically developed. Most programs currently lack that theory- and evidence-base and are not systematically developed (Schaafsma et al., 2013). It is therefore vital that the focus is not exclusively on increasing the number of people that teach sex education, but also on developing and using good quality sex education programs. 


\section{Appendix A}

Statements of 10 paid care staff members regarding sexuality-related topics. These were gathered through semi-structured interviews.

\section{Teaching sex education}

When

A number of reasons for teaching sex education were given:

- When somebody is exerting sexually inappropriate behavior/ when there is a problem.

- When a client has a question/ indicates it wants education.

- When something relevant is on TV/ during the dishes.

- When you have certain doubts concerning a client of if you don't know the situation of the client (regarding sexuality).

- When you encounter something (in that area).

- When somebody show interest in having children.

- When somebody needs help with sex.

- It is usually after something has happened.

- You can give it some attention when they are younger.

How

- Never while sitting at the table, but for example during the dishes.

- Sometimes jokingly.

- Some clients take courses, but they are already interested.

- Using a program that uses many pictures and letting a client experience how it feels to be taken hold of.

- When someone wants children, ask questions. Make use of role-playing games.

- Watching video's together with the client.

- Make use of TV-programs, start a conversation when something (sexuality-related) is on.

- Making agreements about boundaries with the client and putting that on paper (about printing porn pictures).

- Using 3-dimensional signposts.

- Explaining how to masturbate using a fake penis.

- Consulting a book on how to do it (teach sex education).

- We have boxes (with materials) for teaching sex education.

- You have to adapt the materials to the level of the client.

- Usage of icons in combination with pictures. Pictures are probably too difficult, photos are good. 
- Teaching sex education with two people due to vulnerability (of the educator). The downside is that the client might be more tight-lipped.

- Using a book and a video of "Lief en Lijf".

- A lot of things are mentioned casually, that works better than having a one-on-one conversation (about sexuality).

- Ask questions/ interrogate.

- We have a small group that gathers and discusses a different topic each time.

- Using the Internet for photo or video material.

- "Praten over seks" (Dutch materials) was used.

- Having a conversation with a young man once or twice a month.

\section{Problems}

- It is too burdensome to sit at the table/ when you sit down for it people will get nervous.

- It is usually is not a very "lively" topic (in other words, it is not regularly a topic of conversation).

- How do you do it preventively?

- How do you get to the people who do not go to a course out of their own?

- You work in a very verbal way and clients are often not able to do that.

- You overestimate clients a lot of the times.

- You have to find out what the true question (of the client) is.

- Many times you think how can you start the conversation/ I have been looking for how to start the conversation.

- I think images are too difficult.

- Teaching sex education with two people due to vulnerability (of the educator). The downside is that the client might be more tight-lipped.

- It is more difficult to educate people who live on their own and have had a relationship.

- I have searched things on the Internet, it did became more clear, however maybe not clear enough.

\section{Problems when teaching sex education}

On the level of the client

- When they don't want to talk about it, they don't want to talk about it.

- What you see is that clients develop feelings for their caregiver.

- You tend to overestimate the level of the client.

- At a certain point you will use street-language, otherwise you will found out that they do not understand it. 
- In other areas here level (of knowledge/skills) was high, but not in that (sexuality) area.

- Clients are very good at copying, but that does not mean they understand it.

- She said she knew what French kissing was, but when I asked a few extra questions it turned out she did not have a clue.

- You never know whether the other has understood or not.

- Masturbation does not have to pleasurable; it can also be compulsive behavior.

- Sex education by paid care staff can also cause confusion, because they are also involved in the daily living activities (groceries, medical business).

- I have a client who does not know any boundaries; it would get confusing for him if I taught him sex education.

- The attitude of clients is that they know everything already.

- It is also a difficult topic for the client.

- When there is no apparent need, the subject will not be discussed.

- When a person lives by himself or herself, works and already had a relationship en indicates that it is not necessary, then you have no entrance.

- I cannot come up with something too simple, because then the door closes.

- Somebody might be able to explain the theory, but not put it into practice.

- Clients can say it's ok, but might not feel confident to talk about it. Maybe it is ok, but it can also be that it is too difficult for them and that they think never mind.

- The material did not suit her, she didn't understand it.

- I educated her on the subject of pregnancy, but apparently it did not stick.

- I noticed that clients felt very ashamed to talk about it (because we don't talk about it).

- Client stops saying things when you continue to question them.

- It has not been discussed enough and when I would suddenly ask about it, it becomes to intimate. Or maybe they don't know what I am talking about.

- Maybe they have a question, but are not confident enough to ask it.

- Clients might keep a lot of things to themselves.

- Icons are not always clear. They cannot always link the pictures and the real situation. Photos might be confronting, but more clear.

On the level of the paid care staff member

- It is not discussed enough.

- It is difficult to talk about/ embarrassment.

- It is easier not to do anything about it.

- It is difficult to do when I don't feel safe. 
- You can't just sit down for it, because that will make it too burdensome.

- Staff members can hardly rely on others.

- Sexuality is more common than staff members notice.

- You miss a bit of working experience/education.

- How do you do it preventively?

- You, as a staff member, are vulnerable when you teach sex education.

- It is difficult to start/ How do you begin?/ What do you discuss and what not?

- Not knowing where you can find information/ You are sometimes limited in your options.

- Overestimating your client/ the tendency to skip things.

- You are confronted with your own values/ your own frame of reference is not always correct.

- Not making much use of a real program.

- You are usually very verbally (and client does not always understand it).

\section{Personal attitudes}

- I don't think it is difficult (to teach sex education).

- I think it is important to know certain things about clients.

- Now that we are discussing this subject, I wonder why I have never asked those questions (about sexuality).

- I notice that it is still a taboo here, but also in the care for elderly. It is pretty difficult (for other people) to talk about it.

- I think education belongs here. People just need to make time for it.

- You have to do so much and you can't do everything.

- We don't really talk about it. It is unknown territory, (because) we work with the elderly.

- People are rather giggly about it.

- I think that some people are a bit embarrassed by it.

- I think people are very wary about it (teaching sex education).

- I try my best. I do what I can within the possibilities and opportunities provided by the organization.

- I blame myself for not asking my client about it in advance.

- A mother said: If there is not indication of love then we shouldn't discuss sex.

- I do not involve myself in the love life of my neighbor, so why would I get involved with someone who happens to live here. 


\section{Reasons for teaching sex education}

- When something happens / when there is a problem/ when they exert sexually inappropriate behavior.

- When they don't know how to do something: friendship vs. relationship, inappropriate behavior, respecting boundaries.

- When a client wants children.

- When a client has experienced abuse.

- Asking questions in response to the client's support plan.

- When the time is ripe, if it ever is ripe (e.g. when somebody is ready for a relationship).

- When the client has a question.

\section{Colleagues}

\section{Attitude of colleagues}

- It is easy to talk to them about it.

- I hope they feel confident to say it when they do not feel comfortable with a client.

- Colleagues are in general positive, but it is influenced by experience and upbringing.

- When it is necessary it is discussed with colleagues.

- General things can be discussed in team meetings.

- We are open about it.

- People are giggly about it. For the rest we don't do much about it together.

- I can identify the colleagues who don't have problems with it.

- I think some (colleagues) feel embarrassed about it.

- If I don't start talking about it, not much will be said by my colleagues.

- I don't think my colleagues have the same attitude, sexuality is more my thing.

\section{State of affairs}

- When I observe something, I contact the responsible paid care staff member.

- It is important to be up-to-date on the activities of each others clients' regarding sex education.

- $\quad$ First we discuss among colleagues what we can do about the situation. Only after that we contact the head of the team or a sexologist.

- It is discussed among colleagues, if it is necessary.

- General things can also be discussed in team meetings.

- It is discussed during a meeting with the client, if it is necessary.

- When in doubt I contact the head of the team. 
- We have meetings once every six weeks, but we haven't had a case regarding sexuality yet.

- I contacted the head of the team regarding a question of a client.

- People are giggly about it, but don't do anything about it.

- When I client doesn't want me to write it down, I don't discuss it with my colleagues.

- I do have meetings with colleagues about the content of care provision.

- I identify the colleagues who do not have any problems with it.

- Everything tries to solve it on their own.

- The subject is incidentally discussed during meetings.

\section{Presence of sex education materials}

- There is material at another location; I do not have anything here.

- I know there is material.

- There is no information or material here.

- We have boxes for providing education.

- The sexologist has materials.

- We have a book on pregnancy and a book about sex, but they did not match (the level of the client).

- Those things developed by the sexologist are in every house.

\section{Problems of clients regarding sexuality}

- Problems within the relationship.

- Wanting to have children/ Having children.

- Sexually inappropriate behavior.

- Lack or incomplete knowledge regarding sexuality.

- Divergent sexual expressions (e.g. interest in children, boy who wants to become a girl).

- Problems with masturbation, mainly males.

- Need for sexual experiences.

- Negative experiences/ sexual abuse.

\section{Education}

- I think it is in every education.

- Sexuality was not part of my education.

- Something has been said about sexuality (in 1973/1979). I had a course within the organization.

- It was not discussed in my time. 
- I know there is someone in our team who received training on that subject.

- We do not receive training when there are new materials.

- What I received during my education was limited, I cannot even remember.

- I am going to take a course on sexuality.

\section{Policy}

- Policy can be found on the intranet.

- The policy dictates that sexuality belongs to people with intellectual disabilities and should be discussed. People should be stimulated in their development regarding sexuality. People should be protected against sexual abuse.

- Sexuality is a compulsory part.

- As normal as possible, adjusted where it is needed.

- I think it is aimed at working on it proactively.

- Sexuality is starting to become more important.

- $\quad$ There is a committee of 6 people who develop the policy regarding sexuality.

- I think it can always be discussed en I think the organization facilitated that.

- I expect there to be policy, but I don't know.

- The history of the client regarding sexuality is not always known when the client comes to the organization.

- $\quad$ There are protocols concerning intimacy and sexual abuse. 



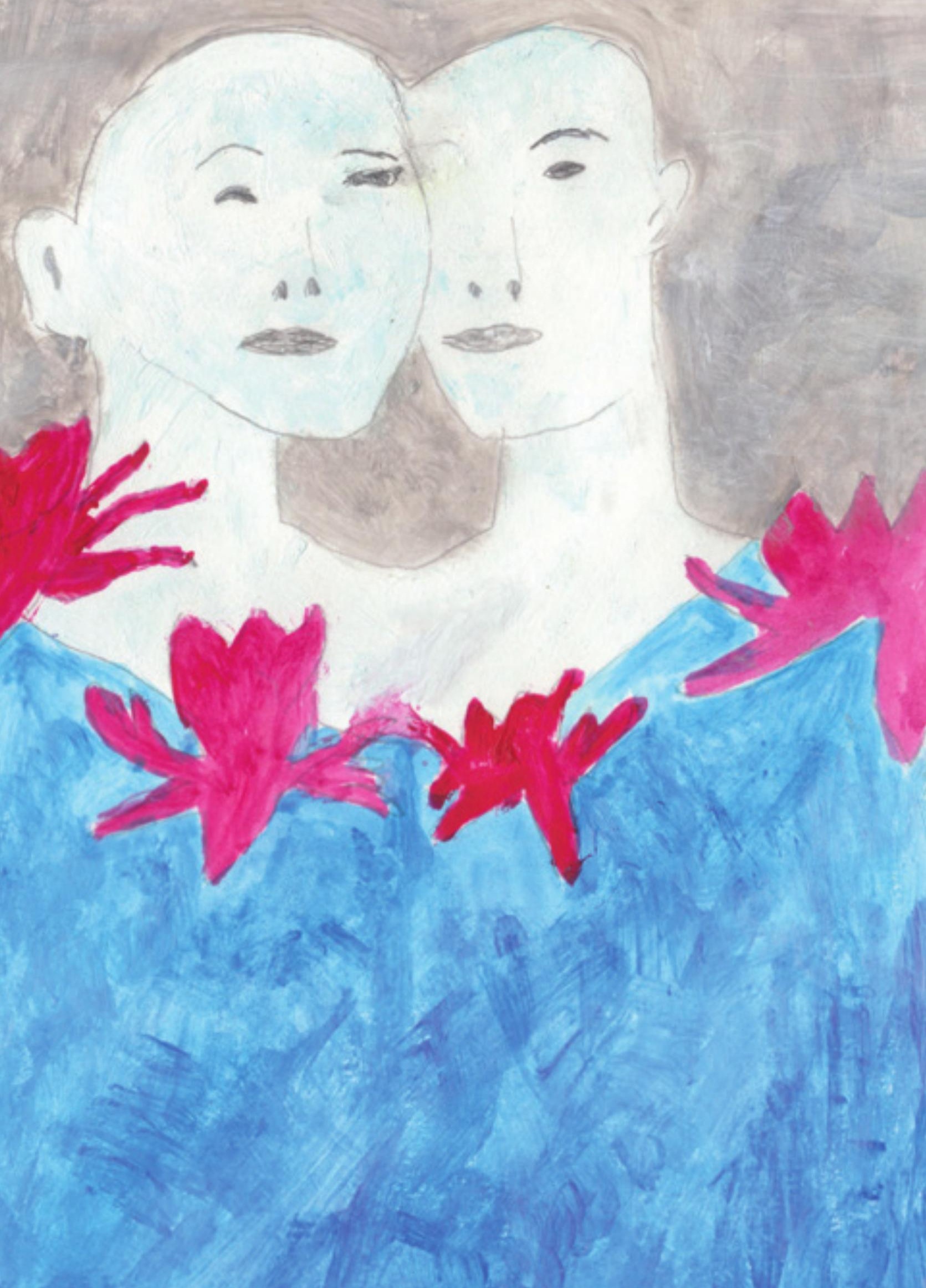




\section{Chapter 4:}

\section{People with intellectual}

disabilities about sexuality: important implications for the development of sex education 


\section{Abstract}

Background Existing sex education programs have failed in involving people with intellectual disabilities in the development of these programs. Not involving the target population decreases the likelihood that the sex education program will be effective. This study was conducted to assess the perspectives of people with intellectual disabilities on several sexuality-related topics.

Methods Semi-structured interviews were held with 20 people with intellectual disabilities covering topics such as: sex education, relationships, sex, social media, parenthood and support.

Results The reported frequency of sex education the participants receive is low. Their knowledge regarding sex education is mainly limited to topics such as safe sex, contraception and STI's and tends to be superficial. Additionally, knowledge on safe sex does not always translate to safe sex behavior. Finally, relationships are important for most participants; mainly because they don't want to be alone.

Conclusions There is a need for high quality sex education. Sex education should be lengthier and taught more frequently, focusing on a variety of sexualityrelated topics. Furthermore, sex education should include the improvement of sexuality-related skills as well. To increase the likelihood of a program to be effective it is advisable that a theory-and evidence-based framework, such as Intervention Mapping, is used for its development. 


\section{Introduction}

Sex education programs have been developed with the purpose of improving sexual health, which is defined by the World Health Organization as: "a state of physical, emotional, mental and social well-being in relation to sexuality; it is not merely the absence of disease, dysfunction or infirmity. Sexual health requires a positive and respectful approach to sexuality and sexual relationships, as well as the possibility of having pleasurable and safe sexual experiences, free of coercion, discrimination and violence. For sexual health to be attained and maintained, the sexual rights of all persons must be respected, protected and fulfilled" (WHO, 2006). In practice, this means that sexual health is not only about preventing sexually transmitted infections (STI's), unwanted pregnancies and negative sexual experiences, such as sexual abuse, but also about providing people with the means to experience sexuality in a positive way. These concepts are reflected in the themes that are commonly addressed in sex education programs: prevention of unwanted pregnancies, HIV/ STI infection, friendships and sexual relationships, prevention of sexual intimidation, sexual abuse and sexual violence, and homosexuality (Schaalma et al., 2009a).

However, the exact goals of the programs and how these should be addressed depend on the needs of the target population and the context in which sex education is provided. In program development, this is determined in the "needs assessment" (Bartholomew et al., 2011; pp.171). In the needs assessment, program developers establish what the current situation regarding a health problem is and what the situation should be after the program. Behaviors and its relevant determinants (e.g. knowledge, attitudes, self-efficacy) of the current health problem are identified and desired behavioral outcomes are determined.

Regarding the sexual health of people with intellectual disabilities, some issues have already been identified by previous studies. First of all, people with intellectual disabilities report experiences of sexual abuse (Eastgate et al., 2011; McCarthy, 1996; Stoffelen et al., 2013; Yacoub \& Hall, 2009) and the risk on experiencing sexual abuse can be three times higher when compared to their nondisabled peers (Rapport commissie Samson, 2012). Furthermore, they experience more difficulties in finding, forming and maintaining the relationships they desire so much (Abbott \& Burns, 2007; McCarthy, 1996). These problems may, in some degree, be caused by deficits in sexual knowledge (Healy et al., 2009; Kelly et al., 2009; Leutar \& Mihokovic, 2007; McCarthy, 2009; Murphy \& O'Callaghan, 2004; Siebelink et al., 2006) and a general lack of social, behavioral and decision skills (Egemo-Helm et al., 2007; Hayashi et al., 2011; Khemka et al., 2005; Miltenberger et al., 1999).

However, environmental factors play an important role in health issues as well (Bartholomew et al., 2011). With regard to people with intellectual disabilities, caregivers, such as parents or paid care staff, can influence their sexual well-being. For example, opportunities for people with intellectual disabilities to have sexual 
experiences are decreased, because privacy is not provided to them (Evans et al., 2009; Healy et al., 2009; Lesseliers, 1999); couples are not allowed to be alone (Lesseliers, 1999) or parents and staff members impose restrictive rules on them regarding their relationships (Lesseliers, 1999; Löfgren-Mårtenson, 2004). Additionally, studies among paid care staff have shown that they do not talk about sexuality with their clients (Abbott \& Howarth, 2007; Kok et al., 2009) or that when they do it is usually reactively (Abbott \& Burns, 2007; Abbott \& Howarth, 2007; Schaafsma et al., resubmitted).

Nevertheless, people with intellectual disabilities have expressed a desire for companionship: wanting someone to love, having a person that can take care of them and having a person to take care of (Abbott \& Burns, 2007; Healy et al., 2009; Kelly et al., 2009). To ascertain that these wishes are met, factors such as knowledge and skills need to be improved. This can be achieved by providing sex education (Bruder \& Kroese, 2005; Schaafsma et al., submitted-a).

There are still some areas that are unexplored; for example, more and more people use the internet nowadays and have a profile page on social network sites. Here they meet old friends, make new friends and find potential love interests. A study by Szwedo, Mikami and Allen (2012) has shown that social network sites can have a positive impact on the mental well-being of people who are less socially successful in real-life. This is partly because people get more time to think about how to interact with the other person when they are in an online environment.

Additionally, people who find it hard to interpret body language, will not experience this as an obstacle when they are interacting online with other people. People with intellectual disabilities are well known to have difficulties with social interactions, and might benefit from online relationships. Furthermore, the topic of having children is one that is relatively unexplored; most research on parenthood focus on women who are pregnant or couples who already have children (Baum et al., 2010).

It is therefore important to expand the needs assessment regarding the sexual health of people with intellectual disabilities, because sexual health is more than safe sex. This paper describes an exploratory study that was conducted to establish the perspectives of people with intellectual disabilities concerning several sexuality-related topics. The main topics in this study were sex education, relationships, sex, social media, parenthood, and support. The perspectives of the participants were determined by doing semi-structured interviews with people with intellectual disabilities themselves. Suggestions are made for the development of future sex education programs. 


\section{Methods}

\section{Participants and recruitment}

Of the 20 participants who took part in this study, 10 of them were male and 10 were female. The average age was 28.9 years with a range of $15-52$ years. No information was requested on the level of their disability, but due to the way the participants were recruited we expect most of them to have an IQ level between 50 and 75 (mild/borderline intellectual disability). Of the participants, 8 lived by themselves and 12 lived in a group home. Most people living by themselves are older than 30; most people living in a group home are under the age of 30 (for more details, see table 1 ).

Table 1. Age of the participants and their living situation.

\begin{tabular}{llllll}
\hline \multicolumn{7}{c}{ Number of participants } \\
\hline Age & Male & Female & Own* $^{*}$ & Group* $^{*}$ \\
& $<20$ & 1 & 4 & 0 & 5 \\
& $20-29$ & 4 & 2 & 1 & 5 \\
& $30-39$ & 4 & 1 & 4 & 1 \\
\hline Mean age & 1 & 3 & 3 & 1 \\
\hline
\end{tabular}

* living environment: own = by themselves, group = in a group home

Participants were recruited through organizations that are specialized in the care for people with intellectual disabilities. We also recruited some participants through self-advocacy groups. Potential participants were provided with a leaflet that contained information about the researcher who did the interview, the purpose of the study, confidentiality of the interview and data processing. This leaflet was developed with people with intellectual disabilities themselves to increase understandability. People were given time to consider participating in the study. When interested to participate, the researcher set up an appointment with them. Interviews took place in an environment where the participant felt most comfortable.

\section{Procedure, ethical considerations and interview topics}

Ethical approval was acquired from the Ethics Committee of the Faculty of Psychology and Neuroscience at Maastricht University.

The informed consent procedure was based on a procedure developed by Thomas and Kroese (2005), which includes some questions at the end to check the participants' understanding of the study. 
The researcher would go through the information that was provided in a leaflet with the potential participant before the start of the interview. First the purpose of the study was explained. Second, participants were explained that the interview data would be treated confidentially; this meant that no other person apart from the researcher would have access to the original content of the interview. Third, the only reason for involving a third party would be when the participant would disclose an abusive or harmful situation. If this is something that has not been disclosed before, or would still negatively impact the participants' wellbeing, then the researcher would suggest contacting someone that can help the participant. Finally, some questions regarding the study were asked to check whether the participant had understood everything. Everything that happened during the interview or steps that were taken in response to the outcomes of the interview were done with full consent and full cooperation of the participant.

The interviews were semi-structured and the interview topics were: sex education, relationships, sex, social media, parenthood, and support (Appendix A). Sex education was chosen, because the study was conducted to improve future sex education programs, so it was important to find out what the current situation regarding sex education was. Common themes in sex education are relationships and sex, which is why these were included as well. Social media and parenthood were included, because these themes are common topics of discussion in the field of intellectual disabilities, but not much is known about what people with intellectual disabilities themselves have to say about it. And finally, support was included, because environment plays an important role in the lives of people with intellectual disabilities. Without proper support it is expected that sex education can not have a positive influence on the sexual health of people with intellectual disabilities. The complete list can be found in Appendix A and includes examples of questions.

\section{Data processing and analysis}

The interviews were recorded with a digital voice recorder and then transcribed. Transcripts were imported into a software program for qualitative data analysis (NVivo 9). The interviews were semi-structured; as a consequence, the coding scheme is similar to the topic list for the interviews (Appendix A) and contains the topics: sex education, homosexuality, relationships, sex, parenthood, social media, negative experiences support and advice for sex education. The different themes were analyzed after coding the interviews. 


\section{Results}

\section{Sex education}

Of the 20 participants 19 report to have received some form of sex education: 6 of the young adults received sex education at school, the other 4 reported to have received sex education from a staff member, a parent or by reading a book. The older adults received sex education from a parent, teacher or a course given by an organization that supports people with intellectual disabilities.

Interviewer (I): "Did your parents start talking about it (sex) or did you ask them?"

Respondent (R): "Uhm, I started and I found it very pleasant. They were really glad that I started talking about it." (Male, 30-39)

All participants mentioned receiving sex education once or twice during their life.

I: "When did you receive sex education?"

$R$ : "I received sex education last year, but if you would ask me questions about it I wouldn't know what to say." (Female, $<20$ )

\section{Topics \& knowledge}

A lack of knowledge regarding sexuality became apparent in the number of topics that were mentioned during the interviews. Topics that were mentioned the most were safe sex, which included condom-use, contraception and sexually transmitted infections (STI's). Less mentioned topics were development of the fetus, friendship, pregnancy, female body, lover boys and boundaries. Furthermore, all participants indicate that safe sex is sex with a condom. They knew that condoms prevent pregnancies and diseases. Most also mentioned contraceptives like the pill, and fewer mention contraceptives like female condom, intra-uterine device or contraceptive injection. When asked to name some STI's, they often named HIV and Aids, and less frequently name Chlamydia, Herpes, Gonorrhea or genital warts.

I: "Did they tell you which diseases you can get?"

R: "Aids, and uhm, HIV. But also other genital diseases that can make your genitals smell bad and stuff." (Female, 20-29)

In general the knowledge on STI's is poor. When asked: "Do you know when you are sick (have an STI)?" Most answered that you know when you get tested. Only few mentioned some symptoms like: fever, lump on the genitals, itchiness or pain.

Participants also had some incorrect or incomplete knowledge concerning sexuality, such as not being sure about whether the pill also protects against STI's; 
that when a woman is on birth control a condom is not needed; not knowing whether the condom protects against STI's; that you have to use a condom when the woman is on her period even when she is on birth control; you're not allowed to have sex when you have an STI; and that you can only get an STI from a girl who slept with many boys.

$R$ : "But the disease can only occur when the girl has slept with several boys". (Male, 20-29)

\section{Materials}

Some mentioned that teachers or caregivers used materials, such as a broom or a banana for demonstrating condom-use. Other sources of information were books, pictures, videos, doll of human body and magazine for teenagers.

$R$ : "The only thing I can remember is that our teacher took a broomstick and put a condom on it". (Male, 30-39)

It seems that a variety of sources were used for teaching sex education. Furthermore, these resources seem to be a mishmash of materials, lacking any theory- or evidence-base.

\section{Attitudes}

Participants indicated that getting sex education was interesting, fun and nice; however, they also mentioned class members to be a bit giggly during sex education or being ashamed of getting sex education and acting a bit tough.

$R:$ :I thought that sex education was really interesting. But there were always a few people in the classroom that started laughing really loud and asking themselves how useful it is. They were disrupting the lesson."(Male, 30-39)

\section{Homosexuality}

Of the participants, 13 expressed positive attitudes towards homosexuality with statements, such as: "(Gay) people should be able to make their own decisions about such matters" or "They are just (normal) people" and "You should let people be (themselves)". However, some indicated that they feel like it is still a taboo sometimes.

One person indicated that he thought homosexuality was a bit strange; also saying that his father would not want anything to do with him anymore if he were gay. Another person said she just didn't like it; also, because they talk in such a posh way. 
R: "I have no problems with it (homosexuality) (...) everybody should decide for themselves. If it makes them happy it's fine by me." (Female, 40+)

One homosexual man explained that it was already a difficult process to accept that you have an intellectual disability and that being gay makes it even more difficult compared to intellectually disabled people who are heterosexual.

R: "I find it (homosexuality) a bit strange actually."

I: "Strange?"

R: "I actually do. And I think the same way about it with girls and girls."

I: "And why is that?"

$R$ : "Well, it looks a bit weird (...) Look, I think a boy and a girl is a good combination. I think it is just strange when boys and boys are together and girls and girls." (Male, 20-29)

So in general the attitudes towards homosexuality were positive. However, some negative connotations were identified in the conversations Most participants reported not having that many experiences with gay people or did not know a lot of gay people.

\section{Relationships}

Half of the participants were in a relationship and two indicated that they were in the process of having a relationship at the time of the interview. Two of the older female participants were married.

There were some interesting issues in their current relationships. Some of the participants mentioned things about their relationship that can be interpreted as divergent from what most people perceive as being normal. One young male participant was looking for long distant relationships on purpose, saying that they are less troublesome than short distance relationships. Another young male participant claimed that his girlfriend is giving more attention to other guys, implying she is cheating on him, supporting this notion by saying that she has a large number of male friends on her social network page. One young female participant has been in a relationship with a 16-year older male. And lastly, a young female participant indicated to have a lot of problems in her current relationship, such as disputes, verbal abuse and issues concerning the drug-use of her boyfriend.

I: "Does he still do drugs?"

R: "No, he doesn't do drugs, although he is still addicted to weed. And I find that really annoying. This is a really, how should I say this, difficult issue in our relationship." (Female, 20-29) 
Issues in previous relationships were also described. In some of these issues the environment had a large, negative, influence, such as parents interfering in the relationship; peers spreading lies about cheating; restrictive rules imposed by staff members hindering the relationship; problems in the home environment.

\author{
I: "But the relationship did end?" \\ R: "Yes." \\ I: "How did that happen?" \\ R: "People were telling stories that were not true." \\ I: "What kind of stories?" \\ $R:$ "That I was seeing someone else." \\ I: "And then she broke up with you?" \\ R: "Yes." \\ I: "Because she didn't believe you?" \\ $R:$ "No, she didn't believe me." (Male, 20-29)
}

The impression arises that some have deviant ideas about what a relationship is. In their eyes, you can have a relationship after just one kiss, one conversation. This might indicate that some find it difficult to assess the current relationship status between them and their potential love interest.

Most partners are met through the institution where they live, where they work, through the internet or through friends. Most of them would like to do fun things with their partner. They would like their partner to be nice. Some mentioned traits like: sweet, spontaneous, grateful, respectful, decent, not doing strange things, not doing drugs. They usually did not refer to the looks of a partner, but to personality traits.

Most find having a relationship important, because they do not want to be alone. They want someone to share their life with and want someone so that they can be there for one another. Some said being single is no fun; however, one person explicitly said that she wants to be single and another girl was indifferent about having a relationship, she sees both the advantages as the disadvantages of having a relationship.

I: "Why is a relationship important?"

$R$ : "You can share something with someone. Now I am just alone." (Male, 20-29)

Sex

Experiences

Of the participants 14 indicated to have experience with having sex. Most participants, who have had sex, reported using or having used condoms. Some said that 
they do not find it necessary to use condoms in a relationship, especially when the female partner is on birth control.

\section{I: "Did you use condoms?" \\ R: "No, I was already on birth control back then." (Female, 40+)}

Some deviant remarks are important to mention. One woman said she never uses condoms, because she believes that they should only be used if you have sex dates. Another guy admits that he did not always use condoms, because it feels better and more intimate to have sex without a condom. And finally, one gay man said he always wants to have safe sex, but it went wrong a few times, resulting in a HIV infection. According to the participant, this happened because his sex-partner said he would use a condom, but ended up not doing that.

\section{Beliefs}

Positive things that were said about sex were: "sex is like a glass of beer"; "sex is addictive"; "sex is pleasure for two"; "sex makes you feel good"; and "sex is important". But also: "it is okay if it doesn't happen"; "sex belongs within a serious relationship"; "sex is not important, but it can be important for maintaining a relationship"; "I am not ready for it"; and "in order to have sex, you have to love and respect each other".

R: "It (sex) is some kind of addictive thing, I don't know.

I: "Could you do without?"

$R$ : "No, I am really honest about that. I could do without, but not for a long period of time." (Male, 30-39)

For some participants, sex is not the most important thing. Others however, do think it is important. They like it and indicated that it feels good, but some do point out that sex should be enjoyable for both people and that love and respect are also important.

\section{Parenthood}

Of the participants 14 indicated that they want to have children or had wanted to have children at some point in their life. Some of them believed that they would be good parents; however, some of them also expressed some concerns. The younger participants mainly indicated that they want to enjoy life first before having any children. Others had concerns regarding whether they are able to raise a child.

R: "Taking care of a child 24 hours a day. I am not sure whether I want that or whether I am able to do that. Because I also have my own problems (...) I already 
have enough difficulties with myself, what if the child has the same genes as I do?" (Female, 20-29)

When asked what you need to raise a child, most answers refered to materialistic things, such as money, a house, good food, toys, clothing and diapers. Most also indicated that they first need a good job, a good relationship and a house.

The interviews gave no indication to whether the topic of parenthood has been seriously discussed with others, even though many indicated to have a child wish.

\section{I: "Do you ever talk about it (parenthood) with someone?"}

R: "This is actually the first time." (Male, 30-39)

\section{Internet/ social media}

It becomes clear from the interviews, that social media play a role in the lives of people with intellectual disabilities. Most of the participants have a profile page on a social network site, such as Facebook or Hyves (Dutch social network site). These profile sites are used to keep in contact with friends. Some indicated to have over 200 hundred friends on their profile page. It is also clear from the responses of the participants that profile sites are at one moment popular and the other moment out of the picture (Hyves). None of the participants used Twitter, some explained that they do not understand how it works. A medium like Twitter proofs to difficult to comprehend.

R: "I have Hyves, but I don't have Facebook, because it seems that a lot of private data is made public, at least that is what I heard. I don't know whether it is true or not. And I don't have Twitter, because I don't even know how it works." (Male, 30- 39)

There are also some social network sites that are mainly used for trying to find a boyfriend or girlfriend. The one mentioned most is Badoo. Two have indicated to have found a girlfriend through such a site; however, one had never met that girlfriend in real-life and the other relationship ended after two days. So it seems that dating sites are an easy way to get into contact with other people; however, so far it does not look like it really leads to a relationship that most perceive as being a normal relationship.

Additionally, some participants indicated to have issues with social network sites, such as receiving negative messages or no responses to messages at all. What is also interesting is that some participants, who have received unwanted sexually oriented messages, do seem to adequately dispose of these people by blocking and deleting the sender of the messages. 
R: "You get messages of people who want to humiliate you. They say racist things, without a reason (...) This happened once (...) Of course I blocked him, so he would never be able to contact me again." (Female, 30-39)

\section{Negative experiences and sexual abuse}

\section{Sexual abuse}

Of the participants 4 disclosed experiences of sexual abuse. All of them were under the age of 23 and placed out of their homes. One of them was a male participant who reported to have been sexually abused by another boy up to the age of 18 for a longer period of time. This happened while he was in boarding school. He explains he was forced to perform oral sex, while being threatened by a knife or gun.

R: "I was sexually abused there (boarding school) for 7 years by another boy. He put a knife to my throat and a gun against my head. I went to the staff, but they did nothing. I also went to the police, but they collaborated with the boarding school, and they did nothing as well. I was thinking what now? I was powerless." (Male, 20-29)

The other 3 cases concerned female participants. One was forced to have sex with two boys, while being threatened by a knife. One of the boys was forced by the other boy to have sex with her. Another female participant was forced to have sex with 16-year older man, with whom she was reported to be in a relationship with at the time. And the third female participant explained that she was forced to perform a hand job on a cousin of hers.

\section{Inappropriate touching}

One of the older men spoke of an experience he had with another man on vacation. They slept in the same room and the other man touched his penis and he did not like that. An older female participant kicked a man in his private parts when he did not listen to her refusal. A younger male participant did a similar thing to a girl when she tried to force him to have sex with him while he did not want to. He kicked her in her stomach, since he saw no other way out.

$R$ : "Yes, I mean he wanted all kinds of things from me and I told him not to touch me, but he wouldn't listen. I then kicked him in his privates and then he had to go to the hospital." (Female, 40+)

Other negative experiences

One older male participant used a razor for pleasuring himself, but it caused injuries to his private parts. He also mentioned that in his previous relationships women would at a certain point say that he has a small penis and is not good in 
bed. Another older male participant explained that he has been used by former girlfriends for money. They would let him buy clothes for them when they went shopping. He also caught a girlfriend cheating on him with another man in his own apartment. An older female participant told about a forced divorce. Things were not going well between her and her husband and caregivers tried to force them to get a divorce against their will. In the end they did not go through with it, because they did not want to divorce each other. It is clear, that this experience left an emotional scar on the participant. Two younger female participants explained they had experiences with guys harassing them over the telephone.

\section{Support/ environment}

\section{Paid care staff}

All participants receive some sort of professional support. Some live within institutions and receive support around the clock; others live by themselves and receive support a few hours a week. Whatever the living situation, paid care staff members play a role in the lives of all participants; 6 participants even reported to be able to go to their paid care staff member for support concerning sexuality-related issues.

$R:$ "These staff members are very trustworthy (...) They do everything for me, I only have to ask them". (Male, 20-29)

However, 7 other participants felt less comfortable talking to the staff about sexuality, explaining that "it's none of their business"; "it would make them feel embarrassed"; "they always talk about the same things, safe sex and condom-use"; and "it is a bit scary to ask the staff members".

I: "Have you ever talked about sexuality with one of the staff members?"

$R$ : "Yes I have. But they always talk about the same things, about condom-use and safe sex, they all say the same things". (Female, 20-29)

Of the participants 4 experienced the involvement of staff members more as interference; one explained about rules imposed by staff members about visiting a dating site. Another participant was forced to divorce her husband, because the support agency felt that it was better for them, but in the end did not go through with it. Another reported that a female staff member wanted to talk to him about sex, but he felt that she had nothing to do with it, since she was "not his mother". And the last person indicated that she wanted more privacy and did not want them to keep an eye on her and her boyfriend all the time.

A girl said something about what a staff member said to her during a conversation about her boyfriend, revealing an ambivalent attitude towards relationships: 
R: "She says: I think everything is okay as long as nothing happens". (Female, $<20$ )

\section{Family}

Family members are not mentioned very often as a support group. Five participants reported to get support from family members or ask for support from family members regarding sexually related topics. These family members can be siblings, parents or aunts and uncles.

\section{Friends}

Only one girl explained she talks about sex with her friends. Three participants mentioned to have many friends, while half of the participants indicated to have between one and five friends. However, they did not mention to talk to their friends about sexuality-related issues. Two participants who were asked the question "who are your friends" answered with the following question: "What are friends actually?". This may imply that they are unsure about who their friends are or whether the people they call friends are truly their friends.

Three have had negative experiences with telling colleagues or friends about their personal lives. They described that they found out that their colleagues or friends would pass on personal information to others, so now they are careful with sharing personal information with other people.

It seems that friends are not the most important group of people for support regarding sexuality-related issues. Nor does it seem that they talk a lot about such topics with their friends. Moreover, it seems that most participants only have a small group of people they call friends. Some do not even mention friends in the interviews.

\section{Advice for sex education by participants themselves}

We asked participants what would be important to tell someone who has not received sex education yet. Almost all participants agreed that safe sex is an important topic that people should know that you should use a condom and that women should use some form of contraceptive. Fewer of them would give some advice about the consequences of not having safe sex, 8 talked about STI's, 2 talked about unwanted pregnancies and 8 participants also mentioned topics that are more on an emotional level. Things such as: "you should be sweet to each other"; and "you shouldn't do things that you don't want to do".

R: (About sex) "They should take it slow and be nice with each other. And if they don't want to (do it), then don't (...) It is important that you find it enjoyable." (Male, 30-39) 


\section{Limitations}

There are some limitations to this study that need to be taken into consideration: The data retrieved from the interviews is in general superficial, due to broad range of topics.

Half of the participants are older people who generally live by themselves; while the other half exists of younger people who live in an institution, due to outof-home placement. Next to differences in age, they also come from very different backgrounds. The young people usually reported problems in the home environment and this is reported less by the older participants.

It has been shown that young adults with intellectual disabilities that have been placed out of their homes run a risk for being sexually abused that is three times higher then their peers (Rapport commissie Samson, 2012). It is therefore expected that more cases are reported by this group of participants.

\section{Conclusions and recommendations}

The goal of this study was to identify what the views of people with intellectual disabilities are on several sexuality-related topics. Additionally, the results are used to provide some implications for future sex education programs. The implications will be discussed in four sections: sex education topics, the frequency in which sex education is taught, determinants and behaviors that need to be addressed, and the context in which sex education is provided.

\section{Sex education topics}

The topics of sex education that are mentioned by the participants seem to be limited and mainly focused on safe sex, condom-use, contraception and STI's. The same results were found in a study by Löfgren- Mårtenson (2011). It is evident that these topics do not cover the entire area of sexuality. As mentioned in the introduction, sex education encompasses several topics: prevention of unwanted pregnancies, HIV/ STI infection, friendships and sexual relationships, prevention of sexual intimidation, sexual abuse and sexual violence, and homosexuality (Schaalma et al., 2009a). Different explanations are possible for the limited amount of topics that have been reported: 1) other topics are not discussed, which would explain why the results are no different from what was found among a non-disabled population (Grauvogl et al., 2012); 2) other topics have been discussed but knowledge about these topics have not been retained; or 3) other topics are not as strongly associated with sex education, and were therefore not mentioned during the interviews.

Moreover, it seems that the knowledge the participants possess is superficial. For example: when asked "How do you know when you are sick (have an STI)?", 
most answered that you know when you get tested. Only few mention symptoms such as fever, lumps on the genitals, itchiness or pain. This lack of depth could be because the education they receive lacks depth or that the information they receive is not retained or too complex to fully understand.

Furthermore, people with intellectual disabilities express the need to find a partner, mostly because they do not want to be alone; which was found by Lesseliers (1999) as well. However, it is known that people with intellectual disabilities have many problems with finding, forming and maintaining relationships (Abbott \& Burns, 2007; Abbott \& Howarth, 2007); which might be due to a lack of knowledge (Healy et al., 2009; Kelly et al., 2009; Leutar \& Mihokovic, 2007; McCarthy, 2009; Murphy \& O'Callaghan, 2004; Siebelink et al., 2006), support (Abbot, 2007; Kok et al., 2009; Lafferty et al., 2012) and skills (Egemo-Helm et al., 2007; Hayashi et al., 2011; Khemka et al., 2005; Miltenberger et al., 1999) in that area. The relationships some reported to have in the interviews were not what most people would consider to be normal healthy relationships. Moreover, some reported to have problems in assessing the relationship status. It is therefore important in sex education to address finding, forming and maintaining relationships as well.

It is clear that most of the participants use social media and find it a useful medium to easily come into contact with other people. It is an environment in which they are like anyone else, but it also makes them vulnerable to negative reactions due to its anonymous nature; however, it is still unclear what the quality of these relationships are. Are they actually real relationships? Some participants do view them as real relationships, but they appear to be superficial. What do people with intellectual disabilities expect of these relationships and what does it add to their social environment and well-being? A study by Szwedo et al. (2012) examined online relationships of young adults and found that forming online relationships can be beneficial for the mental well-being of people who are less socially accepted or capable in forming meaningful relationships in real-life. Two explanations for why it is beneficial to this group of people are provided. The first is that there is more time online to respond to a message and the second that there is no interference of body language online. Body language is hard to interpret for many people with intellectual disabilities, and this barrier is lacking in the online world. This means, that online relationships might actually be beneficial for people with intellectual disabilities, since we know they have issues with forming and maintaining relationships in real-life (Abbott \& Burns, 2007; Abbott \& Howarth, 2007).

When the use of social media would be included in sex education, some things need to be considered. First of all, developers have to be up-to-date on what is "in". For example, including Twitter seems useless, because people with intellectual disabilities find it too complicated. We should also try to establish what the value of online relationships is to people with intellectual disabilities and what they expect of these relationships. Are their expectations realistic? Or do these expecta- 
tions need to be adjusted? Additionally, due to the anonymous nature of the Internet, people in general are more prone to negative reactions online (Jones et al., 2013); the same goes for people with intellectual disabilities. The participants did express good skills to cope with these issues; however, some might not be so capable; meaning that attention needs to be given to this topic. Finally, it is important to have some idea of what they do online, because there seems to be a fine line between social network sites and dating sites. This distinction should be made clear to people with intellectual disabilities.

Pornography is a subject that was not discussed during the interviews; however, the Internet does make pornography easily accessible and most participants have Internet access. It is reported that porn can be inappropriately used by men with intellectual disabilities, because of lack of boundaries and restrictions (Cambridge \& Mellan, 2000). Exposure to porn can lead to an overestimation of the amount of sexual activity in the population and to erroneous ideas about sexuality, such as that sexual pleasure can be obtained without having to be affectionate towards your partner (Zillman, 2000). Moreover, both legal as illegal porn is easily accessible; however, most people with intellectual disabilities might not be aware what is legal and what is not. Sex education could be used to teach people with intellectual disabilities about what legal and illegal porn is and that porn does not equal normal sexual activities.

Finally, most participants expressed a desire of wanting to have children or have had that wish in the past, but are now too old to have children. Unfortunately, unlike safe sex, having children does not seem to be a topic that is discussed often. One participant even talked about it for the first time. Moreover, people with intellectual disabilities should also be taught about the psychological impact of having a baby; especially since the needs of the baby that they describe focus mostly on materialistic things. This could indicate that participants have no realistic idea of what it takes to have and raise a child. Tools like realistic baby dolls, which need to be fed and also cry like real babies, might help people with intellectual disabilities to form a more realistic image of what the impact is of having a baby. Furthermore, it should be discussed what people with intellectual disabilities mean by having a good job, a house and a good relationship, which seem to be requirements for some of the participants for having children, and whether these requirements are realistic in their situation.

Even though current research on parenthood seems to focus on supporting women who are pregnant or couples that already have children, and not on supporting couples or individuals who want to have children (Baum et al., 2010); the results of these studies are also applicable to future parents with intellectual disabilities. There is, for example, a need for parental skills. These parenting skills can be divided in four areas: basic bodily needs, skill development, emotional development and social development (Health Council of the Netherlands, 2002; pp. 78). Parents need to learn more about: child development; how to stimulate child de- 
velopment through play; how to discipline children; how to recognize when children are at risk; and how to "react to the challenges of adolescence" (McConnell et al., 1997). Moreover, people working with parents-to-be should spend time with them and ensure they understand the information that is given to them (Baum et al., 2010). Additionally, a study by Feldman and Case (1999) found that some of these parental skills can be improved with low cost and low tech instructional materials.

\section{Frequency}

It appears that the frequency of sex education sessions is low or it might be that the participants do not remember all the times that they have received sex education. Whether it is a low frequency or they just have forgotten about it, studies show that maintenance of knowledge and skills is needed in order to maintain high levels of skills and knowledge (Schaafsma et al., submitted-a). This means that during their entire lifespan, people with intellectual disabilities should receive some kind of booster sessions to reactivate the knowledge or skills they have acquired in previous sessions.

Additionally, having just as few instructional contacts during a sex education program is probably not enough to attain the right amount of knowledge and skills to significantly improve one's sexual health. McDermott, Martin, Weinrich and Kelly (1999) demonstrated that the amount of sexual knowledge that is acquired is closely related to the number of instructional sessions a person with intellectual disabilities receives; meaning that more sexual knowledge is acquired when sex education is composed of a larger number of sessions. Additionally, having an intellectual disability makes it even more difficult to obtain and retain knowledge and skills in just a few sessions. This would imply that the number of times the participants of this study have received sex education is not sufficient for obtaining the right (amount of) sexual knowledge.

In short, sex education programs should consist of multiple instructional sessions and include booster sessions to ensure knowledge and skills are maintained.

\section{Determinants and behaviors}

It is safely to assume that the quality of sex education that was provided to the participants in this study can be improved. First of all, when teaching sex education the focus should not only be on increasing knowledge (e.g. you should use a condom when you have sex), but also provide people with the right skills to actually perform the correct behaviors (e.g. actually using a condom when you have sex); because knowledge about behavior not always lead to the correct behavior (Bruder \& Kroese, 2005). One participant in this study showed that he intended to always use condoms, but ended up contracting an HIV infection. 
Furthermore, educators, whether these are the parents, staff members or teachers, should be able to teach sex education properly. They should be able and have the confidence to cover all important parts of sex education. Ideally, educators would use materials that have been proven to be effective; however, the effectiveness of current materials for people with intellectual disabilities in the Netherlands, are unknown (Schaafsma et al., 2013). Therefore, educators should use materials that they feel comfortable working with, while being critical about the content of the materials, until effective sex education programs have been developed.

Not many participants are negative towards homosexuality; however, it does seem that most of them do not know many people who are homosexual. Discussing sexual diversity might therefore be an important addition to sex education. Additionally, caretakers are also not always aware of the needs of people with intellectual disabilities who are homosexual (Stoffelen et al., 2013) and might be able to identify their needs when discussing this topic.

Finally, most of the participants have experiences with having sex. When it comes to their attitudes towards sex, some participants indicated it is important and some indicated it is not. In general it seems that for most participants it is more important to be together with someone than to have sex; which is in concordance with previous research (Lesseliers, 1999). Furthermore, even though a few positive things have been said about sex, some also shared some negative experiences, such as sexual abuse and unwanted touching by another person. This is in accordance with other studies that have shown that people with intellectual disabilities are extra vulnerable to sexual abuse (Rapport commissie Samson, 2012; Van Berlo et al., 2011). Additionally, especially for women, sex is not always experienced as something pleasurable (Bernert \& Ogletree, 2013; Fitzgerald \& Withers, 2011; McCarthy, 1999; Shandra \& Chowdhury, 2012). They tend to play a rather passive role in sex (Fitzgerald \& Withers, 2011; McCarthy, 1999) and most sexual acts are geared towards pleasuring the penis (McCarthy, 1999; pp. 141). Even though this study did not discuss sexual acts with the participants, this might give some explanation to why many participants find being with someone more important than the act of sex itself; especially since half of the participants were female.

In order to improve the sexual health of people with intellectual disabilities, negative experiences should be prevented or at least reduced. Knowledge about people's own needs, desires and boundaries are important, but skills to protect one self are important as well. Even though many sex education programs focus on teaching knowledge (Schaafsma et al., 2013), there are studies that have improved self-protection skills in people with intellectual disabilities (Egemo-Helm et al., 2007; Haseltine \& Miltenberger et al., 1990; Lumley et al., 1998; Miltenberger et al., 1999; Watson et al., 1992). These skills should be addressed in future sex education programs as well. 


\section{Environment and Context}

It remains unclear who should be responsible or who are most suitable for teaching sex education. Education on sexuality-related topics seems to come from different resources; from parents, staff members or teachers. Some use supportive materials when teaching sex education and some do not; however, it seems that they do use a mishmash of materials (e.g. using a broomstick or a banana to demonstrate condom-use). Other research shows that even porn is sometimes used for sex education (Cambridge \& Mellan, 2000). It cannot be assumed that everybody is able to teach sex education, due to barriers potential educators might experience, but also due to lack of adequate materials. Research among staff members have shown that staff members may have conservative attitudes (Abbott \& Howarth, 2007; Evans et al., 2009; Gilmore \& Chambers, 2010; Meaney-Tavares \& GavidiaPayne, 2012) or, as was found in this study, may have ambivalent attitudes towards sexuality-related issues. For example, they might express a positive attitude towards people with intellectual disabilities having a relationship; as long as nothing happens (i.e. they don't have sex). Rohleder (2010) found similar ambivalent attitudes in their study, where staff reported to recognize the need for sex education, but also experienced a certain anxiety about the potential harm that sex education might cause, such as expression of sexually inappropriate behavior. Furthermore, staff members have been shown to have a lack of experience in dealing with sexuality (Abbott \& Howarth, 2007; Evans et al., 2009; Gilmore \& Chambers, 2010; Meaney-Tavares \& Gavidia-Payne, 2012), report a lack of training in the area of sexuality (Abbott \& Burns, 2007; Evans et al., 2009; Grieveo et al., 2007), and might therefore lack the ability to teach sex education. Additionally, staff members usually teach sex education reactively (Abbott \& Burns, 2007; Abbott \& Howarth, 2007; Schaafsma et al., 2013), in response to problems, as opposed to teaching sex education preventively. Parents have shown to have even more conservative attitudes towards the sexuality of people with intellectual disabilities than staff members (Cuskelly \& Bryde, 2004), which would make them even more unsuitable to teach sex education.

In conclusion, it can not be assumed that parents, staff members and teachers are all capable of teaching sex education without having received some training or guidance. There are certain barriers that might prevent them from adequately teaching sex education (Schaafsma et al., resubmitted); meaning, that when you want to improve sex education, attention needs to be given to the people who have to teach sex education (Schaafsma et al., 2013); and a proper program should be developed that makes it possible for them to teach sex education (Bartholomew et al., 2011). Literature on, for example, shared decision-making might provide some ideas on the necessary skills for teaching sex education. This literature poses that in order for patients to leave the doctor's office more independent, self-reliant and able than before he or she has arrived, doctors should enable shared decisionmaking; which requires skills such as developing a partnership, determining the 
patient's needs and wishes, identifying choices, discussing choices with the patient, negotiate a decision and resolve conflicts (Godolphin, 2009). Many of these skills are useful for sex educators as well.

With regard to friends, it does not seem they are the most important group of people for support regarding sexuality-related issues. Nor does it seem that they talk about such topics with their friends; which does not seem to be uncommon (Löfgren-Mårtenson, 2004). This might be because friends are not always the most trustworthy people in their environment. But it could also be that friends do not have a lot of knowledge about the topic or do not feel comfortable talking about the subject. For many people with intellectual disabilities school seems to be the most important source of information (Löfgren-Mårtenson, 2004). Moreover, it seems that most participants only have a small group of people they call friends. Some even express ambivalent attitudes towards their friendships, questioning what friendship actually is; which has been found in other research as well (Mason et al., 2013). Some do not even mention friends in the interviews.

\section{Improving sex education}

Summarizing, sex education can be improved by focusing on more sexualityrelated topics than safe sex and prevention of STI's and pregnancy. Additionally, topics such as online relationships, social media, pornography and parenthood should be added. These topics should not be discussed superficially, but more indepth. It would help when educators receive specific program goals from the sex education program, which specifies what people with intellectual disabilities need to know, do and want exactly after completing the program. In this way educators can check whether everything was understood. This is actually a very important part in program development (Bartholomew et al., 2011) and it is something that most sex education programs currently lack (Schaafsma et al., 2013/ submitted-a).

Also, increasing the sexual knowledge of people with intellectual disabilities is not enough; other determinants, such as skills are important as well. Solely increasing knowledge will not necessarily lead to the desired behavior (e.g. condomuse) (Bruder \& Kroese, 2005). Moreover, developers should make sure that programs have multiple instructional sessions (McDermott et al., 1999) and booster sessions to ensure maintenance of knowledge and skills.

Furthermore, it is also the responsibility of program developers to identify the most ideal context for teaching sex education and the most suitable group of people for teaching sex education. Additionally, they should identify potential barriers within this group of people and reduce these barriers, to ensure that people with intellectual disabilities receive proper sex education.

Finally, sex education programs should be systematically developed with a theory- and evidence-base, using a protocol for program development, such as Intervention Mapping (Bartholomew et al., 2011). Developing programs with such 
a protocol will increase the likelihood that the sex education program will be effective in improving the sexual health of people with intellectual disabilities (Albarracín et al., 2005; Bos et al., 2008; de Bruin et al., 2010; Mullen et al., 1985; Peters et al., 2009; van Achterberg et al., 2010; van Empelen et al., 2003). 


\section{Appendix A}

\section{Interview questions:}

\section{Sex education}

- What do you know about sex education?

- What do you thing of sex education?

- Have you ever received sex education?

- (If no) Would you like too?

- Where can you find information on sexuality-related matters? (Internet, friends, books?)

- Can you go to someone when you have sexuality-related questions? (Parents, staff members, teachers?)

\section{Relationships}

- Are you in a relationship?

- (If no) Do you want a relationship?

- (If yes) Who is the person you have a relationship with?

- Have you had previous relationships?

- (If yes) How many relationships have you had?

- What do you like to do with your girl/boyfriend? What would you like to do with you girl/boyfriend?

- What is the difference with normal friendship?

- How do you get a girl/boyfriend?

- What do others (parents, staff members) think of you having a relationship?

- Do you find it important to have a relationship?

Sex

- What is sex? Could you explain it to me?

- What do you think about sex?

- Have you ever had sex?

- Have you ever done something you didn't like?

- Has you partner ever done something he or she doesn't like?

- What do you know about homosexuality?

- What is safe sex?

- Do your friends talk about sex? What do they think about sex?

- Is sex important?

\section{Social media}

- Do you have a profile page on Hyves/ Facebook/ Twitter/ Partyflock etc.?

- Have you ever had an online girl/boyfriend? 
- Have you had sex chats (online)?

- Do you own a webcam?

- Has anyone every shown you their private parts or other naked body parts on the Internet?

- Have you ever shown you own private parts or other naked body parts on the Internet?

Parenthood

- Have you ever thought about having children?

- Would you like to have children?

- What would others think of you having a baby?

- Would you be able to take of a baby?

- What do you need in order to take care of a baby? 


\section{Ha}

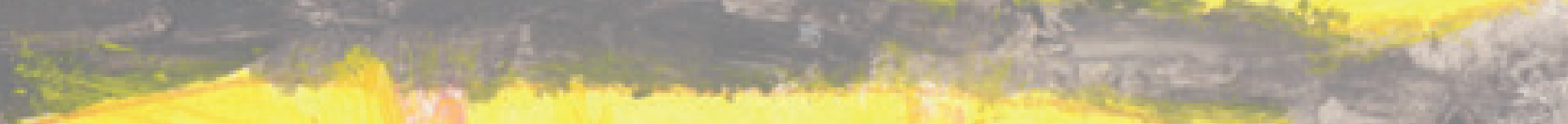

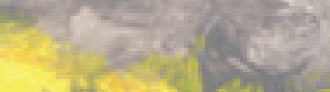

कrothe
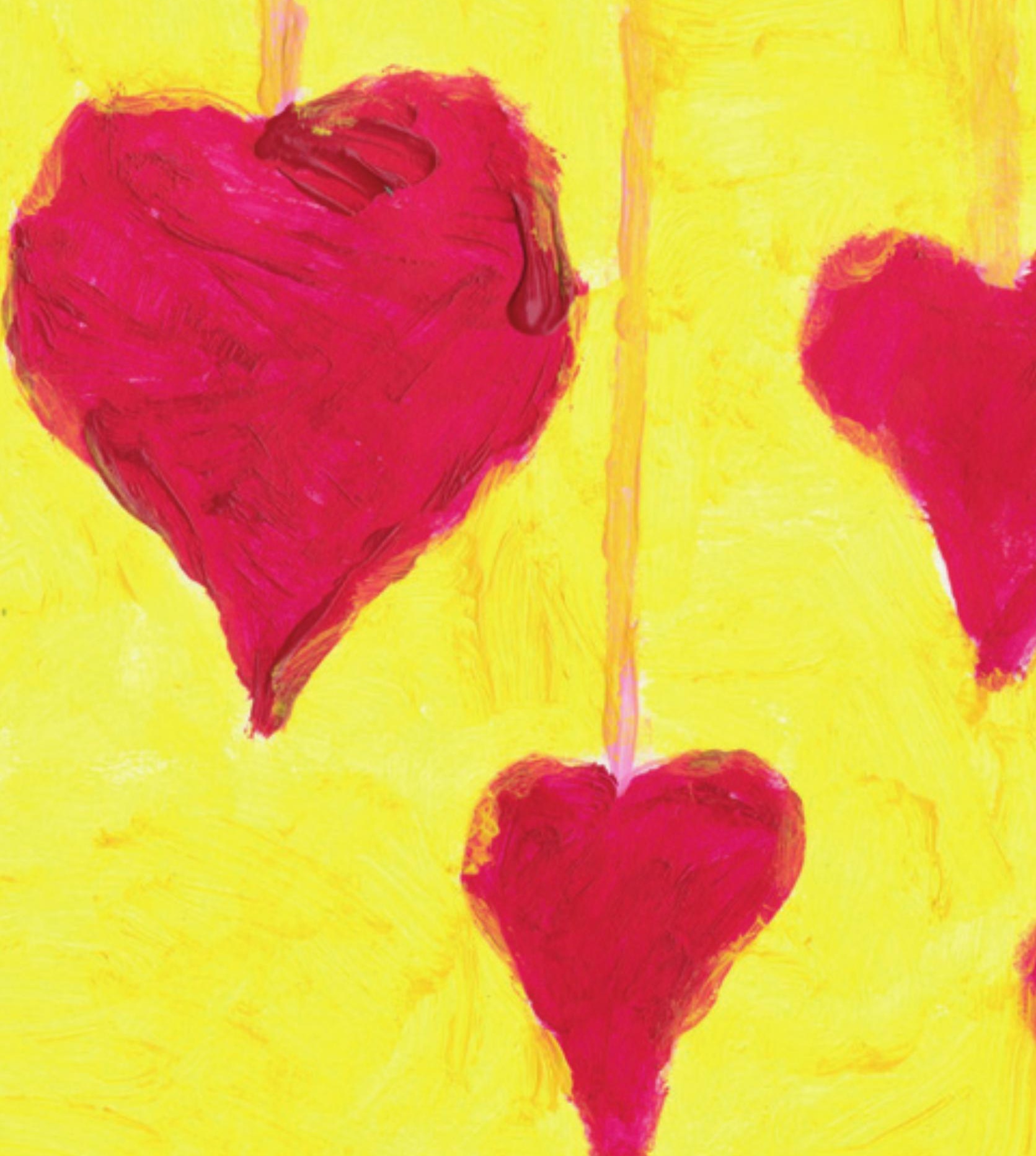


\section{Chapter 5:}

\section{Identifying effective methods for teaching sex education to people with intellectual disabilities: a systematic review}

teaching sex education to people with intellectual disabilities: a systematic review. 


\section{Abstract}

Background Sex education for people with intellectual disabilities is important. However our knowledge about effective methods for teaching sex education to this population is limited. This study reports the results of a systematic review identifying useful methods for sex education for people with intellectual disabilities.

Methods Twenty papers were included based on two criteria: the topic was effectiveness of sex education programs and the population that was being studied were people with intellectual disabilities.

Findings Useful methods for increasing knowledge, improving skills and improving attitudes were reported. However, generalization of skills to real-life situations is often not achieved. There are indications that maintenance of knowledge and skills needs extra attention. Detailed descriptions of the program materials, program goals and the methods used in the program were lacking.

Discussion Although there is some evidence for effective methods improving knowledge, attitudes and skills with regard to sex education, it is unclear under which conditions the methods work, due to the lack of detailed descriptions. It would therefore be preferable that this information is also provided in the papers or in online supplements. 


\section{Introduction}

Having positive sexual experiences will enhance a person's quality of life. On the contrary, having negative sexual experiences will decrease a person's quality of life. People with intellectual disabilities report to have more negative sexual experiences (Eastgate et al., 2011; McCarthy, 1996; Stoffelen et al., 2013; Yacoub \& Hall, 2009) and have been shown to run a higher risk for being sexually abused compared to non-disabled peers (Rapport commissie Samson, 2012; Van Berlo et al., 2011).

So why are they more vulnerable for negative sexual experiences? People with intellectual disabilities lack knowledge or possess erroneous ideas or attitudes regarding sexuality-related topics, such as masturbation, pregnancy, safe sex, reproduction and same-sex relationships (Healy et al., 2009; Kelly et al., 2009; Leutar \& Mihokovic, 2007; McCarthy, 2009; Murphy \& O'Callaghan, 2004). Moreover, people with intellectual disabilities demonstrate unsatisfactory levels of social, behavioral (Egemo-Helm et al., 2007; Hayashi et al., 2011; Miltenberger et al., 1999) and decision-making skills (Khemka et al., 2005). Clearly, these deficiencies are not unexpected knowing that people with intellectual disabilities, in general, have problems with retaining knowledge and acquiring skills (Schalock et al., 2012; Schalock et al., 2010).

Sex education could be used as a tool to improve sexual knowledge and attitudes regarding sexuality, and protective skills of people with intellectual disabilities. Nonetheless, there are some steps that need to be taken to ensure the effectiveness of such a program. First, it is important to start with identifying or conducting studies that will give an understanding of the behaviors that negatively affect the sexual health of people with intellectual disabilities; this is called the needs assessment. Concurrently, the implementation and evaluation of the sex education program are anticipated. Next, it is decided what people with intellectual disabilities need to know, do, feel and want in order to have an impact on their sexual health; these are the goals of the program. Subsequently, methods are chosen that have been proven to be effective in achieving these goals (Bartholomew et al., 2011). These are the first steps that need to be taken before the program materials can actually be produced.

Although this sounds very commonsensical and straightforward, it is known that these steps are not always taken by program developers and that programs are not always developed with a theory- and evidence-base (Schaafsma et al., 2013). This decreases the quality of the programs, because non theory- and evidence-based programs are not as effective as theory- and evidence-based programs (Albarracín et al., 2005; Bos et al., 2008; de Bruin et al., 2010; Mullen et al., 1985; Peters et al., 2009; van Achterberg et al., 2010; van Empelen et al., 2003). Moreover, existing sex education programs are usually not evaluated for their effectiveness (Blanchett \& Wolfe, 2002; Schaafsma et al., 2013; Whitehouse, 1997). 
There is an extensive body of literature that gives us information on which theory-and evidence-based methods are useful for changing knowledge, skills, attitudes, risk perception and other important determinants (Bartholomew et al., 2011); however, this information is not based on studies aimed at people with intellectual disabilities. It is therefore possible that some of these methods might not be useful in programs targeting people with intellectual disabilities; because some of these methods require, for example, high levels of cognitive skills (e.g. planning coping responses).

This review aims at compiling a body of literature that will provide more information on what methods can be used effectively in sex education programs for people with intellectual disabilities. More specifically, this review focuses on studies that have investigated the effectiveness of sex education or sex educationrelated materials.

\section{Methods}

\section{Literature search and selection}

The literature search consisted of three steps. The first step was creating a search string that was used to search through the relevant databases. The second step was asking known experts in the field of sexuality and intellectual disabilities whether they were aware of any relevant studies for this review. And finally, it was checked in Web of Science in which publications our final selection of articles were cited.

The search string contained three concepts: intellectual disability, sexuality and education. Synonyms and related terms were identified for the three concepts (see Table 1).

Table 1. Keywords that were used for building the search string.

\begin{tabular}{lll}
\hline Concept & Synonyms or related terms & Search field \\
\hline Sexuality & $\begin{array}{l}\text { Sex or sexual* or condom-use or safe sex or birth } \\
\text { control or contraception or family planning or } \\
\text { homosexual* or gay or lesbian or bisexual* }\end{array}$ & Abstract, title, keywords \\
& $\begin{array}{l}\text { Educat* or promotion or intervention or curriculum } \\
\text { or teaching or training or campaign or course or } \\
\text { leaflet or folder or movie or film or video or media } \\
\text { or quiz or exercise or instruction or learning or class } \\
\text { or seminary or counseling or therapy }\end{array}$ & Abstract, title, keywords \\
Intellectual disability & $\begin{array}{l}\text { Mental* retard* or intellectual disabilit* or learning } \\
\text { disabilit* or developmental disabilit* or cognitive } \\
\text { disabilit* or intellectual impairment or mental } \\
\text { deficiency or mentally defective or psychosocial } \\
\text { retard* }\end{array}$ & Abstract, title, keywords \\
& & \\
\hline
\end{tabular}


The databases that were used to find articles were Pubmed, Psycharticles, CINAHL, PsychINFO and Psychology and Behavioral Sciences Collection. Articles that appeared in the last 30 years were included (for an overview of the search strategy, see Figure 1). The search string was run for the first time in October 2011. Combining the articles found in the five databases resulted in a list of 838 articles. Two reviewers checked the articles between 1981 and 1998 and two other reviewers checked the articles between 1999 and 2012. In the first selection, articles were included based on the following criteria: the article is about sexuality, the target population is people with intellectual disabilities and the paper should be related to sex education. Only journal articles that were written in English were included. Disagreements by the two reviewers were checked by a third reviewer, who then decided to include or exclude the paper. This resulted in a selection of 284 articles. One person then checked the abstracts of the articles; excluding articles on a number of criteria (see Figure 1). This resulted in a list of 59 articles. The complete content of these articles was checked. It was important that the article contained research investigating the effectiveness of sex education materials, a sex education program or materials related to sex education; such as teaching selfprotection skills. This reduced the list to 23 articles. Consequently, Web of Science was used to check in which papers these 23 articles were cited. This resulted in 4 new additions to the list. Finally, to make sure the most recent publications were included, the search string was run again in January 2013. This did not result in any new additions. This list of 27 articles was checked again by two reviewers. Disagreements by the two reviewers were checked by a third reviewer, who then decided to include or exclude the paper. This resulted in a final list of 20 articles that were included in this paper (see Appendix A).

Experts in the field of intellectual disabilities were asked whether they were aware of any papers that should be included in this review; this did not result in any new additions.

\section{Results}

The articles were compared on a number of topics. First of all, the materials and theoretical methods used to teach knowledge, improve attitudes or increase skills are reported. This is important, because effectiveness of the materials is directly related to the quality and content of these materials. Second, the design and the measurements used in the papers were examined, because the quality of the design and measurements greatly influence the generalizability and credibility of the results. And finally, we checked the results of the studies to see whether there are any indications that certain methods are effective in teaching people with intellectual disabilities about sex education. 


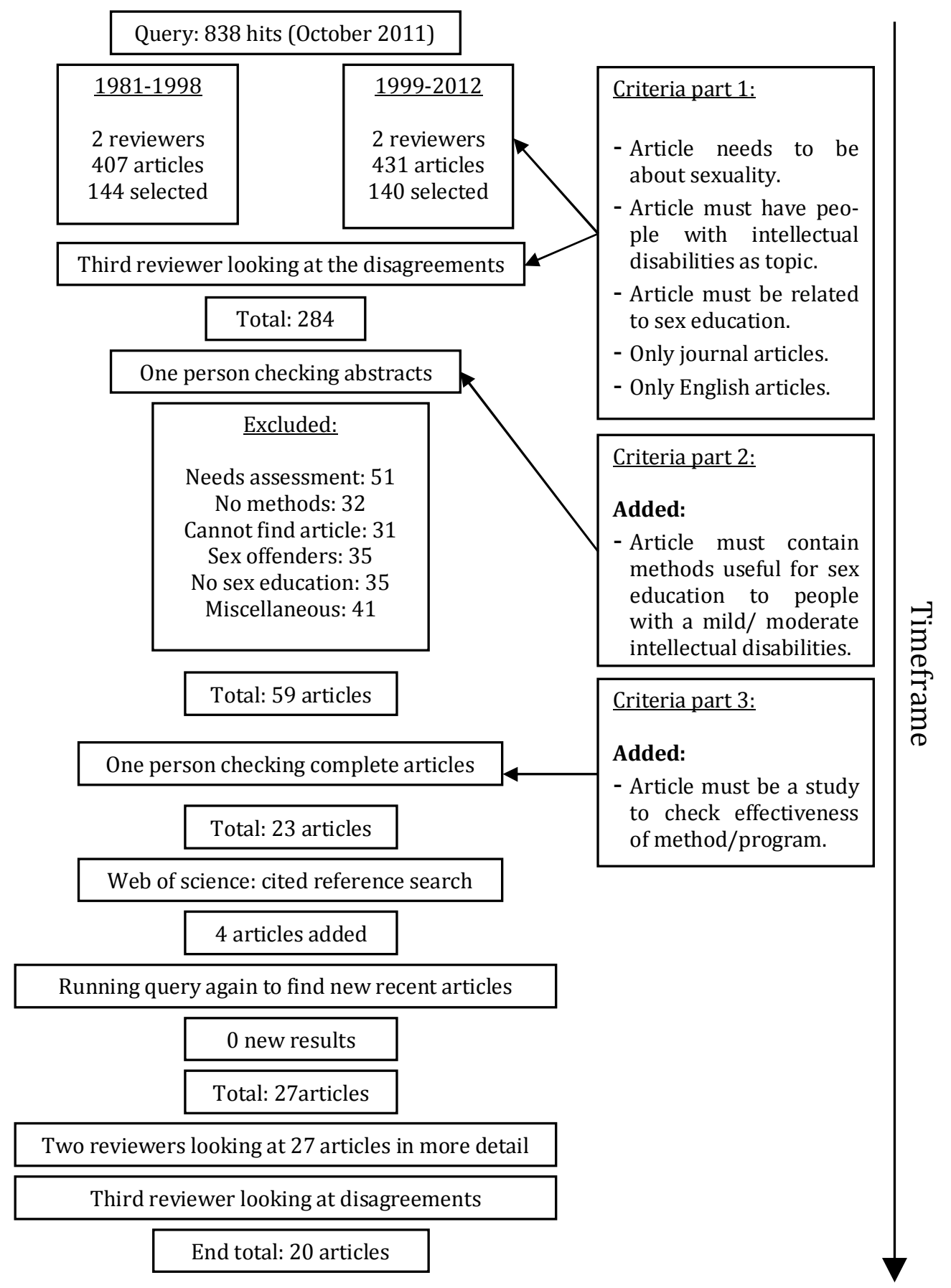

Figure 1. The review process. 


\section{Sex education material/ program}

In 15 articles $(1,3,5,7-11,13,15-20)^{5}$ a description is provided of the sexualityrelated topics that are being addressed in the program. Furthermore, 15 articles $(1,3-6,8-12,14,16,17,19,20)$ report methods that are used to teach knowledge, skills or attitudes. But both the descriptions of the topics as the descriptions of the methods were in general very broad and nonspecific (see Appendix A). Nor is any reasoning provided for the choice of topics or the methods used in the program. Additionally, the goals of the program or materials are in most cases not reported in the papers. Finally, no support can be found that the sex education programs or materials have been systematically developed or contain a theory- and evidencebase.

\section{Reported methods}

In the papers comparable methods to teach participants skills and/or improve their knowledge are reported: (Corrective) feedback $(1,3,7-9,11,16,17,20)$, roleplay/practice skills/ guided practice $(3-7,9,11,13,15-17,19,20)$, modeling $(3,5$, $8,9,13,16,17,20)$, rehearsal $(1,3,5,7-9,11,16)$, reinforcement $(1,8-11,16,17)$, imagery/ images $(5,10,15,18-20)$ and discussion $(5,7,10,13,15,19)$. However, details were not provided on how these methods were executed; nor were any parameters for use provided, so it is unknown whether the methods were implemented correctly.

\section{Study designs}

Two types of quasi experimental study designs were commonly reported in the papers: the multiple baseline design $(1,3,5,9,11,16-18)$ or a pretest/ posttest design with $(4,6-8,15)$ or without $(2,10,12-14,19,20)$ a follow-up measurement. The duration between the post-test and the follow-up lay between $1 / 3$ weeks and 6 months. Out of the 12 studies that used a pre-test/ post-test design, 4 did not use a control group $(10,12,14,20)$.

\section{Measurements}

Of the 13 studies $(3,5,7-9,11-13,15-17,19,20)$ that focused on skill acquisition, 3 studies $(2,6,14)$ focused on attitude change and knowledge improvement, and two studies $(4,18)$ only focused on knowledge improvement. Of the 13 studies that focused on skill acquisition, $6(3,5,7,9,11,16)$ used some form of an ecologically valid assessment, such as an in situ assessment or naturalistic observation. The other studies used measurements such as role-play (17), demonstration of skills

\footnotetext{
5 The numbers refer to the articles in Appendix A.
} 
(20), and a questionnaire or interview/self-report $(8,13,15,19)$ to measure skill level. The 3 studies which focused on improving knowledge and changing attitudes, used questionnaires as measurements.

\section{Reported findings}

\section{Knowledge}

The general goal, as stated in these papers, is increasing knowledge in the area of sexuality. An increase in knowledge was reported in 13 studies $(1,2,4-6,8-10,14$, $15,17,18,20)$; indicating that it is possible to improve the sexual knowledge of people with intellectual disabilities.

\section{Attitudes}

There were 3 studies $(2,4,14)$ that included attitudes in their outcomes. All 3 studies reported an improvement in the attitudes of their participants towards sexuality-related topics. Participants showed a more liberal attitude after the program than before the program.

\section{Skills}

Of the 13 studies that included skills training, $5(3,5,9,11,16)$ focused on selfprotection skills. In general the training contained the steps: 1) verbally refuse request; 2) remove yourself out of the situation; and 3) report incident. The results of these studies showed that these skills can be taught, but generalization of the skills to real-life situations was not achieved for all participants.

The 8 other studies $(7,8,12,13,15,17,19,20)$ focused on improving a range of skills: social skills, protective skills, decision-making skills, behavioral skills and dating skills. One major limitation is that 5 of these studies $(8,12,13,15,19)$ assessed skill levels through a questionnaire or verbal report. The other three used role-play (17), demonstration of skills (20) or observation (7) to assess the skill level.

\section{Discussion}

This review was conducted to identify effective methods for teaching sex education tot people with intellectual disabilities. The various studies that were included in the review were compared on a number of topics: the sex education materials that were used, the methods that were described, the design of the study, measurements used to measure effectiveness of the sex education materials and the results of the studies.

There are some indications that skills, knowledge and attitudes can be improved and increased. It also became apparent that some studies used comparable 
methods. Nevertheless, there are some matters in these studies that need improvement. What is being taught to people with intellectual disabilities and how it is being taught does not seem to be the focus of the research papers. It seems as if the underlying assumption is that the sex education materials and programs used in the studies are effective in positively changing the determinants (e.g. knowledge, skills and attitudes) they focus on, since no evidence is provided on the quality of the programs in this paper or in another source. Since it is not uncommon in the field of sex education geared towards people with intellectual disabilities that programs have no theory- and evidence-base and have not been evaluated (Blanchett \& Wolfe, 2002; McCabe, 1993; Schaafsma et al., 2013; Whitehouse, 1997), it is might be that the programs and materials in the papers of this review lack a theory- and evidence-base as well. One paper even explicitly mentions that the programs are practice-based (Garwood \& McCabe, 2000). However, it is not entirely certain, because no detailed descriptions of the materials are provided. This is an important issue, because programs have been shown to be more effective when they are developed with a theory- and evidence-base (Albarracín et al., 2005; Bos et al., 2008; de Bruin et al., 2010; Mullen et al., 1985; Peters et al., 2009; van Achterberg et al., 2010; van Empelen et al., 2003).

In addition, most of the goals that have been described by the papers are broad and nonspecific. For example, a goal described by some of the studies is increasing the sexual knowledge of the participants (Caspar \& Glidden, 2001; Dukes \& McGuire, 2009; Garwood \& McCabe, 2000; Lindsay et al., 1992; Lumley et al., 1998; McDermott et al., 1999; Robinson, 1984; Valenti-Hein et al., 1994; Wells et al., 2012; Zylla \& Demetral, 1981). What is missing here is the question of what people with intellectual disabilities need to know, do and feel exactly in order to increase their positive sexual experiences. This question leads to much more specific goals. This is precisely what protocols for program development such as Intervention Mapping do (Bartholomew et al., 2011). Specific goals are defined and methods are chosen that match these goals. Producing specific goals for sex education programs and describing them in the research papers, such as the papers in this review, in detail is essential for measuring the true effectiveness of sex education materials or programs. The only papers that do describe specific goals are the ones investigating self-protection skills training (Egemo-Helm et al., 2007; Haseltine \& Miltenberger, 1990; Lumley et al., 1998; Miltenberger et al., 1999; Watson et al., 1992). They propose a specific number of steps a participant needs to perform in order for the program to be successful (refuse request, leave the situation and report incident).

Similar to the way goals have been reported in the papers, the reported methods used in the sex education materials and programs were not clearly described as well. Similarities in reported methods between the different papers were found, which gives us an indication to what might be useful for sex education; however, the papers do not specify what is done exactly. This is essential, because it has 
been shown that theoretical methods only work under certain circumstances (Bartholomew et al., 2011; pp. 309). To make it possible for other program developers to successfully replicate effective programs and use the methods described by these programs, it would make sense to describe the methods in detail and include the 'parameters for use' as well (Abraham \& Michie, 2008; Schaalma \& Kok, 2009b).

But what can be said about the methods that have been identified? It seems that methods such as modeling, role-play, rehearsal and practice skills could be quite useful for teaching people with intellectual disabilities skills. This is in line with Bruder and Kroese (2005) who concluded that three elements are essential when teaching protective behaviors: 1) information and instruction; 2) modeling and rehearsal of skills in role-play; and 3) testing and rehearsing skills during in situ assessment (e.g. in real-life situations). These elements are important because having the knowledge on how to perform the correct behavior does not necessarily lead to the correct behavior, and correct behavior performed during role-play assessment does not necessarily generalize to correct behavior in real-life situations (Egemo-Helm et al., 2007; Lumley et al., 1998; Miltenberger et al., 1999; Watson et al., 1992). Moreover, where modeling is a theoretical method known from literature; role-play, rehearsal and practice skills are actually part of the method 'guided practice'. This method is defined as: "Prompting individuals to rehearse and repeat the behavior various times, discuss the experience, and provide feedback". And the method comes with clear parameters for use: "subskill demonstration, instruction, and enactment with individual feedback; requires supervision by an experienced person; some environmental changes cannot be rehearsed" (Bartholomew et al., 2011; pp. 342). Also, reinforcement and corrective feedback seem to be commonly used methods. Nonetheless, there is no evidence that parameters for use have been taken into account by developers of the program materials, since detailed descriptions are lacking. Therefore it is unknown whether the methods are applied effectively.

Another interesting difference between the studies is the study design. The studies in this review use two different types of quasi experimental study designs, a pre-test/ post-test design or a multiple baseline design. Both designs have their advantages and disadvantages. The advantage of a multiple baseline design is that it measures the effect of a program using a small sample of participants. However, program effectiveness might be more sensitive to the influence of individual characteristics. It is therefore hard to assess the generalizability of a program with a multiple baseline design. For assessing generalizability a design with a larger sample is needed. Not to mention that a multiple baseline design is very timeconsuming and therefore expensive, due to the multiple measurement points. For generalizablity of a program, a pre-test/ post-test design with a control group seems to be more appropriate. A control group is important, since it is not possible to assign the results on the post-test to the program when a control group is lack- 
ing (e.g. improvement could be due to the passing of time). This kind of design also requires a larger sample, which reduces the influence of individual characteristics on the results. However, a large sample is not always available, especially in minority populations; which would make a multiple baseline design a good second choice.

Regarding measurements, testing and rehearsing skills in situ is important (Bruder \& Kroese, 2005), because generalization from a practice-environment (e.g. role-play assessment) to a real-life environment is not always successful (EgemoHelm et al., 2007; Lumley et al., 1998; Miltenberger et al., 1999; Watson et al., 1992), as was mentioned before. Moreover, measuring skills with a verbal report, such as an interview or questionnaire, is also possible; for example, the participant could be asked a question about condom-use, to see whether the frequency has been increased after the program. However, next to the possibility of receiving socially desirable answers from the participants, these kinds of measurements are really inaccurate and unrealistic when it is about behaviors that do not happen frequently, such as sexual abuse. For example, the researcher could ask the participants what they would do in sexually abusive situations, but the answer will not necessarily reflect the true response in such a situation. Therefore, in situ assessment would be more suitable than verbal report for assessing outcomes such as social skills (Garwood \& McCabe, 2000; Hayashi et al., 2011), decision-making skills (Khemka et al., 2005) and self-protection skills (Lee, 1998).

\section{Limitations}

The articles included in this review were journal articles available online. An attempt was made to retrieve some articles by sending the authors a request by email; however, this was not always successful. Moreover, no grey literature or books were included.

Additionally, the sex education materials that were used in the studies were not further investigated. This review only looked at the information that was provided in the paper itself. Of course, we are fully aware that word restrictions of the journals can influence the amount of information that is provided in the articles about the sex education materials.

Finally, the papers that were included contained methods that might be useful for sex education. Of course, other fields of research may also contain information on what methods might be useful for teaching sex education; however, these were not explored in this review. 


\section{Recommendations}

Summarizing, there is a need for more detailed descriptions of program materials, goals of the program and methods used in the program, so that there will be a better understanding of what is effective for this target population. Schaalma and Kok (2009) go even further by saying that program descriptions should not only describe what is included in the program, but also why it is included in the program. Program developers have to find a balance between what would be effective in the ideal world and what is feasible, efficient and ethical in the current context. Reporting when and how the program development was affected by practical or political decisions will contribute to the quality of future programs. Additionally, Abraham en Michie (2008) make a plead for more standardized taxonomy of methods, since this will make it easier for other program developers to replicate effective programs.

A problem could be that journals may have restrictions regarding the number of words; however, it becomes more and more common to publish supplements online as well. This gives researchers the opportunity to publish program manuals containing detailed descriptions on the methods that were used in the program. Additionally, this prevents details from getting lost or misplaced over time, which increases replicability of the program and makes it possible for other researchers to critically scrutinize the content of the research paper (Peters et al., 2012). This will, in the long run, improve the quality of research.

Of course, it is also important that sex education programs and materials are theory- and evidence-based, since these programs are more likely to be effective that non theory- and evidence-based programs (Albarracín et al., 2005; Bos et al., 2008; de Bruin et al., 2010; Mullen et al., 1985; Peters et al., 2009; van Achterberg et al., 2010; van Empelen et al., 2003). Future program developers could look at information on existing theoretical methods for improving determinants such as knowledge, attitudes and skills (Abraham \& Michie, 2008; Bartholomew et al., 2011). However, these methods have been rarely tested on people with intellectual disabilities, so additional research is needed to find out which methods would be suitable for this target population. Additionally, it is useful to further investigate the applicability of the methods used in the papers of this review, taking their parameters for use into account (see Table 2), and targeting goals that are more specific; because goals of current sex education programs are broad and nonspecific, making them easier to achieve.

It is important that sex education programs do not only address knowledge regarding how to do something, but also teach the skills on how to do it. Moreover, generalization of skills to real-life situations should be considered, because knowledge about the correct behavior does not necessarily lead to a change in behavior, and demonstration of behavior during role-play assessment does not automatically lead to the correct behavior in real-life situations (Bruder \& Kroese, 2005; Caspar 
\& Glidden, 2001; Dukes \& McGuire, 2009; Garwood \& McCabe, 2000; Lindsay et al., 1992; Lumley et al., 1998; McDermott et al., 1999; Robinson, 1984; Valenti-Hein et al., 1994; Wells et al., 2012; Zylla \& Demetral, 1981).

Table 2. Methods mentioned most frequently in the papers; plus the definition and parameters for use (Bartholomew et al., 2011).

\begin{tabular}{lll}
\hline Method & Definition & Parameters for use \\
\hline Modeling & $\begin{array}{l}\text { Providing an appropriate model being } \\
\text { reinforced for the desired action. }\end{array}$ & $\begin{array}{l}\text { Attention, remembrance, self-efficacy } \\
\text { and skills, reinforcement of model, } \\
\text { identification with model, coping model } \\
\text { instead of mastery model. }\end{array}$ \\
\hline Guided practice & $\begin{array}{l}\text { Prompting individuals to rehearse and } \\
\text { repeat the behavior various times, } \\
\text { discuss the experience, and provide } \\
\text { feedback. }\end{array}$ & $\begin{array}{l}\text { Subskill demonstration, instruction, } \\
\text { and enactment with individual } \\
\text { feedback; requires supervision by an } \\
\text { experienced person; some }\end{array}$ \\
& $\begin{array}{l}\text { environmental changes cannot be } \\
\text { rehearsed. }\end{array}$ \\
\hline Reinforcement & $\begin{array}{l}\text { Linking a behavior to any consequence } \\
\text { that increases the behavior's rate, } \\
\text { frequency or probability. }\end{array}$ & $\begin{array}{l}\text { Needs to be tailored to the individual, } \\
\text { group, or organization, to follow the } \\
\text { behavior in time, and to be seen as a } \\
\text { consequence of the behavior. }\end{array}$ \\
& $\begin{array}{l}\text { Giving information to individuals and } \\
\text { environmental agents regarding the } \\
\text { extent to which they are accomplishing } \\
\text { learning or performance, or the extent } \\
\text { to which performance is having an } \\
\text { impact. }\end{array}$ & $\begin{array}{l}\text { Feedback needs to be individual, follow } \\
\text { the behavior in time, and be specific. }\end{array}$ \\
\hline (Corrective) feedback & \\
\hline
\end{tabular}

Therefore, researchers and program developers should also consider assessing skills in situ when evaluating a sex education program. This will provide a more accurate representation of skills than a role-play assessment. Of course, in the context of sex education, in situ assessment will not always be appropriate or possible. For example, it is not possible to assess condom-use directly; therefore self-report measurements would be more appropriate in this kind of situation.

Finally, it is important to consider the type of research design for testing the effectiveness of the sex education program or materials. This depends of course on sample size; where multiple baseline design might be more suitable with smaller samples and pre-test/ post-test design with larger samples. Also, follow-up measurements are necessary to see whether the effects of the sex education program are maintained. 


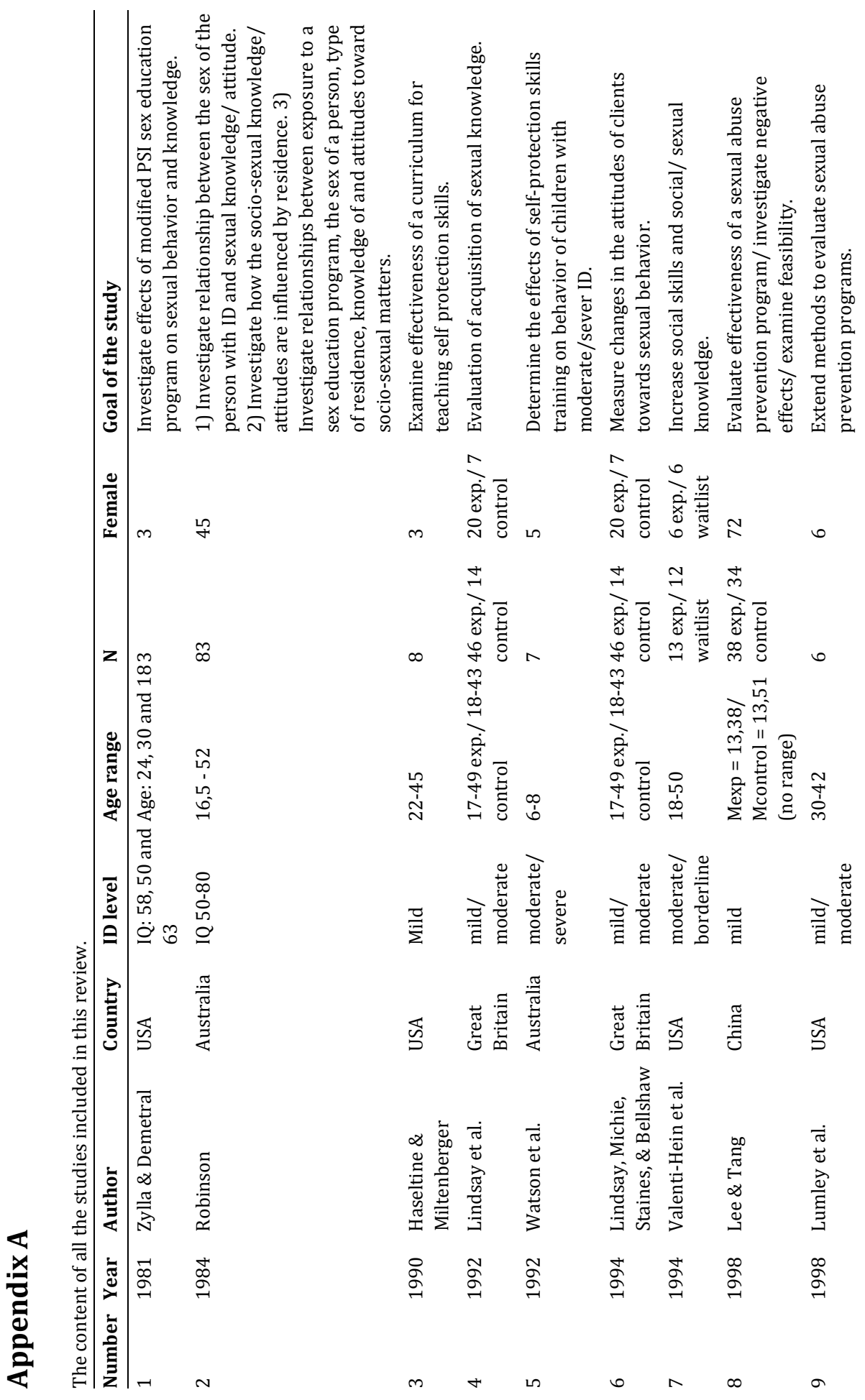



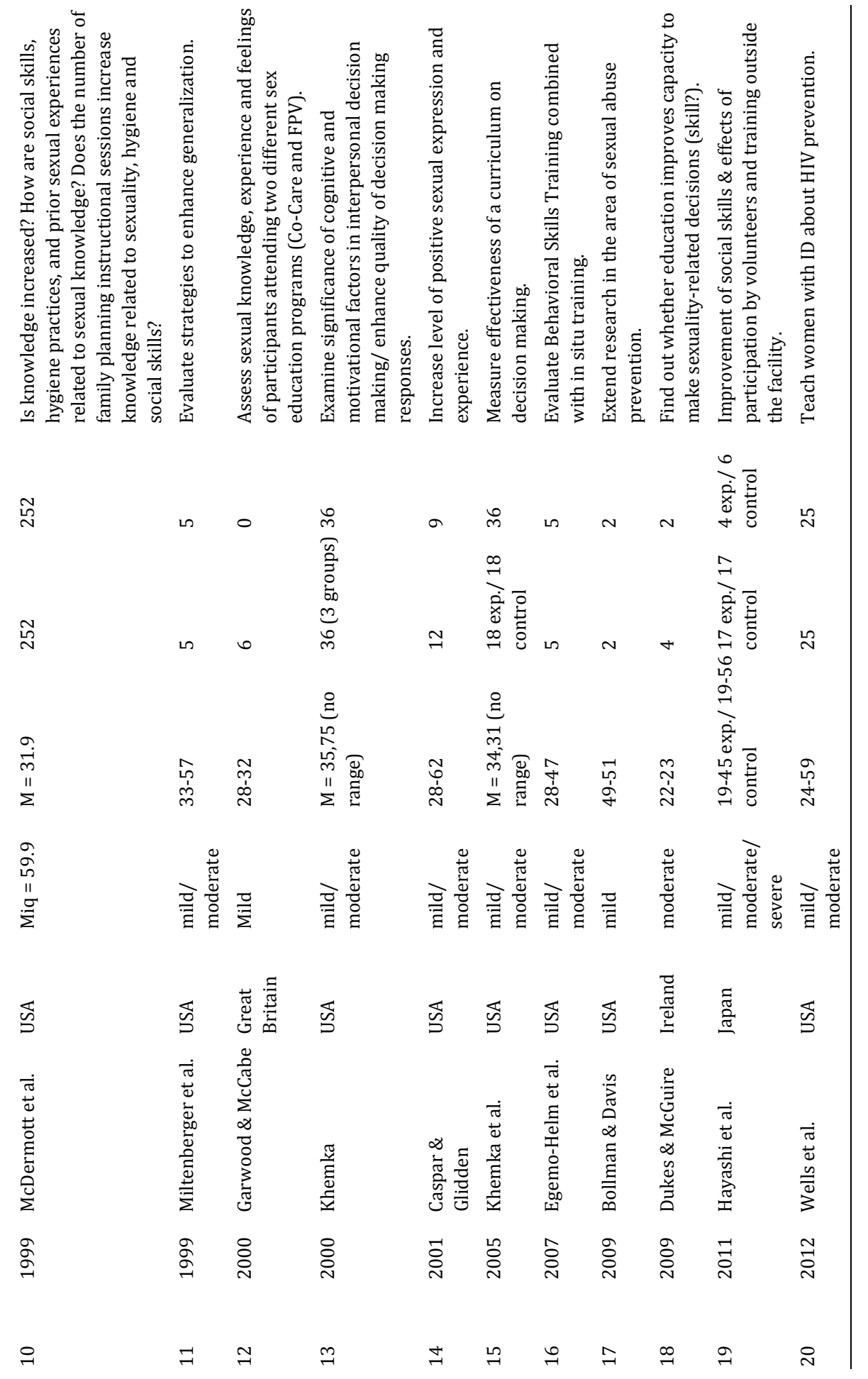


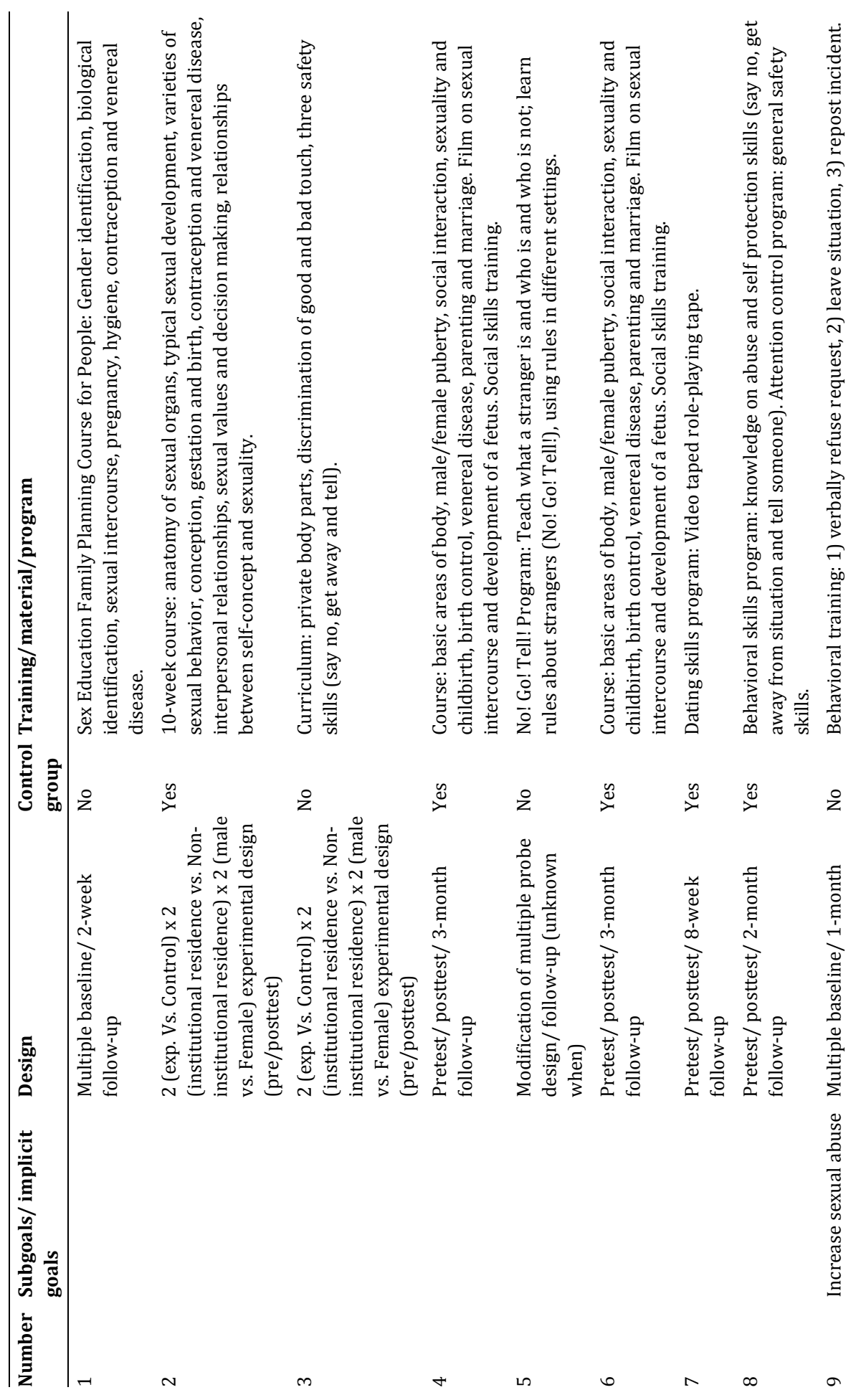



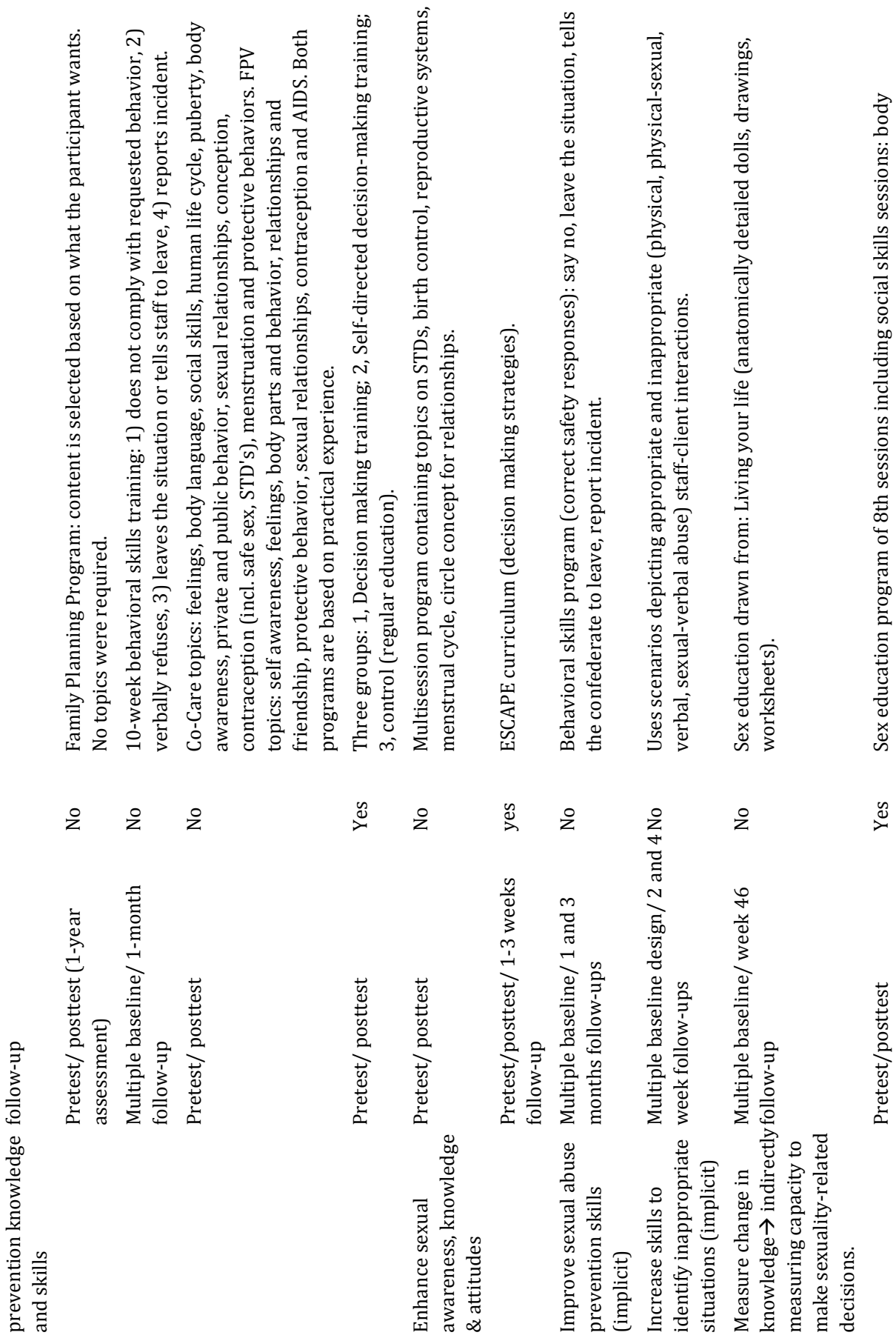

그

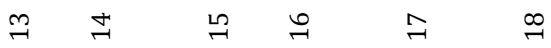

구 
Chapter 5
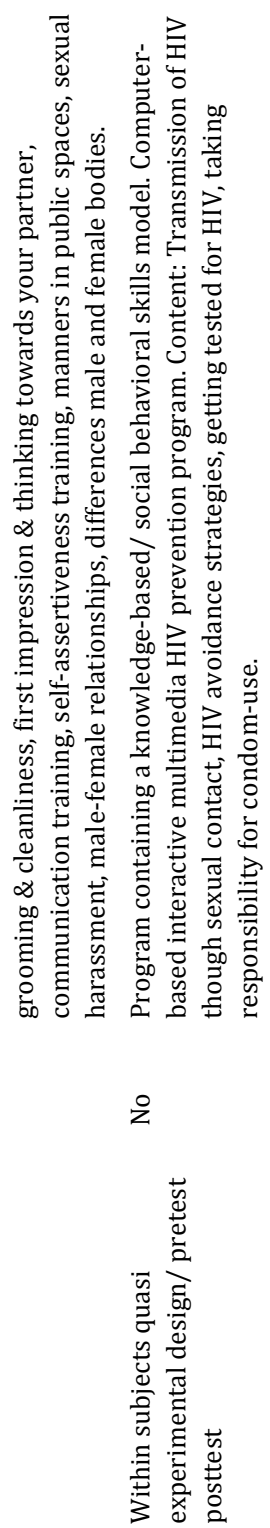

ำ 


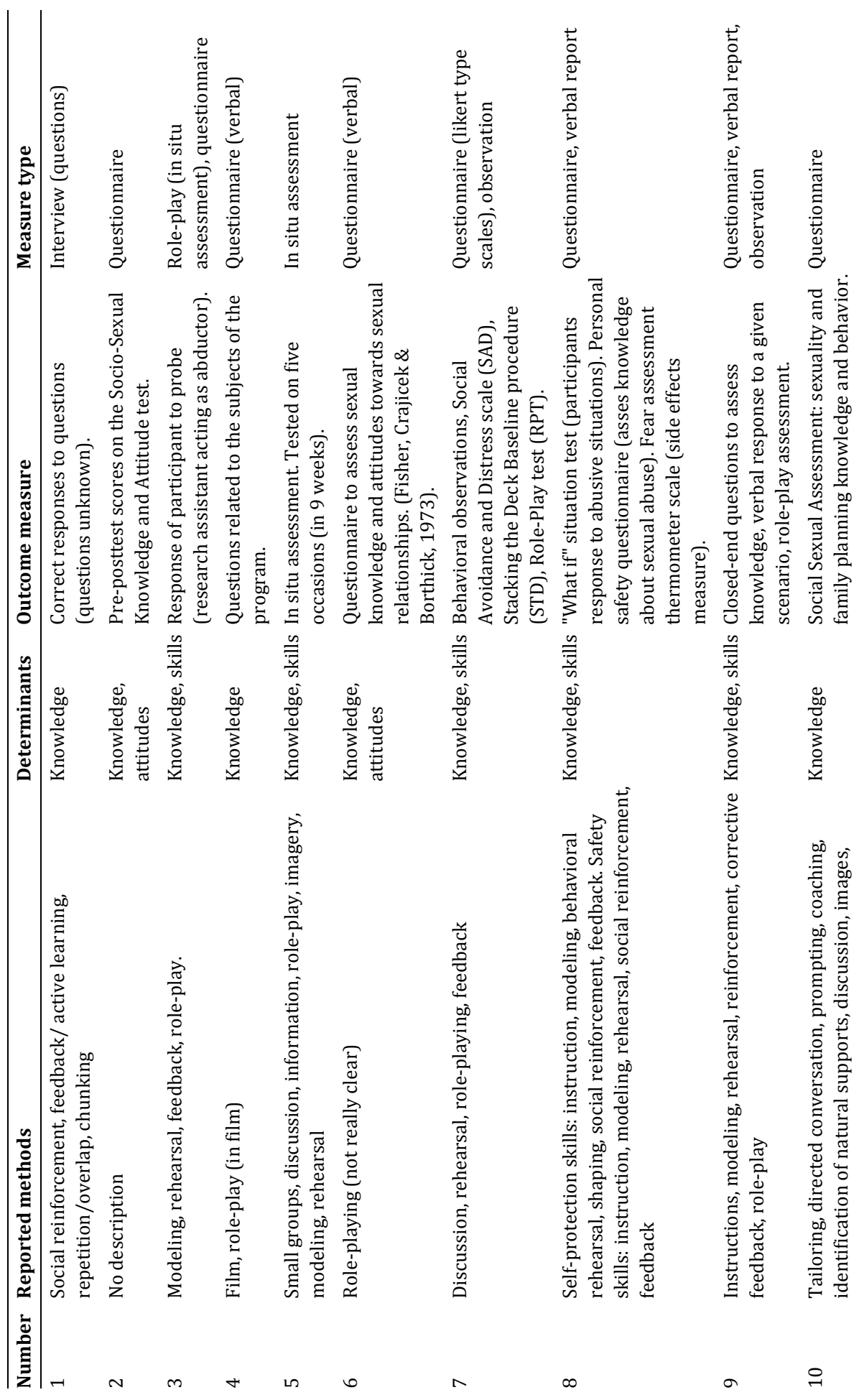



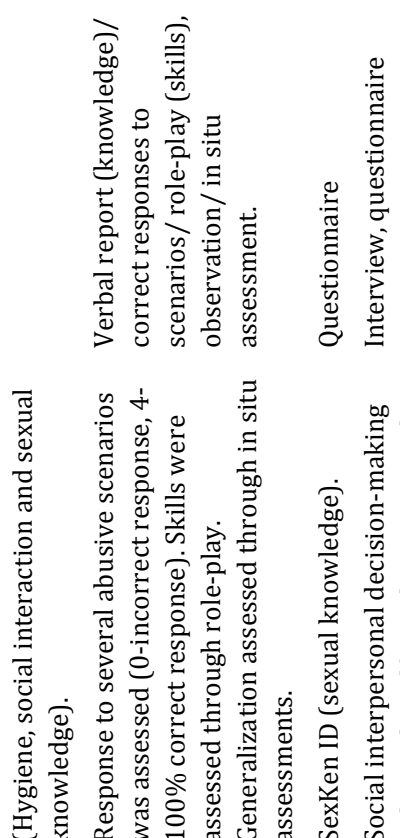
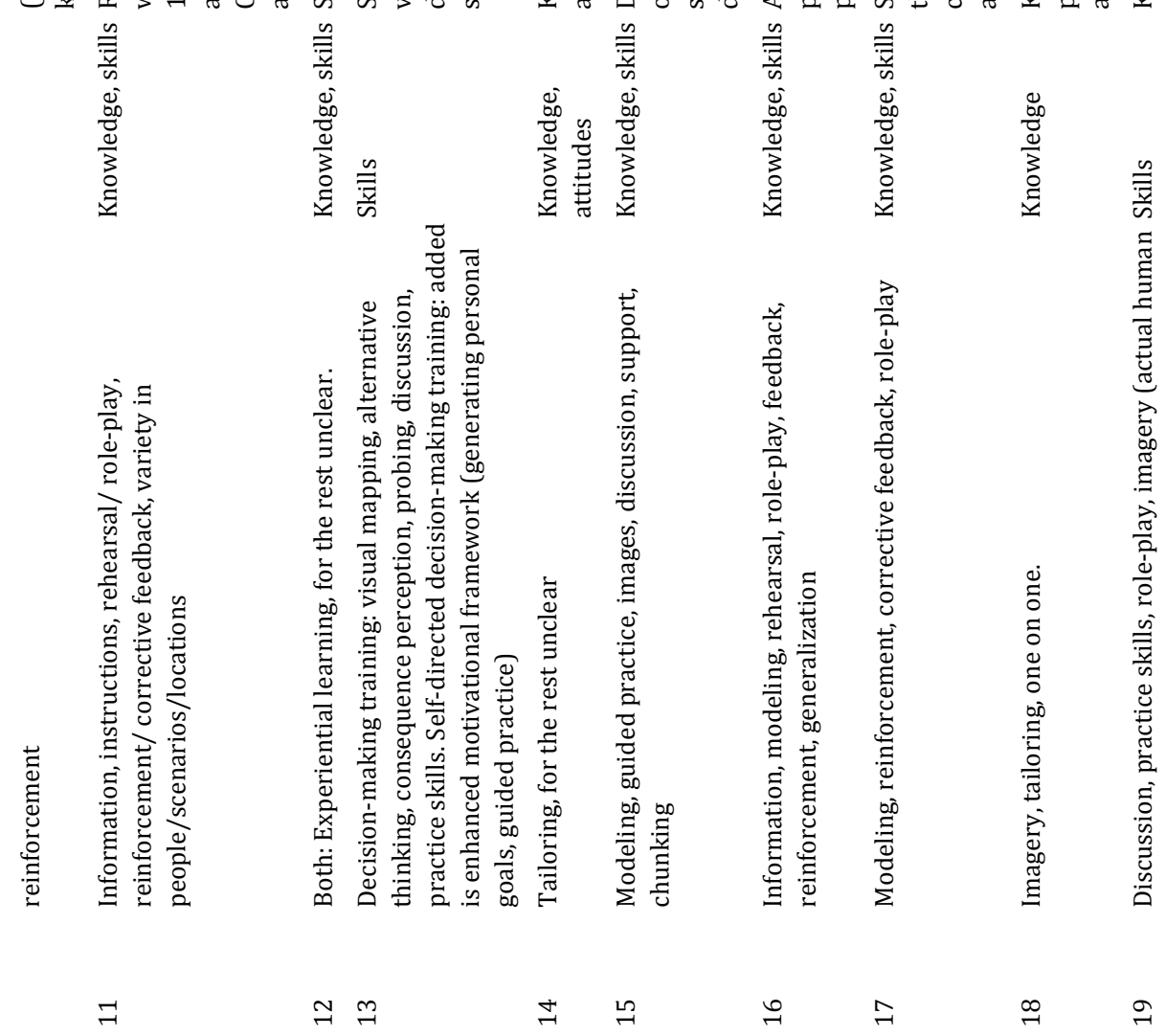

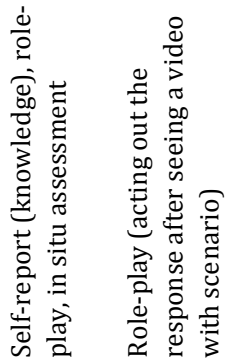

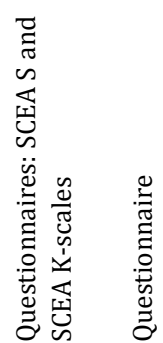

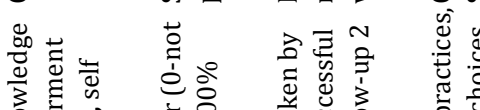

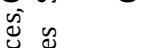

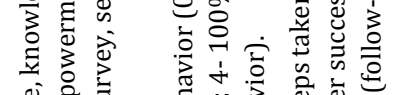

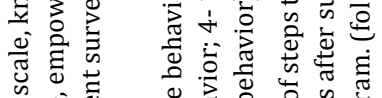

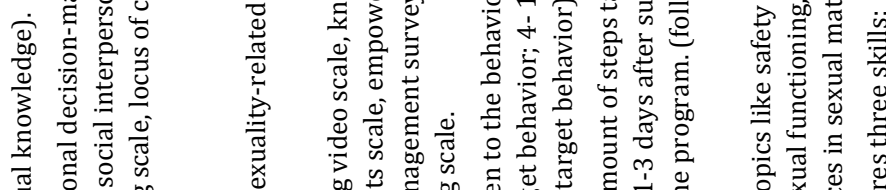

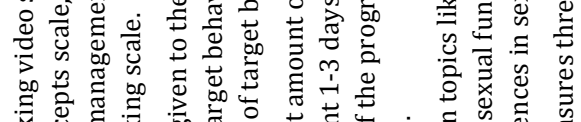

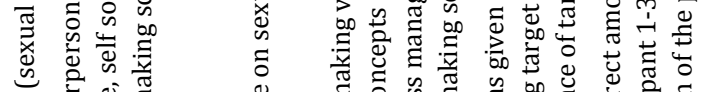

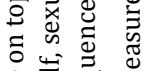

落.

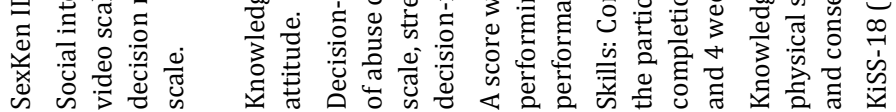


Identifying effective methods for sex education

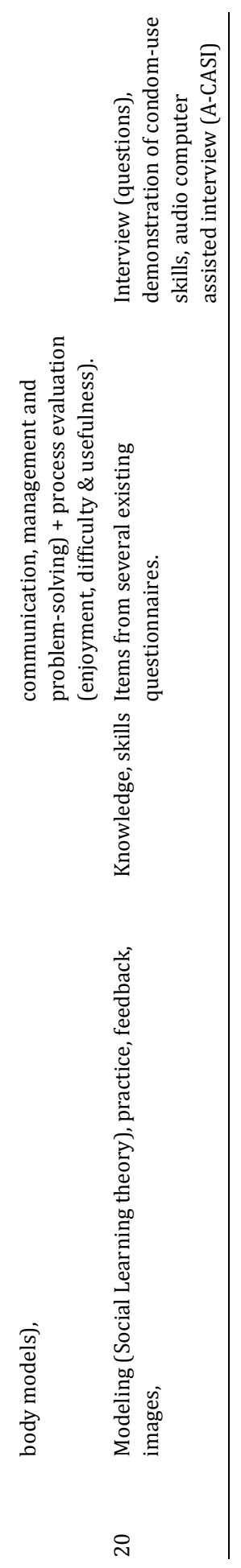




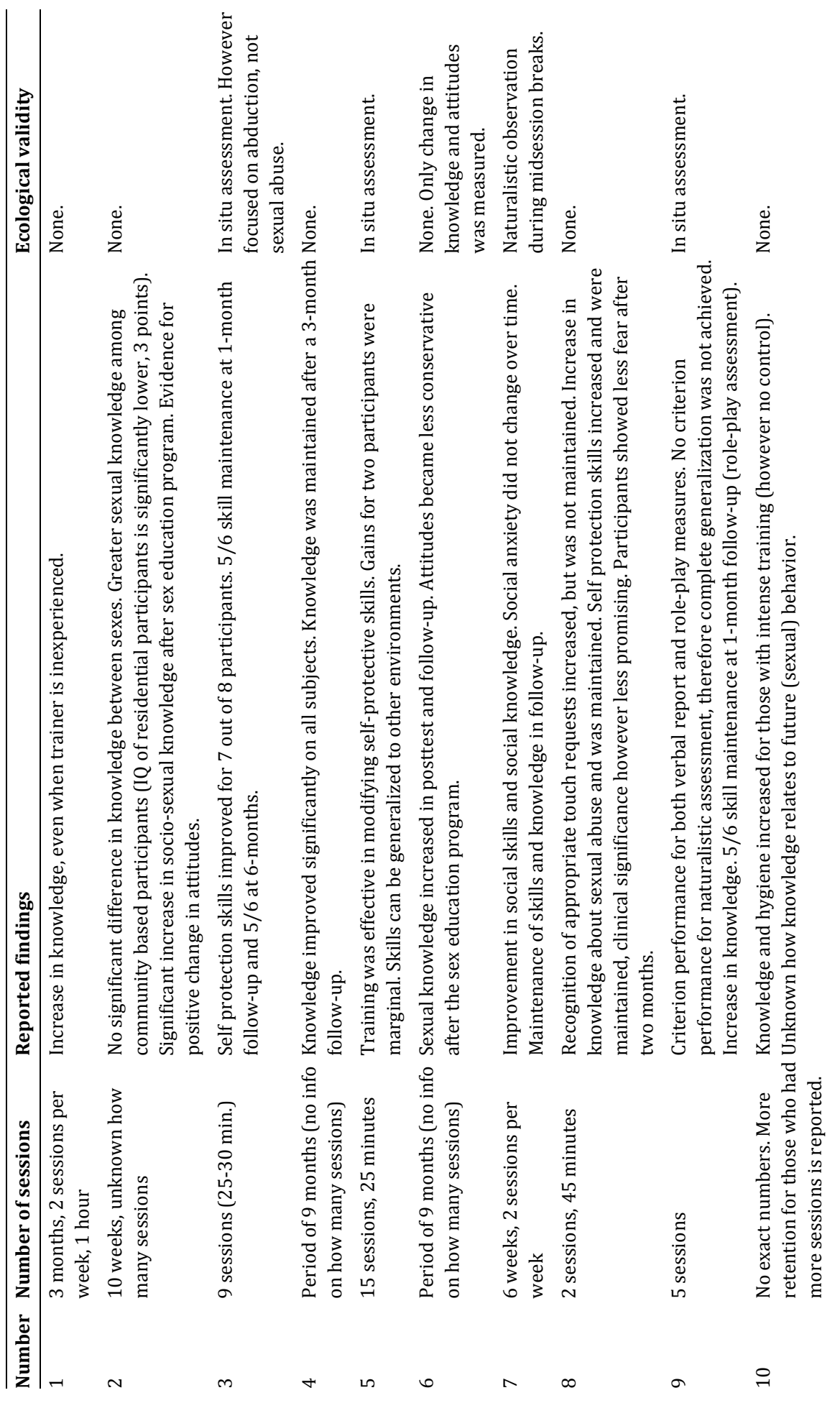




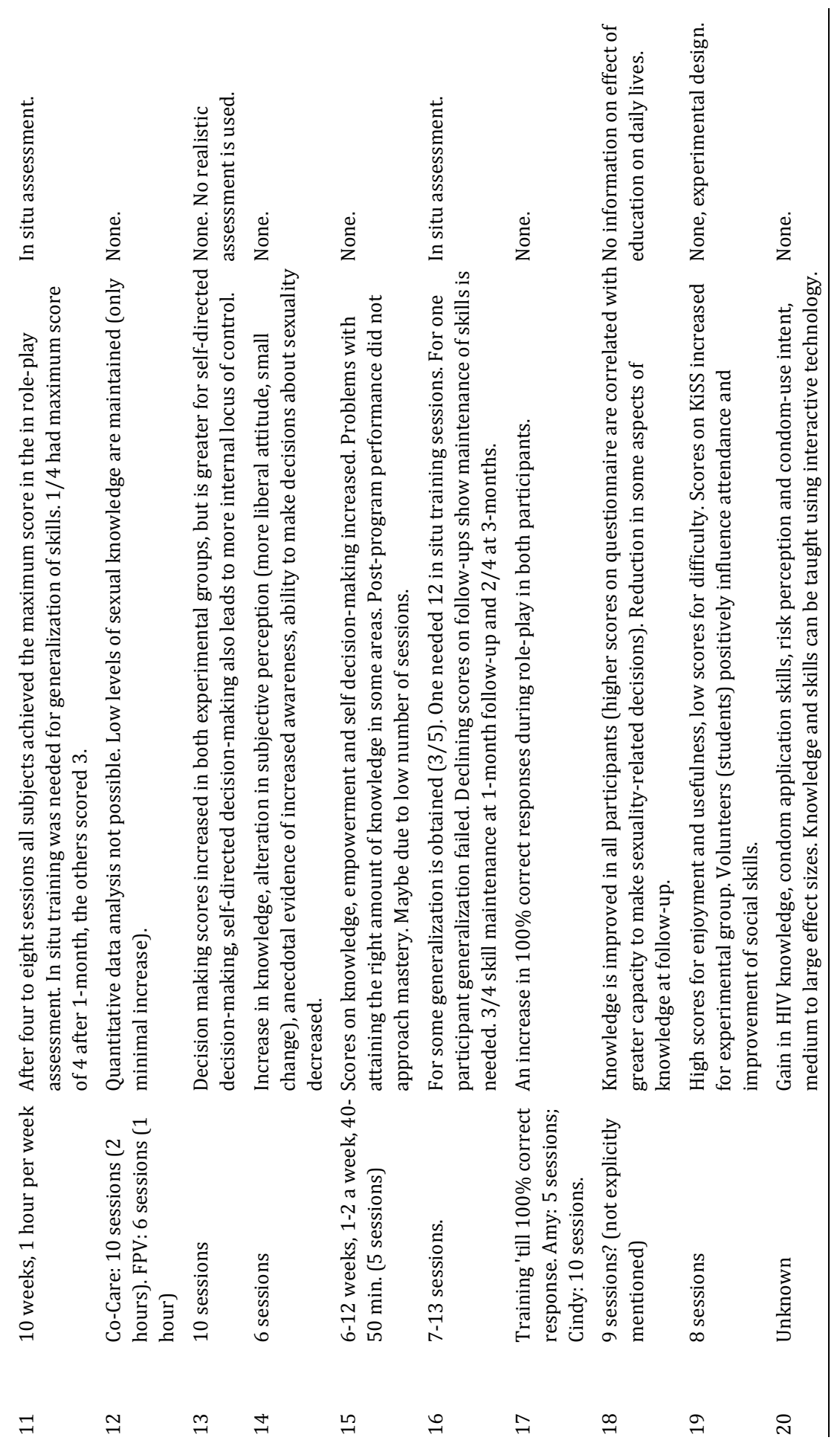


Chapter 6

General Discussion 


\section{General discussion}

The studies that have been conducted in this PhD project were aimed at gathering scientific evidence for improving future development of sex education programs for people with intellectual disabilities, using Intervention Mapping (Bartholomew et al., 2011) as a guideline. This final chapter summarizes the important findings of the previous chapters and provides recommendations for professionals working in the field of intellectual disabilities, researchers and future developers of sex education programs geared towards people with intellectual disabilities.

\section{Issues with current sex education programs}

The research project started with identifying existing sex education programs for people with intellectual disabilities in the Netherlands (study 1, chapter 2). This study was conducted in order to learn from the experiences of professionals who have already developed sex education programs; which is an important step to take before developing new program materials. Program developers of 5 sex education programs were interviewed on a number of topics, which were based on the six Intervention Mapping steps. Several issues were identified with current sex education programs that led to further research.

First, it was found that program developers had not executed proper needs assessments; they were not able to mention what kind of problem they were targeting with their sex education program nor were they able to mention the factors underlying the problem. Conducting a proper needs assessment is essential for developing effective programs. Program developers get a deeper understanding of the health problem and its related factors after conducting a proper needs assessment and this will lead to better decisions about what needs to be changed in order to have a positive impact on the sexual health of people with intellectual disabilities. In other words, it will not be possible to state specific and effective program goals, when a program developer fails to conduct a proper needs assessment. Factors that might have a huge impact on the problem might not be identified or considered, and therefore not addressed in the sex education program; which decreases the likelihood that the program will be effective.

Second, normally a proper needs assessment will lead to very specific program goals that will indicate what exactly needs to be changed in order for the program to have a positive health outcome. Therefore, it is not unexpected that the goals that have been stated by the existing sex education programs are not up to standard, because a proper needs assessment is lacking. Consequently, the goals are in general broad and nonspecific. The problem with having such broad goals is that they will most likely be achieved by the program, but not necessarily make a valuable contribution to the sexual lives of people with intellectual disabilities. For example, when the goal is increasing the sexual knowledge of people with intellec- 
tual disabilities, it is most likely that the sexual knowledge will be increased after the program. Does this really say something about the quality of the program? Will it improve safe sex behavior or self-protection skills? Positive effects on knowledge will, in this case, not say anything about whether the program positively contributes to the sexual health of people with intellectual disabilities.

Third, people with intellectual disabilities, the persons receiving the sex education, were identified as the target population; however, it is also important to consider environmental agents when developing a program. Paid care staff was mentioned by most program developers as the population that should teach sex education, but these staff members were not really taken into account in the development process. For example, it was said that staff members might feel uncomfortable talking about sex with their clients, but no explicit measures were taken to make staff members more comfortable or to support them. Not taking these kinds of barriers into account will again decrease the likelihood that sex education programs will be effective.

Furthermore, none of the relevant populations, such as people with intellectual disabilities or paid care staff members, were involved in the development process. Involvement of these groups is important, because they are the experts when it comes to information on the issues, needs, wishes and thoughts of their own population regarding sexuality. Tailoring programs to their needs, to the context in which they live or to the way they are used to communicate, increases the likelihood that the program will be successful.

Fourth, theory and evidence were not used in the development of sex education programs; which is not uncommon in this field (Griffiths et al., 2007). The content was, in most cases, based on the experience of the program developers themselves. They did mention using methods that are well known in the literature; however, methods have parameters for use, and these were not explicitly taken into account in the development of the program. It is very likely that the program developers were not aware of such parameters. Parameters for use provide information on under which circumstances a method will work. Not taking these parameters for use into account will most likely decrease its effectiveness. It is known from literature that not using a theory- and evidence-base decreases the likelihood that the program will be effective (Albarracín et al., 2005; Bos et al., 2008; de Bruin et al., 2010; Mullen et al., 1985; Peters et al., 2009; van Achterberg et al., 2010; van Empelen et al., 2003).

Additionally, an implementation and evaluation plan was not anticipated, nor was the program evaluated for its effectiveness; which does not seem to be unusual in the field of sex education for people with intellectual disabilities (Griffiths et al., 2007; Whitehouse, 1997). No information on the effectiveness of existing programs makes it difficult for other program developers to learn from these programs. Whitehouse and McCabe found similar results (1997), stating that programs are usually developed from the perspectives of the program developers and 
are in most cases not evaluated. It appears that not much has been improved in the last 15 years (study 1/Schaafsma et al., 2013; Whitehouse, 1997)

\section{New needs assessment}

The absence of a proper needs assessment in the development of sex education programs for people with intellectual disabilities, which included the failure to involve the target population and environmental agents in the development process, led to two additional studies. One was talking to people with intellectual disabilities themselves to assess their views on sex education and sexuality-related topics (study 3, chapter 4). The second one was to find out whether paid care staff members, who support people with intellectual disabilities, were indeed the ideal population to teach sex education, by conducting interviews and subsequently a cross-sectional survey to identify whether paid care staff members teach sex education or not and why they teach sex education or not (study 2, chapter 3).

\section{Perspectives of people with intellectual disabilities}

The topics that stood out in the interviews with 20 people with (mild) intellectual disabilities (study 3, chapter 4) were the low frequency of sex education that was reported, the low quality of sex education, the limited amount and superficiality of knowledge on sexuality, the negative experiences that were described and their need for a relationship.

Most participants reported to have only received some kind of sex education once or twice during their lifetime. Considering that people with intellectual disabilities have problems with retaining information (Schalock et al., 2012; Schalock et al., 2010) and are extra vulnerable to sexual abuse (Rapport commissie Samson, 2012; Eastgate et al., 2011; McCarthy, 1996; Van Berlo et al., 2011; Stoffelen et al. , 2013; Yacoub \& Hall, 2009), it is clear that sex education should be provided more frequently. Moreover, having multiple instructional sessions in a program leads to better results (McDermott et al., 1999); plus, providing booster sessions after completing the program is necessary to ensure maintenance of what is learned during the program, whether this is knowledge or skills (Egemo-Helm et al., 2007).

Additionally, the quality of sex education appeared to be low. Education was provided by a number of different sources: parent, staff members or teachers. The materials that were used can be defined as a mishmash of materials, such as the use of a broom or a banana to demonstrate condom-use. From the descriptions of the participants it did not seem that the education, in general, took place systematically and over a longer period of time.

Knowledge of the participants was limited to topics such as safe sex, condomuse, contraception and sexually transmitted infections (STI's). Additionally, the knowledge they did report to have on the subjects tended to be superficial and in some cases erroneous. For example, a participant was unsure about whether con- 
traception prevents STI's or not. This is in line with what was found in previous studies, namely that knowledge on sexuality-related topics is in general low or lacking (Griffiths et al., 2007; Healy et al., 2009; Kelly et al., 2009; Lesseliers, 1999; Leutar \& Mihokovic, 2007; McCabe, 1999b; McCarthy, 2009; Murphy \& O'Callaghan, 2004). However, this does not seem to be unique for people with intellectual disabilities, as young adults seem to show the same lack of knowledge (Grauvogl et al., 2012), but those levels might not be as low as those of people with intellectual disabilities ( McCabe et al., 1999b). There are a few possible explanations for this lack of knowledge. One is that the educators, whether these are staff members, parents or teachers, only address topics such as safe sex, condom-use, contraception and STI's, which causes knowledge gaps in other sexuality-related areas. Additionally, the topics may be discussed superficially, which would explain the lack of depth in their knowledge. Of course this might also be due to their disability that information is not retained or too complex to comprehend. Increasing the frequency would at least provide people with intellectual disabilities the opportunity to better remember and comprehend the information they receive.

Furthermore, people with intellectual disabilities report more cases of sexual abuse (Eastgate et al., 2011; McCarthy, 1996; Stoffelen et al., 2013; Yacoub \& Hall, 2009) and run a higher risk for being sexually abused (Rapport commissie Samson, 2011; Van Berlo et al., 2011) compared to their non-disabled peers. A combination of measures is needed in order to reduce sexual abuse or other negative sexual experiences. Sexual knowledge and skills need to be improved, especially regarding subjects such as sexual boundaries and self-protection. Parents, staff members and teachers should talk more regularly about sexuality; mainly because previous studies and the current study show that it does not happen very often (Abbott \& Howarth, 2007; Kok et al., 2009). Talking about the topic might lead to earlier detection of problems in this area. However, it must be avoided that sex education focuses too much on the prevention of negative aspects of sexuality. For example, most participants indicate that a (sexual) relationship is important to them, because they want someone to be with and share their life with (study 3, chapter 4). It would therefore make sense to include a theme in sex education that addresses topics such as finding, forming and maintaining relationships; especially since they experience problems in this area (Abbott \& Burns, 2007; Abbott \& Howarth, 2007; McCarthy, 1996).

\section{Paid care staff as educators}

Staff members were indicated, by program developers, as the population of people who should use sex education programs (study 1, chapter 2); probably because they fulfill an important role in the lives and the well-being of people with intellectual disabilities. They can therefore be considered to be an important environmental factor. However, up until now it was never assessed whether they are an ideal population to teach sex education; with the result that potential barriers, which might have a negative impact on the quality of sex education taught by staff 
members, were not taken into account during the development of the materials. Previous studies show, for example, that staff members generally do not talk about the subject (Abbott \& Howarth, 2007; Kok et al., 2009) or are not prepared to deal with sexual issues (Howard-Barr et al., 2005). Also, staff members primarily encourage friendships instead of sexual relationships (Healy et al., 2009; Kelly et al., 2009; Löfgren-Mårtenson, 2004), or feel the pressure to limit the sexual expression of their client (Lafferty et al., 2012); which might explain why staff members teach sex education in response to problems rather than as a tool to prevent problems (Abbott \& Burns, 2007; Abbott \& Howarth, 2007; Griffiths et al., 2007). It was therefore vital to do an assessment to find out whether paid care staff members in the Netherlands teach sex education or not and what the important predictors and barriers of teaching sex education are within this population.

The results of the cross-sectional survey, described in chapter 3 , indicated that only $39 \%$ of the staff members, who are responsible for the well-being of their clients, report to teach sex education. Additionally, results strongly suggest that it mainly happens reactively (i.e. in response to a question or problems); which is in line with previous studies (Abbott \& Burns, 2007; Abbott \& Howarth, 2007; Griffiths et al., 2007). This behavior is opposite from what most sex education programs are developed for, namely to be used as a tool to proactively teach sex education (study1, chapter 2).

Reviewing the data on staff members, it does not seem that the attitudes or self-efficacy regarding teaching sex education were the problem; however, injunctive social norm does seem to be an important predictor. Staff members who indicated that their colleagues and manager believe it to be important that they teach sex education are more likely to actually teach sex education. Changes in sex education behavior would therefore be most likely accomplished by changing the social norms.

Furthermore, it became apparent that most staff members were aware that a policy on the subject of sexuality existed within the organization; however, only $38 \%$ indicated to know most or the entire content of the policy. This might imply that there is a problem with the implementation of the policy in the organization. Lack of policy and clear guidelines on how to deal with the sexuality of clients may lead to idiosyncratic responses (Abbott \& Howarth, 2007; Löfgren-Mårtenson, 2004), which will result in a difference in quality of care; quality that will mostly depends on the motivation and effort exerted by the individual paid care staff member.

\section{Theory and evidence}

Due to the lack of theory and evidence that has been found in existing sex education programs (study 1, chapter 2), a review was conducted to identify effective methods for teaching sex education to people with intellectual disabilities (study 4, 
chapter 5). Included in this review were 20 studies, directed at improving determinants, such as skills, knowledge and attitudes regarding sexuality-related issues.

The results of the review provide indications that the skills, knowledge and attitudes of people with intellectual disabilities regarding sexuality-related topics can be improved through an program; however some issues regarding the content of these papers need to be discussed.

First of all, the studies lack a specific description about the content of the program that has been used to improve knowledge, skills and/ or attitudes; nor is any information provided about the quality of the programs. Research indicates that many sex education programs are not theory- and evidence-based and in many cases have not been evaluated (study1, chapter2; Blanchett \& Wolfe, 2002; Griffiths et al., 2007; McCabe, 1993; Whitehouse, 1997). It is therefore likely that the programs in these studies are not theory- and evidence-based as well. One paper even explicitly mentions that the programs used in their study are practice-based (Garwood \& McCabe, 2000). Because there are no detailed descriptions about what exactly has been taught by the program, it is impossible to figure out what methods are effective for teaching people with intellectual disabilities sex education. Moreover, non theory- and evidence-based programs are less likely to be effective (Albarracín et al., 2005; Bos et al., 2008; de Bruin et al., 2010; Mullen et al., 1985; Peters et al., 2009; van Achterberg et al., 2010; van Empelen et al., 2003). It would therefore be important to provide more information about the program materials and about their theory- and evidence-base; if there is one. A problem could be that journals may have restrictions regarding the number of words an article is allowed to contain; which makes it difficult to provide all the necessary information. However, it becomes more and more common to publish online supplements as well. This provides researchers the opportunity to, for example, publish the program manuals, syntax or data files. More importantly, this prevents details and data of studies getting lost over time, which increases the replicability of the program and makes it possible for other researchers to critically scrutinize the research paper (Peters et al., 2012). This will, on the long run, improve the quality of research that is conducted and improve dissemination of knowledge.

Second, the goals that have been described in the papers of this review are broad and nonspecific, except for the studies regarding self-protection skills. These kinds of goals are very attainable, but will not necessarily lead to a positive change regarding the sexual well-being of people with intellectual disabilities. Program developers will first need to conduct a proper needs assessment. This needs assessment will provide the program developers information on what exactly needs to change in order to truly have a positive impact on the sexual health of people with intellectual disabilities. The description of what exactly needs to be changed will form the goals of the program. This same problem concerning broad and nonspecific goals was also encountered in the existing sex education programs described in the first study (chapter 2). 
Third, the methods that were used in the programs are not clearly described as well; which is again comparable to the results of the first study (chapter 2). Nevertheless, similar methods are reported by the papers in the review, which give an indication of what methods might be useful when developing a program for people with intellectual disabilities; however, the papers do not describe how they have executed the methods exactly. This lack of details forms a problem, because it is known from research that methods only work under certain circumstances, which are called the parameters for use (Bartholomew et al., 2011; pp. 309). Lack of details impedes replicability and adaptability of the method to another program. Chances are that when the method is adapted to another program, these "parameters for use" will not be taken into account, which decreases the likelihood that the program will be effective.

Finally, the results of this review show that knowledge and skills are not always generalized to the real-life situation by people with intellectual disabilities. Therefore, assessing knowledge and skills through self-report measures will not provide an accurate representation of the true impact that sex education has on the sexual health of people with intellectual disabilities. Bruder and Kroese (2005) concluded in their review that three elements are important when teaching protective behaviors: 1) information and instruction; 2) modeling and rehearsal of skills in role-play; and 3) testing an rehearsing skills in situ. This means that knowledge and skills that have been acquired in a training setting need to be reinforced, practiced and assessed in a real-life setting as well.

\section{Recommendations}

\section{For professionals working in the field of intellectual disabilities}

The results from the different studies regarding sex education for people with intellectual disabilities provide professionals in the field of intellectual disabilities some areas which they can improve upon.

\section{Critically assess existing sex education programs}

The first study concerning the development process of existing sex education programs geared towards people with intellectual disabilities revealed that there are a number of issues with these programs (study 1, chapter 2). First of all, none of the programs have been evaluated, so no knowledge on whether the program is effective exists and it is very unlikely that they will be really effective in improving the sexual health of people with intellectual disabilities. However, as long as no properly developed sex education programs exist for people with intellectual disabilities, professionals should critically assess the materials that are available. This means that they should find out which materials are most suitable for their popula- 
tion of intellectual disabled people and also for the people who should teach sex education (e.g. staff members or teachers). Here are a number of pointers:

- Which topics are addressed by the sex education program? Do they cover everything you would like to discuss with your client?

- Do the materials provide information on how to use the materials?

- Do the people who have to use the materials to teach sex education feel comfortable using it? Do they feel able to teach sex education with the materials?

- Will the person who is getting sex education understand the materials?

- Does the program contain a tool to assess the progress of the participant?

\section{Determine program goals}

A second issue with existing sex education programs for people with intellectual disabilities was that it did not contain specific goals. It is therefore important to find out what a person exactly needs and tailor sex education to the needs and wishes of the person receiving sex education. Furthermore, it should be checked whether this causes a positive change. If it does not change anything, goals should be adjusted.

- What does the person want to learn about sexuality? And what does he or she need to learn? Make a list of specific goals with the person who is receiving sex education.

- Assess what the level of knowledge and skills are before sex education and after sex education. Have the goals been achieved?

\section{Teach sex education preventively}

Moreover, organizations, professionals, schools and parents should strive towards teaching sex education preventively as opposed to reactively. Teaching sex education preventively might reduce some of the negative experiences that people with intellectual disabilities otherwise would have. Whether or not sex education is taught preventively is influenced by the staff members, but also by the policy of an organization and the implementation of the policy.

\section{Sex education is more than safe sex and STI/ pregnancy prevention}

During the interviews with people with intellectual disabilities themselves it became clear that their knowledge on sexuality was limited and superficial. One of the explanations might be that only a limited number of topics are discussed during sex education. It would therefore be recommended to address topics during sex education (study 3, chapter 4; Schaalma et al., 2009a) such as:

- Prevention of unwanted pregnancies

- HIV/ STI infection

- $\quad$ Finding, forming and maintaining friendships and sexual relationships

- Prevention of sexual intimidation

- Prevention of sexual abuse and sexual violence 


\section{Chapter 6}

- Homosexuality

- Parenthood

\section{Educate educators}

It is easy to assume that everybody should be able to teach sex education to people with intellectual disabilities; however, in reality this is not the case. Several barriers exist that might prevent people from teaching sex education to people with intellectual disabilities. In our studies we found that for example social norm has a great influence on teaching sex education (study 2, chapter 3). It would therefore be important to create a positive social norm. Additionally, educators should also possess the knowledge and skills necessary for teaching sex education. One must therefore never assume that everybody will be able to teach sex education. This would lead to idiosyncratic responses to sexuality-related situations and consequently lead to differences in the quality of care (study 2, chapter 3; Abbott \& Howarth, 2007; Löfgren-Mårtenson, 2004).

\section{Devise an implementation strategy}

It is important to have a policy regarding sexuality and sex education within the organization, before actually teaching sex education to people with intellectual disabilities. However, just having policy on paper does not necessarily lead to implementation of the policy. Our study showed that most people know where to find policy on sex education, but most do not know what the exact contents are (study 2 , chapter 3 ). It would therefore be beneficial to both construct clear policies on sexuality and sexuality education and come up with an adequate plan to implement these policies. Here are some pointers that will most likely lead to an increase in sex education:

- Enable staff members to talk more frequently about sexuality. Incorporate discussions about sexuality into an existing structure, such as team-meetings or meetings with their clients. This will lead to earlier detection of potential needs, wishes and issues and set a positive norm towards sexuality.

- Provide clear guidelines regarding sex education and ensure implementation of that policy. Just having the policy available on website will probably not lead to any changes.

- Provide education and support. Ensure that staff members feel confident in addressing sexuality-related topics.

\section{For program developers and researchers}

\section{Use an intervention development framework}

Use a framework, such as Intervention Mapping (Bartholomew et al., 2011), to systematically develop a theory- and evidence-based sex education program for people with intellectual disabilities. Many programs up until now have not been 
developed in such a way (study 1, chapter 2; Bartholomew et al., 2011; Griffiths et al., 2007; Whitehouse, 1997); which decreases the likelihood that the program will be effective (Albarracín et al., 2005; Bos et al., 2008; de Bruin et al., 2010; Mullen et al., 1985; Peters et al., 2009; van Achterberg et al., 2010; van Empelen et al., 2003). Moreover, a framework, such as Intervention Mapping, makes it easier to provide a detailed description of the development process and the content of the program. Schaalma and Kok (2009) go even further by saying that program descriptions should not only describe what is included in the program, but also why it is included in the program. Program developers have to find a balance between what would be effective in the ideal world and what is feasible, efficient and ethical in the current context. Reporting when and how the program was affected by practical or political decisions will contribute to the quality of future programs. Additionally, Abraham en Michie (2008) plead for more standardized taxonomy of methods, since this will make it easier for other program developers to replicate effective programs.

Ensuring the development of good quality programs is important. The Netherlands have a registration and recognition system for health promotion programs. Providing a detailed and theoretical sound description is rewarded with recognition level 1, which is "theoretical sound". The three other levels are: 2) probable effectiveness; 3) established effectiveness; and 4) established cost effectiveness (Brug et al., 2010).

\section{Involve relevant populations}

It is important for both research and program development to involve people from relevant populations such as people with intellectual disabilities, educators and implementers. They are important for conducting a proper needs assessment and should be a part of the planning group. Several tools are available for involving people with intellectual disabilities. Besides interviews, the Nominal Group Technique (Tuffrey-Wijne et al., 2007) is also a method for assessing the views of people with intellectual disabilities.

\section{Identify effective methods}

More research needs to be conducted that investigates what kind of theoretical methods are effective for increasing sexual knowledge, skills, attitudes and other relevant determinants. The review in this thesis (study 4, chapter 5) shows that not much is known about what methods work for people with intellectual disabilities. However, it is useful to further investigate the applicability of the methods that were mentioned in the review. Additionally, researchers could look at existing theoretical methods, that are described in the literature, (Bartholomew et al., 2011; pp. 309) and see whether these work for people with intellectual disabilities as well. 
Evaluate the program

Finally, programs do not only need to be theoretically sound, but also need to be tested for its effectiveness, which corresponds with recognition level 2 and 3, "probable effectiveness" and "established effectiveness" (Brug et al., 2010). This is important because program developers need to understand what parts of the program are effective and what parts need to be improved. However, in order to conduct a proper evaluation, it is essential to have measurable outcomes in a wellimplemented program (Rossi \& Freeman, 1993; pp. 218). Therefore, anticipating the implementation and evaluation at the start of the development process is required. 


\section{References}




\section{References}

Abbott, D., \& Burns, J. (2007). What's love got to do with it?: Experiences of lesbian, gay, and bisexual people with intellectual disabilities in the United Kingdom and views of the staff who support them. Sexuality Research \& Social Policy: A Journal of the NSRC, 4, 27-39. doi:10.1525/ srsp.2007.4.1.27

Abbott, D., \& Howarth, J. (2007). Still off-limits? Staff views on supporting gay, lesbian and bisexual people with intellectual disabilities to develop sexual and intimate relationships? Journal of Applied Research in Intellectual Disabilities, 20, 116-126. doi:10.1111/j.1468-3148.2006.00312.x

Abraham, C., \& Michie, S. (2008). A taxonomy of behavior change techniques used in interventions. Health Psychology, 27, 379-387. doi:10.1037/0278-6133.27.3.379.

Albarracín, D., Gillette, J. C., Earl, A. N., Glasman, L. R., Durantini, M. R., \& Ho, M. H. (2005). A test of major assumptions about behavior change: a comprehensive look at the effects of passive and active HIVprevention interventions since the beginning of the epidemic. Psychological Bulletin, 131, 856-897. doi:10.1037/0033-2909.131.6.856

Bartholomew, L. K., Parcel, G. S., Kok, G., Gottlieb, N. H., \& Fernández, M. E. (2011). Planning health promotion programs: An intervention mapping approach (3rd Ed.). San Francisco, CA US: JosseyBass.

Baum, S., \& Alexander, N. (2010). Pregnancy, contraception and women choosing to have a child. In M. McCarthy \& D. Thompson (Eds.), Sexuality and learning disabilities. Brighton: Pavilion Publishing.

Bazzo, G., Nota, L., Soresi, S., Ferrari, L., \& Minnes, P. (2007). Attitudes of social service providers towards the sexuality of individuals with intellectual disability. Journal of Applied Research in Intellectual Disabilities, 20, 110-115. doi:10.1111/j.1468-3148.2006.00308.x

Bernert, D. J., \& Ogletree, R. J. (2013). Women with intellectual disabilities talk about their perceptions of sex. Journal of Intellectual Disability Research, 57, 240-249. doi:10.1111/j.13652788.2011.015 29.x.

Blanchett, W. J., \& Wolfe, P. S. (2002). A review of sexuality education curricula: Meeting the sexuality education needs of individuals with moderate and severe intellectual disabilities. Research and Practice for Persons with Severe Disabilities, 27, 43-57. doi:10.2511/rpsd.27.1.43

Bollman, J. R., \& Davis, P. K. (2009). Teaching women with intellectual disabilities to identify and report inappropriate staff-to-resident interactions. Journal of Applied Behavior Analysis, 42, 813-817. doi:10.1901/jaba.2009.42-813

Bos, A. E. R., Schaalma, H. P., \& Pryor, J. B. (2008). Reducing AIDS-related stigma in developing countries: The importance of theory- and evidence-based interventions. Psychology, Health \& Medicine, 13, 450-460. doi:10.1080/13548500701687171

Bruder, C., \& Kroese, B. S. (2005). The efficacy of interventions designed to prevent and protect people with intellectual disabilities from sexual abuse: a review of the literature. The Journal of Adult Protection, 7, 13-27. doi:10.1108/14668203200500009

Brug, J., Van Dale, D., Lanting, L., Kremers, S., Veenhof, C., Leurs, M., et al. (2010). Towards evidencebased, quality-controlled health promotion: the Dutch recognition system for health promotion interventions. Health Education Research, 25, 1100-1106. doi:10.1093/her/cyq046

Cambridge, P., \& Mellan, B. (2000). Reconstructing the sexuality of men with learning disabilities: Empirical evidence and theoretical interpretations of need. Disability \& Society, 15, 293-311. doi:10.1080/09687590025685

Caspar, L. A., \& Glidden, L. M. (2001). Sexuality education for adults with developmental disabilities. Education \& Training in Mental Retardation \& Developmental Disabilities, 36, 172-177. 
Christian, L., Stinson, J., \& Dotson, L. A. (2001). Staff values regarding the sexual expression of women with developmental disabilities. Sexuality and Disability, 19, 283-291. doi:10.1023/A:101795740 9670

Cuskelly, M., \& Bryde, R. (2004). Attitudes towards the sexuality of adults with an intellectual disability: Parents, support staff, and a community sample. Journal of Intellectual \& Developmental Disability, 29, 255-264. doi:10.1080/13668250412331285136

Cuskelly, M., \& Gilmore, L. (2007). Attitudes to Sexuality Questionnaire (Individuals with an Intellectual Disability): Scale development and community norms. Journal of Intellectual \& Developmental Disability, 32, 214-221. doi:10.1080/13668250701549450

de Bruin, M., Viechtbauer, W., Schaalma, H. P., Kok, G., Abraham, C., \& Hospers, H. J. (2010). Standard care impact on effects of highly active antiretroviral therapy adherence interventions: a metaanalysis of randomized controlled trials. Archives of Internal Medicine, 170, 240-250. doi:10.1001/archinternmed.2009. 536

Dukes, E., \& McGuire, B. E. (2009). Enhancing capacity to make sexuality-related decisions in people with an intellectual disability. Journal of Intellectual Disability Research, 53, 727-734. doi:10.11 11/j.1365-2788.2009.01186.x

Eastgate, G., van Driel, M. L., Lennox, N., \& Scheermeyer, E. (2011). Women with intellectual disabilities: a study of sexuality, sexual abuse and protection skills. Australian Family Physician, 40, 226-230.

Egemo-Helm, K. R., Miltenberger, R. G., Knudson, P., Finstrom, N., Jostad, C., \& Johnson, B. (2007). An evaluation of in situ training to teach sexual abuse prevention skills to women with mental retardation. Behavioral Interventions, 22(2), 99-119. doi:10.1002/bin.234

Evans, D. S., McGuire, B. E., Healy, E., \& Carley, S. N. (2009). Sexuality and personal relationships for people with an intellectual disability. Part II: Staff and family carer perspectives. Journal of Intellectual Disability Research, 53, 913-921. doi:10.1111/j.1365-2788.2009.01202.x

Feldman, M. A., \& Case, L. (1999). Teaching child-care and safety skills to parents with intellectual disabilities through self-learning. Journal of Intellectual \& Developmental Disability, 24, 27-44.

Fishbein, M., \& Ajzen, I. (2009). Predicting and changing behavior: The reasoned action approach. New York: Psychology Press.

Fitzgerald, C., \& Withers, P. (2011). 'I don't know what a proper woman means': what women with intellectual disabilities think about sex, sexuality and themselves. British Journal of Learning Disabilities, 41, 5-12. doi:10.1111/j.1468-3156.2011.00715.x.

Garwood, M., \& McCabe, M. P. (2000). Impact of sex education programs on sexual knowledge and feelings of men with a mild intellectual disability. Education \& Training in Mental Retardation \& Developmental Disabilities, 35, 269-283.

Gilmore, L., \& Chambers, B. (2010). Intellectual disability and sexuality: Attitudes of disability support staff and leisure industry employees. Journal of Intellectual and Developmental Disability, 35, 2228. doi:10.3109/13668250903496344

Godin, G., Gagnon, H., Alary, M., Levy, J. J., \& Otis, J. (2007). The degree of planning: an indicator of the potential success of health education programs. Promotion and Education, 9(3), 138-142.

Godolphin, W. (2009). Shared decision-making. Healthcare Quarterly, 12, 186-190.

Grauvogl, A., S. E., S., Evers, S. M. A. A., \& van Lankveld, J. J. D. M. (2012). Perceptions of sexuality and sexual health among young people in the Netherlands. Sexual and Relationship Therapy, 27, 110121. doi:10.1080/14681994.2012.702894.

Grieveo, A., McLaren, S., \& Lindsay, W. R. (2007). An evaluation of research and training resources for the sex education of people with moderate to severe learning disabilities. British Journal of Learning Disabilities, 35, 30-37. doi:10.1111/j.1468-3156.2006.00401.x 
Griffiths, D., Brown, I., \& Percy, M. (2007). Sexuality and people who have intellectual disabilities. In $A$ comprehensive guide to intellectual and developmental disabilities. (pp. 573-583). Baltimore, MD US: Paul H Brookes Publishing.

Haseltine, B., \& Miltenberger, R. G. (1990). Teaching self-protection skills to persons with mental retardation. American Journal on Mental Retardation, 95, 188-197.

Hayashi, M., Arakida, M., \& Ohashi, K. (2011). The effectiveness of a sex education program facilitating social skills for people with intellectual disability in Japan. Journal of Intellectual and Developmental Disability, 36, 11-19. doi:10.3109/13668250.2010.549463

Health Council of the Netherlands. Contraception for people with mental retardation. The Hague: Health Council of the Netherlands, 2002; publication no. 2002/14.

Healy, E., McGuire, B. E., Evans, D. S., \& Carley, S. N. (2009). Sexuality and personal relationships for people with an intellectual disability. Part I: Service-user perspectives. Journal of Intellectual Disability Research, 53, 905-912. doi:10.1111/j.1365-2788.2009.01203.x

Howard-Barr, E. M., Rienzo, B. A., Pigg, R. M., \& James, D. (2005). Teacher beliefs, professional preparation, and practices regarding exceptional students and sexuality education. Journal of School Health, 75, 99-104. doi:10.1111/j.1746-1561.2005.00004.x.

Jones, L. M., Mitchell, K. J., \& Finkelhor, D. (2013). Online harassment in context: Trends from three Youth Internet Safety Surveys $(2000,2005,2010)$. Psychology of Violence, 3, 53-69. doi:10.1037/ a0030309

Kelly, G., Crowley, H., \& Hamilton, C. (2009). Rights, sexuality and relationships in Ireland: 'It'd be nice to be kind of trusted.' British Journal of Learning Disabilities, 37, 308-315. doi:10.1111/j.14683156.2009.00587.x

Khemka, I. (2000). Increasing independent decision-making skills of women with mental retardation in simulated interpersonal situations of abuse. American Journal on Mental Retardation, 105, 387401. doi:10.1352/0895-

Khemka, I., Hickson, L., \& Reynolds, G. (2005). Evaluation of a Decision-Making Curriculum Designed to Empower Women With Mental Retardation to Resist Abuse. American Journal on Mental Retardation, 110, 193-204. doi:10.1352/0895-8017(2005)110<193:EOADCD>2.0.C0;2

Kirby, D., \& Laris, B. A. (2009). Effective curriculum-based sex and STD/HIV education programs for adolescents. Child Development Perspectives, 3, 21-29. doi:10.1111/j.1750-8606.2008.00071.x

Kok, G., Gottlieb, N. H., Commers, M., and Smerecnik, S. (2008) The Ecological Approach in Health Promotion Programs: A Decade Later. American Journal of Health Promotion, 22, 437-442. doi: 10.4278/ajhp.22.6.437

Kok, G., Maassen, R., Maaskant, M., \& Curfs, L. (2009). Zorgverleners over seksualiteit van mensen met verstandelijke beperkingen; een kwalitatief onderzoek. Tijdschrift voor Seksuologie, 33, 199-206.

Konstantareas, M. M., \& Lunsky, Y. J. (1997). Sociosexual knowledge, experience, attitudes, and interests of individuals with autistic disorder and developmental delay. Journal of Autism and Developmental Disorders, 27, 397-413. doi:10.1023/A:1025805405188

Lafferty, A., McConkey, R., \& Simpson, A. (2012). Reducing the barriers to relationships and sexuality education for persons with intellectual disabilities. Journal of intellectual Disabilities, 16, 29-43. doi: $10.1177 / 1744629512438034$.

Lee, Y. K. S, \& Tang, C. S. K. (1998). Evaluation of sexual abuse prevention program for female Chinese adolescents with mild mental retardation. American Journal on Mental Retardation, 103, 105-116. doi:10.1352/0895-8017(1998)103<0105:EOASAP>2.0.C0;2

Lesseliers, J. (1999). A rigth to sexuality? British Journal of Learning Disabilities, 27, 137-140. 
Leutar, Z., \& Mihokovic, M. (2007). Level of knowledge about sexuality of people with mental disabilities. Sexuality and Disability, 25, 93-109. doi:10.1007/s11195-007-9046-8

Levy, H., \& Packman, W. (2004). Sexual Abuse Prevention for Individuals With Mental Retardation: Considerations for Genetic Counselors. Journal of Genetic Counseling, 13, 189-205. doi:10.1023/B:JOGC.0000028158.79395.1e

Lindsay, W. R., Bellshaw, E., Culross, G., \& Staines, C. (1992). Increases in knowledge following a course of sex education for people with intellectual disabilities. Journal of Intellectual Disability Research, 36, 531-539. doi:10.1111/j.1365-2788.1992.tb00571.x

Lindsay, W. R., Michie, A. M., Staines, C., \& Bellshaw, E. (1994). Client attitudes towards relationships: Changes following a sex education programme. British Journal of Learning Disabilities, 22, 70-73. doi:10.1111/j.1468-3156.1994.tb00119.x

Löfgren-Mårtenson, L. (2004). 'May I?' About sexuality and love in the new generation with intellectual disabilities. Sexuality and Disability, 22, 197-207. doi:10.1023/B:SEDI.0000039062.73691.cb

Löfgren-Mårtenson, L. (2011). "I want to do it right!" A pilot study of Swedish sex education and young people with intellectual disabilities. Sexuality and Disability, 30, 209-225. doi:10.1007/s11195011-9239-z.

Luckasson, R. \& Schalock, R.L. (2013) What's at Stake in the Lives of People With Intellectual Disability? Part II: Recommendations for Naming, Defining, Diagnosing, Classifying, and Planning Supports. Intellectual and Developmental Disabilities, 51(2), 94-101.

Lumley, V. A., Miltenberger, R. G., Long, E. S., Rapp, J. T., \& Roberts, J. A. (1998). Evaluation of a sexual abuse prevention program for adults with mental retardation. Journal of Applied Behavior Analysis, 31, 91-101. doi:10.1901/jaba.1998.31-91

Mason, P., Timms, K., Hayburn, T., \& Watters, C. (2013). How do people described as having a learning disability make sense of friendship? Journal of Applied Research in Intellectual Disabilities, 26, 108118. doi:10.1111/jar.12001.

McCabe, M. P. (1993). Sex education programs for people with mental retardation. American Association on Mental Retardation, 31, 377-387.

McCabe, M. P. (1999). Sexual knowledge, experience and feelings among people with disability. Sexuality and Disability, 17, 157-170. doi:10.1023/A:1021476418440

McCabe, M. P., Cummins, R. A., \& Deeks, A. A. (1999). Construction and psychometric properties of sexuality scales: Sex knowledge, experience and needs scales for people with intellectual disabilities (SexKen-ID), people with physical disabilities (SexKen-PD) and the general population (SexKen-GP). Research in Developmental Disabilities, 20, 241-254. doi:10.1016/S0891-4222(99) 00007-4

McCarthy, M. (1996). The sexual support needs of people with learning disabilities: A profile of those referred for sex education. Sexuality and Disability, 14, 265-280. doi:10.1007/BF02590099

McCarthy, M. (1999). Sexuality and women with learning disabilities. London: Jessica Kingsley Publishers.

McCarthy, M. (2009). Contraception and women with intellectual disabilities. Journal of Applied Research in Intellectual Disabilities, 22, 363-369. doi:10.1111/j.1468-3148.2008.00464.x

McConnell, D., Llewellyn, G., \& Bye, R. (1997). Providing services for parents with intellectual disability: Parent needs and service constraints Journal of Intellectual \& Developmental Disability, 22, 5-17.

McDermott, S., Martin, M., Weinrich, M., \& Kelly, M. (1999). Program evaluation of a sex education curriculum for women with mental retardation. Research in Developmental Disabilities, 20, 93-106. doi:10.1016/S0891-4222(98)00035-3 
Meaney-Tavares, R., \& Gavidia-Payne, S. (2012). Staff characteristics and attitudes towards the sexuality of people with intellectual disability. Journal of Intellectual and Developmental Disability, 37, 269 273. doi:10.3109/13668250.2012.701005

Mendel, P., Meredith, L. S., Schoenbaum, M., Sherbourne, C. D., \& Wells, K. B. (2008). Interventions in organizational and community context: A framework for building evidence on dissemination and implementation in health services research. Administration and Policy in Mental Health and Mental Health Services Research, 35, 21-37. doi:10.1007/s10488-007-0144-9

Miltenberger, R. G., Roberts, J. A., Ellingson, S., Galensky, T., Rapp, J. T., Long, E. S., et al. (1999). Training and generalization of sexual abuse prevention skills for women with mental retardation. Journal of Applied Behavior Analysis, 32, 385-388. doi:10.1901/jaba.1999.32-385

Mullen, P. D., Green, L. W., \& Persinger, G. S. (1985). Clinical trials of patient education for chronic conditions: A comparative meta-analysis of intervention types. Preventive Medicine, 14, 743-781.

Murphy, G. H., \& O'Callaghan, A. (2004). Capacity of adults with intellectual disabilities to consent to sexual relationships. Psychological Medicine, 34, 1347-1357. doi:10.1017/S0033291704001941

Peters, G. J. Y., Abraham, C., \& Crutzen, R. (2012). Full disclosure: doing behavioural science necessitates sharing. The European Health Psychologist, 14, 77-84.

Peters, L., Kok, G., Ten Dam, G., Buijs, G., \& Paulussen, T. (2009). Effective elements of school health promotion across behavioral domains: a systematic review of reviews. BMC Public Health, 9(1), 182. doi:10.1186/1471-2458-9-182

Rapport commissie-Samson. Omringd door zorg, toch niet veilig: Seksueel misbruik van door de overheid uit huis geplaatste kinderen, 1945 tot heden. Amsterdam: Boom; 2012.

Ras, M., Woittiez, I., van Kempen, H., \& Sadiraj, K. Steeds meer verstandelijk gehandicapten? Ontwikkelingen in vraag en gebruik van zorg voor verstandelijke gehandicapten 1998-2008. Den Haag: Sociaal Cultureel Planbureau; 2010.

Reiter, S., Bryen, D. N., \& Schachar, I. (2007). Adolescents with intellectual disabilities as victims of abuse. Journal of intellectual Disabilities, 11, 371-387. doi:10.1177/1744629507084602.

Revelle, W., \& Zinbarg, R. E. (2009). Coefficients alpha, beta, omega and the glb: comments on Sijtsma. Psychometrika, 74, 145-154. doi:10.1007/S11336-008-9102-Z.

Robinson, S. (1984). Effects of a sex education program on intellectually handicapped adults. Australia \& New Zealand Journal of Developmental Disabilities, 10, 21-26.

Rohleder, P. (2010). Educators' ambivalence and managing anxiety in providing sex education for people with learning disabilities. Psychodynamic Practice: Individuals, Groups and Organisations, 16(2), 165-182. doi: 10.1080/14753631003688100

Rohleder, P., \& Swartz, L. (2009). Providing sex education to persons with learning disabilities in the era of HIV/AIDS: Tensions between discourses of human rights and restriction. Journal of Health Psychology, 14, 601-610. doi:10.1177/1359105309103579

Rossi, P. H., \& Freeman, H. E. (1993). Evaluation: A systematic approach (5th ed.). Thousand Oaks, CA US: Sage Publications, Inc.

Schaafsma, D., Kok, G., Stoffelen, J. M. T., \& Curfs, L. M. G. (submitted-a). Identifying effective methods for teaching sex education to people with intellectual disabilities: a systematic review.

Schaafsma, D., Kok, G., Stoffelen, J. M. T., \& Curfs, L. M. G. (submitted-b). People with intellectual disabilities about sexuality: important implications for the development of sex education.

Schaafsma, D., Kok, G., Stoffelen, J. M. T., van Doorn, P., \& Curfs, L. M. G. (resubmitted). Identifying the important determinants of teaching sex education to people with intellectual disabilities: Crosssectional survey among paid care staff. 
Schaafsma, D., Stoffelen, J. M. T., Kok, G., \& Curfs, L. M. G. (2013). Exploring the development of existing sex education programs for people with Intellectual Disabilities: an Intervention Mapping approach. Journal of Applied Research in Intellectual Disabilities, 26, 157-166. doi:10.1111/jar.12017.

Schaalma, H., Reinders, J., \& Kok, G. (2009a). Voorlichting en preventie. In L. Gijs, W. Gianotten, I. Vanwesenbeeck \& P. Weijenborg (Eds.), Seksuologie. Houten: Bohn Stafleu van Loghum.

Schaalma, H. P., Abraham, C., Gillmore, M. R., \& Kok, G. (2004). Sex education as health promotion: What does it take? Archives of Sexual Behavior, 33, 259-269. doi:10.1023/B:ASEB.0000026625.65171.1d

Schaalma, H. P., \& Kok, G. (2009b). Decoding health education interventions: the times are a-changin'. Psychology and Health, 24, 5-9. doi:10.1080/08870440801995802.

Schalock, R. L., Borthwick-Duffy, S. A., Bradley, V. J., Buntinx, W. H. E., Coulter, D. L., Craig, E. M., . . . Yeager, M.H. (2010). Intellectual disability: Definition, classification, and systems of supports (11th ed. of AAIDD definition manual). Washington, DC US: American Association on Intellectual and Developmental Disabilities.

Schalock, R., Luckasson, R., Bradley, V., Buntinx, W., Lachapelle, Y., Shogren, K.A., \& Wehmeyer, M.L. (2012). User's Guide to Accompany the 11th Edition of Intellectual Disability: Definition, Classification, and Systems of Supports. Applications for Clinicians, Educators, Organizations Providing Supports, Policymakers, Family members and Advocates, and Health Care Professionals. Washington: AAIDD.

Schalock, R.L. \& Luckasson, R. (2013) What's at Stake in the Lives of People With Intellectual Disability? Part I: The Power of Naming, Defining, Diagnosing, Classifying, and Planning Supports. Intellectual and Developmental Disabilities, 51 (2), 86-93.

Sequeira, H., Howlin, P., \& Hollins, S. (2003). Psychological disturbance associated with sexual abuse in people with learning disabilities: Case-control study. The British Jounral of Psychiatry, 183, 451456. doi:10.1192/bjp.183.5.451.

Servais, L. (2006). Sexual health care in persons with Intellectual Disabilities. Mental Retardation and Developmental Disabilities Research Reviews, 12, 48-56. doi:10.1002/mrdd.20093

Shandra, C., \& Chowdhury, A. (2012). The first sexual experience among adolescent girls with and without disabilities. Journal of Youth and Adolescence, 41, 515-532. doi:10.1007/s10964-0119668-0.

Siebelink, E. M., de Jong, M. D. T., Taal, E., \& Roelvink, L. (2006). Sexuality and People With Intellectual Disabilities: Assessment of Knowledge, Attitudes, Experiences, and Needs. Mental Retardation, 44, 283-294. doi:10.1352/0047-6765(2006)44[283:SAPWID]2.0.CO;2

Stoffelen, J. M. T., Kok, G., Hospers, H., \& Curfs, L. M. G. (2013). Homosexuality among people with a mild intellectual disability: an explorative study on the lived experiences of homosexual people in the Netherlands with a mild intellectual disability. Journal of Intellectual Disability Research, 57, $257-$ 267. doi:10.1111/j.1365-2788.2011.01532.x.

Szwedo, D. E., Mikami, A. Y., \& Allen, J. P. (2012). Social networking site use predicts changes in young adults' psychological adjustment. Journal of Research on Adolescence, 22, 453-466. doi:10.1111/ j.1532-7795.2012.00788.x

Thomas, G., \& Kroese, B. S. (2005). An investigation of students' with mild learning disabilities reactions to participating in sexuality research. British Journal of Learning Disabilities, 33, 113-119. doi:10.11 11/j.1468-3156.2005.00336.x.

Tuffrey-Wijne, I., Bernal, J., Butler, G., Hollins, S., \& Curfs, L. (2007). Using Nominal Group Technique to investigate the views of people with intellectual disabilities on end-of-life care provision. Journal of Advanced Nursing, 58, 80-89. doi:10.1111/j.1365-2648.2007.04227.x 
Valenti-Hein, D. C., Yarnold, P. R., \& Mueser, K. T. (1994). Evaluation of the Dating Skills Program for improving heterosocial interactions in people with mental retardation. Behavior Modification, 18, 32-46. doi:10.1177/01454455940181003

van Achterberg, T., Huisman-De Waal, G. G., Ketelaar, N. A. B. M., Oostendorp, R. A., Jacobs, J. E., \& Wollersheim, H. C. H. (2010). How to promote healthy behavior in patients? A review of systematic reviews. Health Promotion International, 6, 148-162. doi:10.1093/heapro/daq0 50

van Berlo W, de Haas S, Van Oosten N, Van Dijk L, Brants L, Tonnon, S, Storms O. Beperkt weerbaar: een onderzoek naar seksueel geweld bij mensen met een lichamelijk, zintuiglijke of een verstandelijke beperking. Utrecht: Van Berlo; 2011.

van der Knaap, L. M., Leeuw, F. L., Bogaerts, S., \& Nijssen, L. T. J. (2008). Combining campbell standards and the realist evaluation approach. American Journal of Evaluation, 29, 48-57. doi:10.1177/1098 214007313024

van Empelen, P., Kok, G., van Kesteren, N. M. C., van den Borne, B., Bos, A. E. R., \& Schaalma, H. P. (2003). Effective methods to change sex-risk among drug users: a review of psychosocial interventions. Social Science \& Medicine, 57, 1593-1608. doi:10.1016/s0277-9536(02)00557-9

Watson, M., Bain, A., \& Houghton, S. (1992). A preliminary study in teaching self-protective skills to children with moderate and severe mental retardation. The Journal of Special Education, 26, 181194. doi: $10.1177 / 002246699202600204$

Wells, J., Clark, K. D., \& Sarno, K. (2012). A computer-based interactive multimedia program to reduce HIV transmission for women with intellectual disability. Journal of Intellectual Disability Research, 56, 371-381. doi:10.1111/j.1365-2788.2011.01482.x

Whitehouse, M. A., \& McCabe, M. P. (1997). Sex education programs for people with intellectual disability: How effective are they? Education \& Training in Mental Retardation \& Developmental Disabilities, 32, 229-240.

World Health Organization (2006). Sexual health document series. Defining sexual health. Report of a technical consultation on sexual health, 28-31 January 2002, Geneva: WHO Press.

Yacoub, E., \& Hall, I. (2009). The sexual lives of men with mild learning disability: A qualitative study. British Journal of Learning Disabilities, 37, 5-11. doi:10.1111/j.1468-3156.2008.00491.x

Young, R., Gore, N., \& McCarthy, M. (2012). Staff attitudes towards sexuality in relation to gender of people with intellectual disability: a qualitative study. Journal of Intellectual \& Developmental Disability, 37, 343-347. doi: 10.3109/13668250.2012.704983

Zillman, D. (2000). Influence of unrestrained access to erotica on adolescents' and young adults' dispositions toward sexuality. Journal of Adolescent Health, 275, 41-44. doi:10.1016/j.bbr.2011.03.031.

Zylla, T. M., \& Demetral, G. D. (1981). A behavioral approach to sex education. Sexuality and Disability, 4, 40-48. doi:10.1007/BF01102463 


\section{Summary}




\section{Summary}

People with intellectual disabilities face challenges in the area of sexuality that might differ from challenges their non-disabled peers face. For example, people with intellectual disabilities tend to be less informed about sexuality, have fewer sexual experiences, have more negative attitudes towards sexual activities and have more experiences with sexual abuse, than those without intellectual disabilities. Additionally, people with intellectual disabilities express problems in finding, forming and maintaining (sexual) relationships. These problems greatly influence the sexual health and consequently the quality of life of people with intellectual disabilities.

Many of these problems are influenced by environmental factors, such as parents or paid care staff. For example, people with intellectual disabilities receive less sex education, which could explain their low levels of sexual knowledge and their inability to protect themselves against sexual abuse. Furthermore, people with intellectual disabilities experience restrictive rules and a lack of privacy regarding sexual expressions, which could explain their lack of sexual opportunities. Sex education could be used as a tool to improve some of these problems, both on the individual and environmental level, and consequently improve the sexual health of people with intellectual disabilities.

The first study, described in chapter 2 , was conducted to identify existing sex education programs geared towards people with intellectual disabilities in the Netherlands. This was an important first step to take before considering the development of new sex education materials. The goal of this study was to utilize what is learned from these programs in future development of sex education materials. The program developers of five existing sex education programs were interviewed, using Intervention Mapping as a guideline. Results revealed that the programs were not evaluated; lacked a theoretical basis; did not involve members of relevant populations (e.g. people with intellectual disabilities, paid care staff) in the program development; and lacked specific program goals. In conclusion, future sex education programs geared towards people with intellectual disabilities should be developed using a more systematic and theory- and evidence-based approach, such as Intervention Mapping, to increase the likelihood that the program will be effective in improving the sexual health of people with intellectual disabilities.

Chapter 3 describes a cross-sectional survey conducted among 163 paid care staff members. This study was conducted, because in the first study program developers indicated staff members to be an important population for teaching sex education to people with intellectual disabilities. It was therefore essential to investigate whether they are indeed an ideal population to teach sex education by identifying the factors that influence whether staff members teach sex education to their clients or not. The results show that 39\% of the staff members teach sex education and most likely do this reactively. This is opposite to what most sex educa- 
tion programs are developed for, namely to be used as a tool to proactively teach sex education. Furthermore, injunctive social norms seem to be an important predictor of teaching sex education, whereas attitudes and self-efficacy regarding sex education seem to be positive in both staff members who teach sex education and those who do not. Changes in the sex education behavior of staff members would therefore be most likely accomplished by changing the injunctive social norms. Finally, more than half of the staff members indicated not to be informed about the content of the policy on sexuality in their organization, which might indicate a problem with the implementation of the policy concerning sexuality.

Chapter 4 presents the views of twenty people with intellectual disabilities on sexuality-related topics such as sex education, homosexuality, relationships, sex, parenthood, social media, negative experiences and support. This study was conducted because the first study showed that people with intellectual disabilities were not involved in the development process of sex education materials; consequently, the views of people with intellectual disabilities were not examined in the context of sex education. The results show that the reported frequency of sex education the participants receive is low. Furthermore, their knowledge regarding sex education is mainly limited to topics such as safe sex, contraception and sexually transmitted infections (STI's). Moreover, the knowledge they do have tends to be superficial and is in some cases erroneous. Additionally, knowledge on safe sex does not always translate to safe sex behavior. Finally, relationships are important for most participants; mainly because they don't want to be alone. In conclusion, there is a need for high quality sex education. Sex education should be lengthier and taught more frequently, focusing on a variety of sexuality-related topics, including topics such as (online) relationships, social media, pornography and parenthood. Furthermore, sex education should include the improvement of sexualityrelated skills, such as self-protection and decision-making skills. Finally, a theoryand evidence-based framework, such as Intervention Mapping should be used for the development of sex education materials, to increase the likelihood that the materials will be effective.

Chapter 5 presents the findings of a systematic review that has been conducted to identify effective methods for teaching sex education to people with intellectual disabilities. The first study showed that current sex education programs lacked a theory- and evidence-base, making it very important for future development of sex education programs to identify which theoretical methods are effective in teaching sex education to people with intellectual disabilities. Twenty papers were included based on two criteria: the topic was effectiveness of sex education programs, and the population that was being studied was people with intellectual disabilities. The results present some useful methods for improving knowledge, skills and attitudes and there are indications that maintenance of knowledge and skills is needed. One major problem with the papers was that detailed descriptions of the sex education materials, program goals and the methods used in the 
program were lacking. In conclusion, there is some evidence for effective methods improving knowledge, skills and attitudes with regard to sex education; however, it is unclear under which conditions the methods work, due the lack of detailed descriptions. This impedes replicability and adaptability of existing sex education materials. It would therefore be preferable that this information is also provided in the papers or in (online) supplements.

Chapter 6, the general discussion, provides recommendations to professionals in the field, future program developers and researchers, based on the findings presented in the previous chapters. For professionals working in the field of intellectual disabilities it is important to critically assess existing sex education programs until sex education programs have been developed that have a solid theoretical base or even more preferable, have proven to be effective. Furthermore, existing programs do not contain specific goals; it is therefore important for educators to explore what exactly the person who is receiving sex education needs and want, and to tailor sex education to the needs and wishes of that person. Additionally, the content of sex education should cover more than safe sex, and prevention of STI's and unwanted pregnancy. It could include, for example (online) relationships, social media and parenthood. Moreover, sex education should be given preventively, in order to keep negative experiences such as sexual abuse, from happening. However, not only sex education itself should be improved, some environmental factors need to be changed as well. The people that have to teach sex education need to be properly educated and organizations need to put more effort into implementing sex education in order for it to be successful.

Program developers and researchers need to focus on developing materials more systematically with a theory- and evidence base, using a framework such as Intervention Mapping. Moreover, in the development process, people from relevant populations should be involved; effective methods for teaching sex education should be identified; and programs should be evaluated on effectiveness. 
Samenvatting 


\section{Samenvatting}

Mensen met een verstandelijke beperking ervaren meer problemen op het gebied van seksualiteit dan mensen zonder een verstandelijke beperking. Zo blijkt dat mensen met een verstandelijke beperking vergeleken met mensen zonder een verstandelijke beperking minder kennis hebben op het gebied van seksualiteit, minder seksuele ervaringen hebben, een meer negatieve attitude hebben ten opzichte van seksueel gedrag en meer ervaringen hebben met seksueel misbruik. Daarnaast geven mensen met een verstandelijke beperking ook aan dat zij moeite hebben met het vinden, vormen en onderhouden van (seksuele) relaties. Deze problemen hebben een grote invloed op de seksuele gezondheid en dus ook op de kwaliteit van leven van mensen met een verstandelijke beperking.

Veel van deze problemen worden beïnvloed door omgevingsfactoren, zoals ouders of begeleiders. Zo blijkt dat mensen met een verstandelijke beperking minder seksuele voorlichting krijgen, wat kan verklaren waarom zij weinig seksuele kennis hebben en een rol spelen bij het zichzelf slecht beschermen tegen seksueel misbruik. Daarnaast worden er aan mensen met een verstandelijke beperking strengere regels opgelegd en ervaren ze een gebrek aan privacy op het gebied van seksualiteit, wat kan verklaren waarom zij weinig mogelijkheden hebben om seksueel te experimenteren. Seksuele voorlichting kan als hulpmiddel dienen om een aantal van deze problemen, zowel op individueel als op omgevingsniveau, aan te pakken en daarmee de seksuele gezondheid van mensen met een verstandelijke beperking te bevorderen.

Het eerste onderzoek, beschreven in hoofdstuk 2, betreft het identificeren van bestaande seksuele voorlichtingsprogramma's gericht op mensen met een verstandelijke beperking in Nederland. Dit is een belangrijke eerste stap die gezet moet worden voordat er nieuw seksueel voorlichtingsmateriaal kan worden ontwikkeld. Het doel van deze studie was om de kennis die opgedaan wordt in dit onderzoek, te gebruiken voor de ontwikkeling van nieuwe materialen. Hiervoor zijn de ontwikkelaars van vijf bestaande seksuele voorlichtingsprogramma's geïnterviewd met als richtlijn Intervention Mapping. De resultaten laten zien dat de programma's niet geëvalueerd zijn, geen theoretische basis hebben, de deelnemers uit belangrijke populaties (zoals mensen met een verstandelijke beperking en begeleiders) niet betrokken zijn bij het ontwikkelingsproces en dat er geen specifieke programmadoelen geformuleerd zijn. Concluderend kan er gezegd worden dat toekomstige seksuele voorlichtingsprogramma's voor mensen met een verstandelijke beperking systematisch ontwikkeld moeten worden met als basis theorie en onderzoek. Hierbij kan men gebruik maken van een protocol zoals Intervention Mapping. Dit zal de kans vergroten dat het programma ook daadwerkelijk een positieve bijdrage levert aan de seksuele gezondheid van mensen met een verstandelijke beperking. 
Hoofdstuk 3 beschrijft de resultaten van een cross-sectionele enquête afgenomen onder een populatie van 163 begeleiders. Deze studie is uitgevoerd omdat uit de eerste studie bleek dat programmaontwikkelaars begeleiders zien als een belangrijke groep voor het geven van seksuele voorlichting. Het was daarom van belang om te onderzoeken of deze groep inderdaad geschikt is voor het geven van seksuele voorlichting. Dit vond plaats door middel van het identificeren van factoren die invloed hebben op het wel of niet geven van seksuele voorlichting. De resultaten laten zien dat 39\% van de begeleiders voorlichting geeft en dat dit voornamelijk reactief gebeurt. Dit staat haaks op het doel waarvoor seksuele voorlichtingsprogramma's ontwikkeld zijn, namelijk als hulpmiddel om preventief seksuele voorlichting te geven. Daarnaast blijkt de injunctieve sociale norm een belangrijke voorspeller te zijn voor het geven van seksuele voorlichting. Bovendien kwam naar voren dat attitudes en self-efficacy met betrekking tot seksuele voorlichting positief zijn bij zowel de groep begeleiders die voorlichting gaf als de groep begeleiders die geen voorlichting gaf. Veranderingen in het seksuele voorlichtingsgedrag van begeleiders zullen dan ook naar alle waarschijnlijkheid bewerkstelligd worden door veranderingen in de injunctieve sociale norm. Tot slot gaf meer dan de helft van de begeleiders aan niet op de hoogte te zijn van de inhoud van het beleid rondom seksualiteit binnen hun zorginstelling. Dit kan wijzen op een probleem met de implementatie van het beleid op het gebied van seksualiteit binnen de instelling.

Hoofdstuk 4 geeft een overzicht van de visies van twintig mensen met een verstandelijke beperking op diverse onderwerpen die betrekking hebben op seksualiteit, zoals seksuele voorlichting, homoseksualiteit, relaties, seks, kinderwens, sociale media, negatieve ervaringen en ondersteuning. Deze studie is uitgevoerd omdat uit de eerste studie bleek dat mensen met een verstandelijke beperking niet betrokken werden bij het ontwikkelingsproces van seksuele voorlichtingsprogramma's. Hierdoor zijn de visies van mensen met een verstandelijke beperking in de context van seksuele voorlichting nooit onderzocht. De resultaten laten zien dat de hoeveelheid seksuele voorlichting die de deelnemers hadden ontvangen beperkt is. Daarnaast bleek hun kennis op het gebied van seksuele voorlichting gelimiteerd te zijn tot de onderwerpen veilig vrijen, anticonceptie en seksueel overdraagbare aandoeningen (SOA's). Bovendien bleek deze kennis oppervlakkig te zijn en in sommige gevallen ook foutief. Tevens werd aangetoond dat de kennis over veilig vrijen niet altijd te leiden tot veilig vrij-gedrag. Tot slot gaven deelnemers aan dat ze het hebben van een relatie belangrijk vonden, voornamelijk omdat ze niet alleen wilden zijn. Concluderend kan gezegd worden dat er behoefte is aan seksuele voorlichting van hoge kwaliteit. Seksuele voorlichting zou langduriger moeten zijn, vaker gegeven moeten worden en zich moeten focussen op een verscheidenheid aan seksualiteit gerelateerde onderwerpen, waaronder (online) relaties, sociale media, pornografie en kinderwens. Daarnaast zou seksuele voorlichting zich ook moeten richten op het verbeteren van aan seksualiteit gerelateerde 
vaardigheden zoals zelfbescherming en besluitvorming. Tot slot zou een op theorie en onderzoek gebaseerd protocol, zoals Intervention Mapping, gebruikt moeten worden voor de ontwikkeling van seksueel voorlichtingsmateriaal om de kans op effectief materiaal te vergroten.

Hoofdstuk 5 presenteert de uitkomsten van een systematische review. Deze review is verricht om effectieve methodes voor het geven van seksuele voorlichting aan mensen met een verstandelijke beperking te identificeren. De eerste studie liet zien dat bestaande voorlichtingsprogramma's niet op theorie of onderzoek gebaseerd waren. Het is daarom belangrijk voor de ontwikkeling van toekomstige voorlichtingsmaterialen om methodes te identificeren die effectief zijn voor het geven van seksuele voorlichting aan mensen met een verstandelijke beperking. Twintig studies werden geïncludeerd op basis van twee criteria: het onderwerp betrof de effectiviteit van seksuele voorlichtingsprogramma's en de populatie betrof mensen met een verstandelijke beperking. Uit de resultaten bleek dat er een aantal nuttige methodes gebruikt worden voor het verbeteren van kennis, vaardigheden en attitudes. Echter kwam in de artikelen ook naar voren dat gedetailleerde omschrijvingen van de seksuele voorlichtingsmaterialen, programmadoelen en gebruikte methodes ontbraken. Concluderend kan er gezegd worden dat er aanwijzingen zijn dat er effectieve methodes zijn voor het verbeteren van kennis, vaardigheden en attitudes. Daarnaast blijft het onduidelijk onder welke omstandigheden deze methodes werken door het ontbreken van gedetailleerde omschrijvingen. Hierdoor kunnen bestaande seksuele voorlichtingsprogramma's moeilijk gerepliceerd of aangepast worden. Het is aanbevelingswaardig om een gedetailleerde beschrijving in de toekomst bij te voegen in bijvoorbeeld de vorm van een (online) bijlage.

Hoofdstuk 6, de algemene discussie levert aanbevelingen, die gebaseerd zijn op de voorgaande hoofdstukken, aan professionals die werkzaam zijn in de zorg voor mensen met een verstandelijke beperking, aan toekomstig programmaontwikkelaars en aan onderzoekers. Voor professionals die werkzaam zijn in de zorg voor mensen met een verstandelijke beperking is het belangrijk kritisch te kijken naar bestaande seksuele voorlichtingsprogramma's, totdat er programma's zijn ontwikkeld op basis van theorie en onderzoek of, nog beter, die bewezen effectief zijn. De bestaande programma's bevatten op dit moment geen specifieke doelen. Het is daarom belangrijk dat professionals achterhalen wat de wensen en behoeftes zijn van de persoon die seksuele voorlichting krijgt om vervolgens seksuele voorlichting aan te passen aan deze wensen en behoeftes. Bovendien zou seksuele voorlichting zich, naast veilig vrijen en de preventie van SOA's en ongewenste zwangerschap, ook moeten richten op andere onderwerpen zoals (online) relaties, sociale media en kinderwens. Ook is het aan te raden om seksuele voorlichting preventief te geven zodat voorkomen kan worden dat mensen negatieve ervaringen, zoals seksueel misbruik, opdoen. Het is niet alleen van belang dat seksuele voorlichting verbeterd wordt, ook omgevingsfactoren moeten veranderen. Mensen 
die seksuele voorlichting geven behoren goed opgeleid te worden en organisaties dienen ervoor zorgen dat beleid goed geïmplementeerd wordt.

Programmaontwikkelaars en onderzoekers moeten zich richten op het ontwikkelen van materiaal met een basis die is gebaseerd op theorie en onderzoek. Hierbij kunnen ze gebruik maken van bestaande protocollen, zoals Intervention Mapping. Bovendien zouden ze tijdens het ontwikkelingsproces mensen uit relevante populaties dienen te betrekken, effectieve methodes voor het geven van voorlichting te identificeren en programma's moeten evalueren. 



\section{Eenvoudige samenvatting}


Hoofdstuk 1

Waar gaat dit boek over?

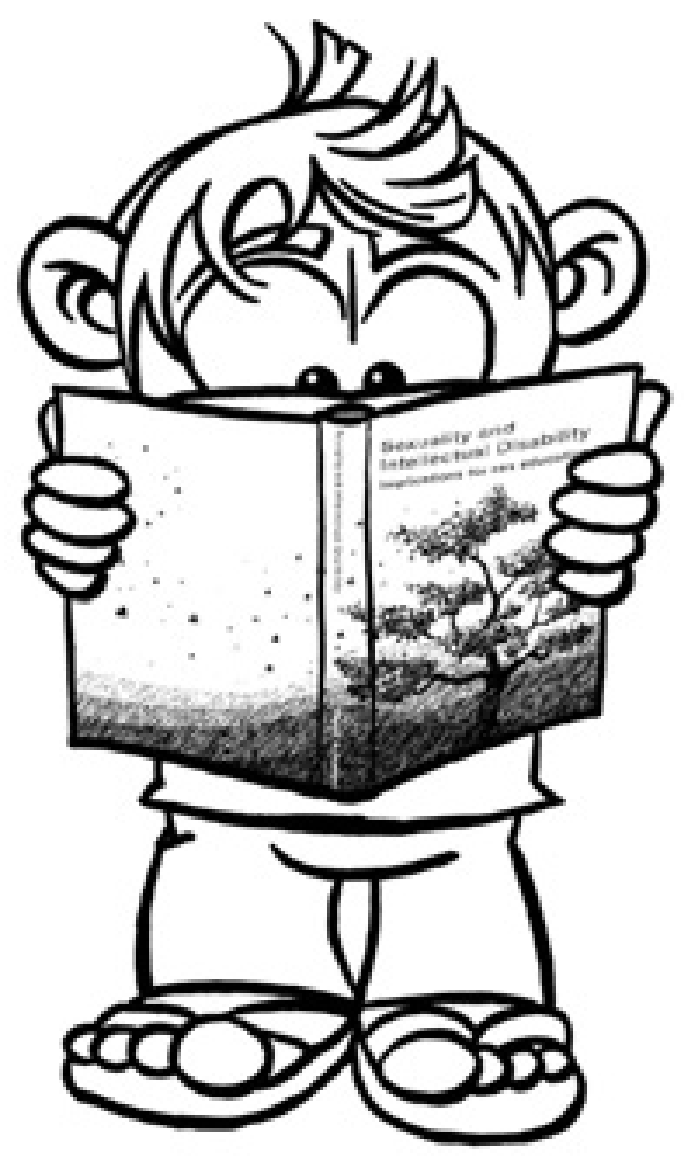


Dit boek gaat over seksualiteit en seksuele voorlichting voor mensen met een verstandelijke beperking.

\section{Waarom hebben we dit boek geschreven?}

We willen de seksuele voorlichting voor mensen met een verstandelijke beperking verbeteren.

\section{Waarom is dat belangrijk?}

Mensen met een verstandelijke beperking

- ervaren problemen op het gebied van seksualiteit;

- hebben te weinig kennis, vaardigheden en ervaringen;

- beperking hebben ook vaak negatieve ervaringen, zoals seksueel misbruik.

\section{Hoe komt dat?}

Mensen met een verstandelijke beperking

- krijgen weinig voorlichting;

- hebben problemen met het onthouden van kennis en het aanleren van vaardigheden;

- krijgen geen privacy.

Ouder en begeleiders

- praten niet over seksualiteit;

- ontmoedigen seksuele relaties;

- leggen strenge regels op.

\section{Wat kunnen we hieraan doen?}

- Goede seksuele voorlichting ontwikkelen.

- We moeten achterhalen welke problemen er zijn.

- We moeten met mensen zelf praten.

- We moeten ook met bijvoorbeeld begeleiders praten. 
Hoofdstuk 2

Bestaande seksuele voorlichtingsprogramma's

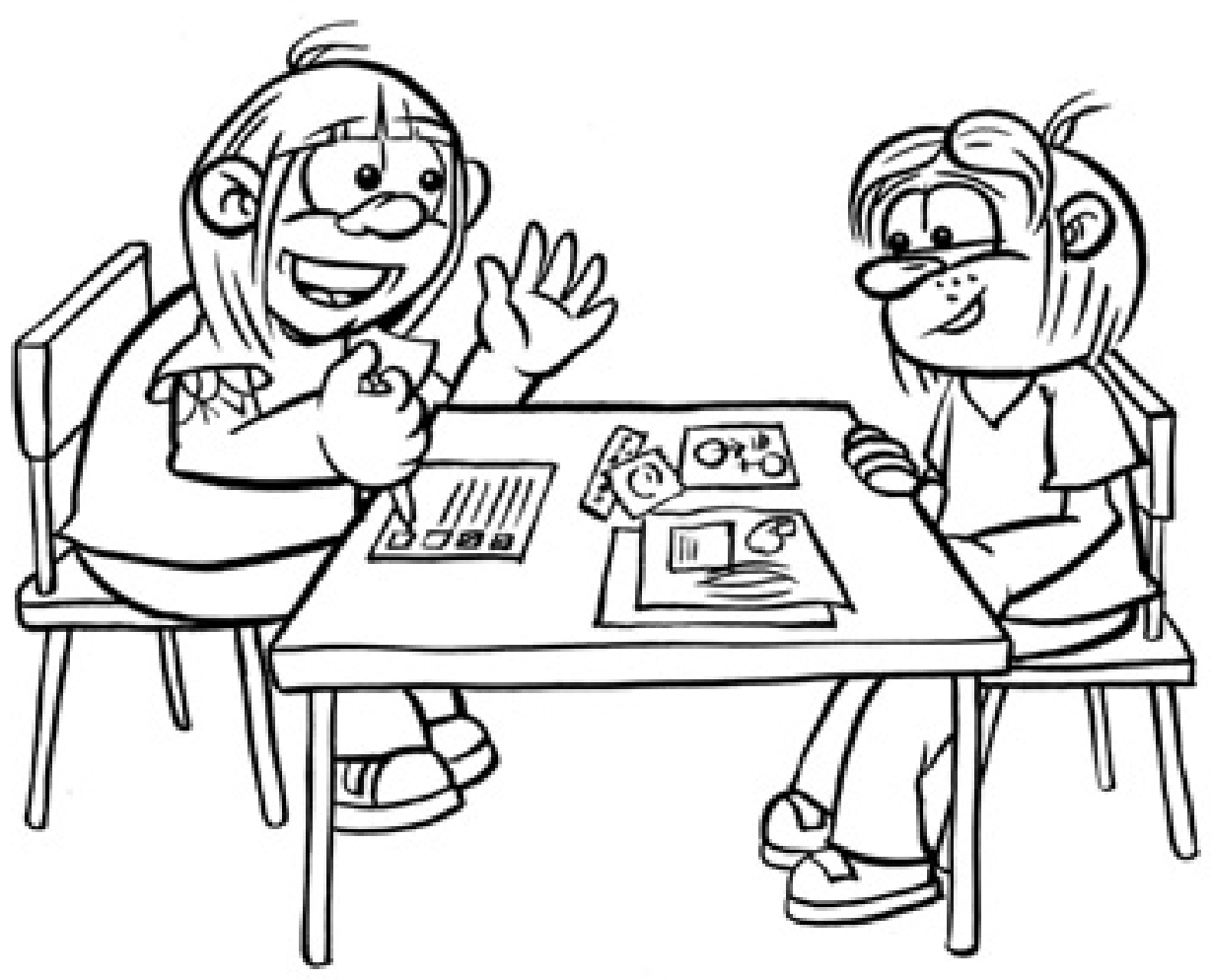




\section{Wat wilden wij te weten komen?}

- Welke seksuele voorlichtingsmaterialen zijn er voor mensen met een verstandelijke beperking?

- Hoe goed zijn deze materialen?

\section{Wat hebben wij gedaan?}

We hebben met mensen gesproken die seksuele voorlichtingsmaterialen hebben gemaakt.

\section{Wij zijn we te weten gekomen?}

- Seksuele voorlichtingsmaterialen zijn niet getest. We weten dus niet of ze echt werken.

- Mensen met een verstandelijke beperking zelf worden niet betrokken bij het ontwikkelen van het materiaal.

- Seksuele voorlichting moet beter gemaakt worden. 
Hoofdstuk 3

Seksuele voorlichting door begeleiders

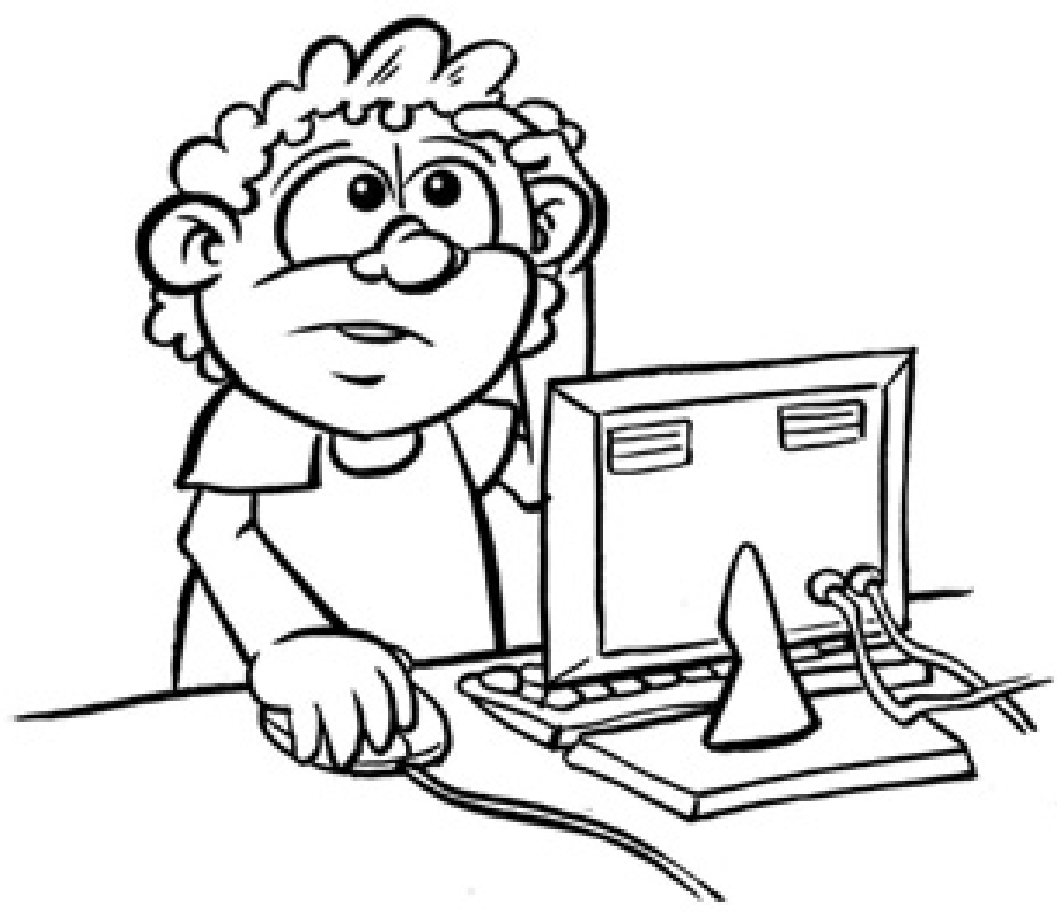




\section{Wat wilden wij te weten komen?}

- Geven begeleiders voorlichting?

- Wanneer geven ze voorlichting?

- Waarom geven ze voorlichting?

Wat hebben wij gedaan?

We hebben 163 begeleiders een vragenlijst laten invullen.

Wat zijn we te weten gekomen?

- $36 \%$ van de begeleiders geeft voorlichting.

- Ze geven pas voorlichting als er iets gebeurd is.

- Wat hun omgeving vindt van voorlichting speelt een belangrijke rol.

- Veel begeleiders kennen het beleid van de instelling op het gebied van seksualiteit niet. 
Hoofdstuk 4

Mensen met een verstandelijke beperking aan het woord

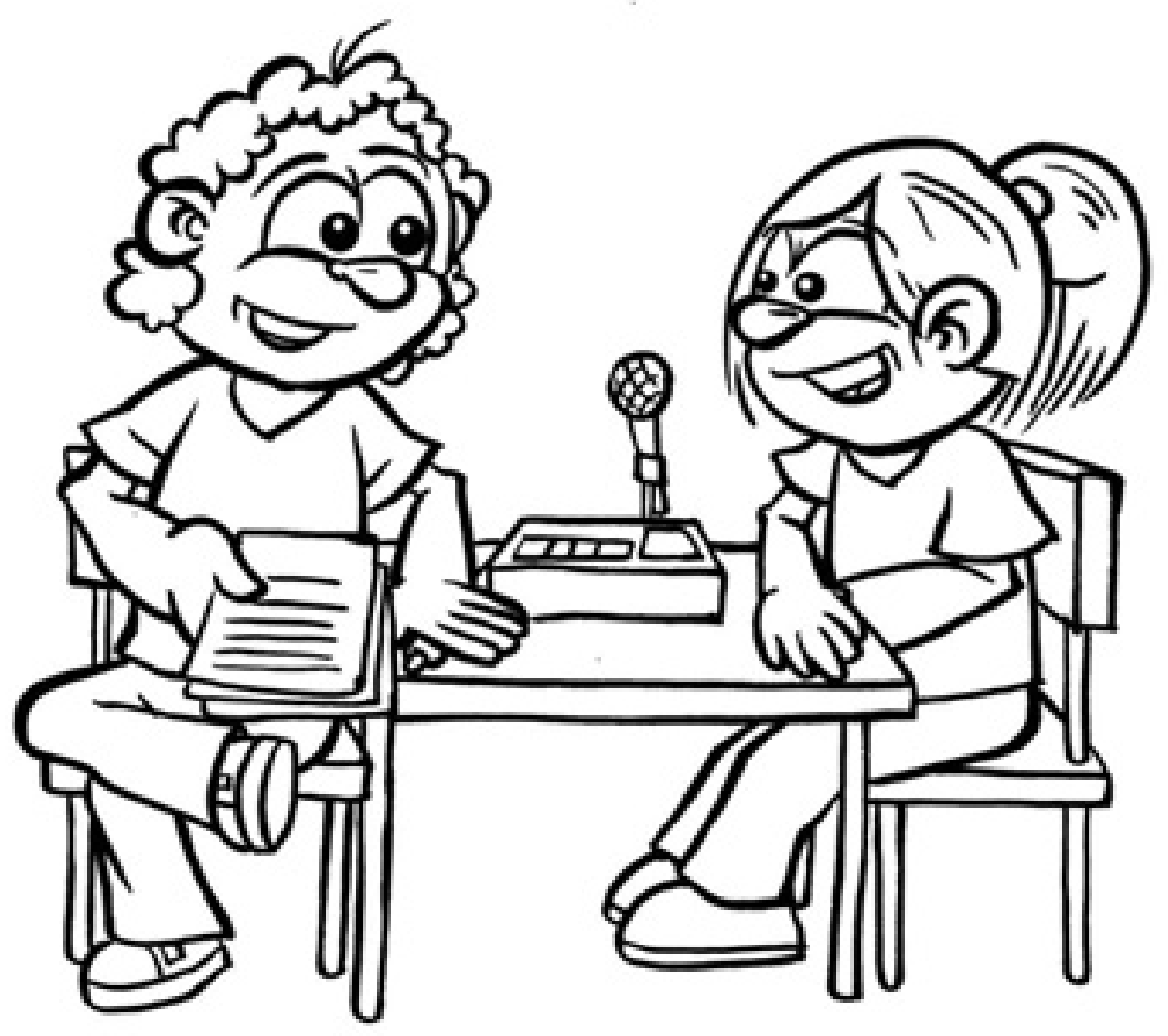




\section{Wat wilden wij te weten komen?}

- Wat weten mensen met een verstandelijke beperking over seksualiteit?

- Wat zijn hun ervaringen?

- Wat vinden zij van seksualiteit?

\section{Wat hebben wij gedaan?}

We hebben gepraat met twintig mensen met een verstandelijke beperking. We hebben gepraat over: seksuele voorlichting, homoseksualiteit, relaties, seks, kinderwens, sociale media, negatieve ervaringen en ondersteuning.

\section{Wat zijn we te weten gekomen?}

De deelnemers

- hebben niet veel seksuele voorlichting gekregen;

- weten niet genoeg over veilig vrijen, anticonceptie en SOA's;

- hebben soms foute kennis;

- vrijen niet altijd veilig;

- vertelden dat ze een relatie belangrijk vonden. Want ze wilden niet alleen zijn.

\section{Wat moet er gedaan worden?}

Seksuele voorlichting

- moet langer duren;

- moet vaker gegeven worden;

- hoort ook aandacht te besteden aan meer onderwerpen die met seks te maken hebben zoals: (online) relaties, sociale media, pornografie en kinderwens;

- moet er voor zorgen dat mensen betere beslissingen kunnen nemen. 
Hoofdstuk 5

Welke methodes werken goed voor seksuele voorlichting?

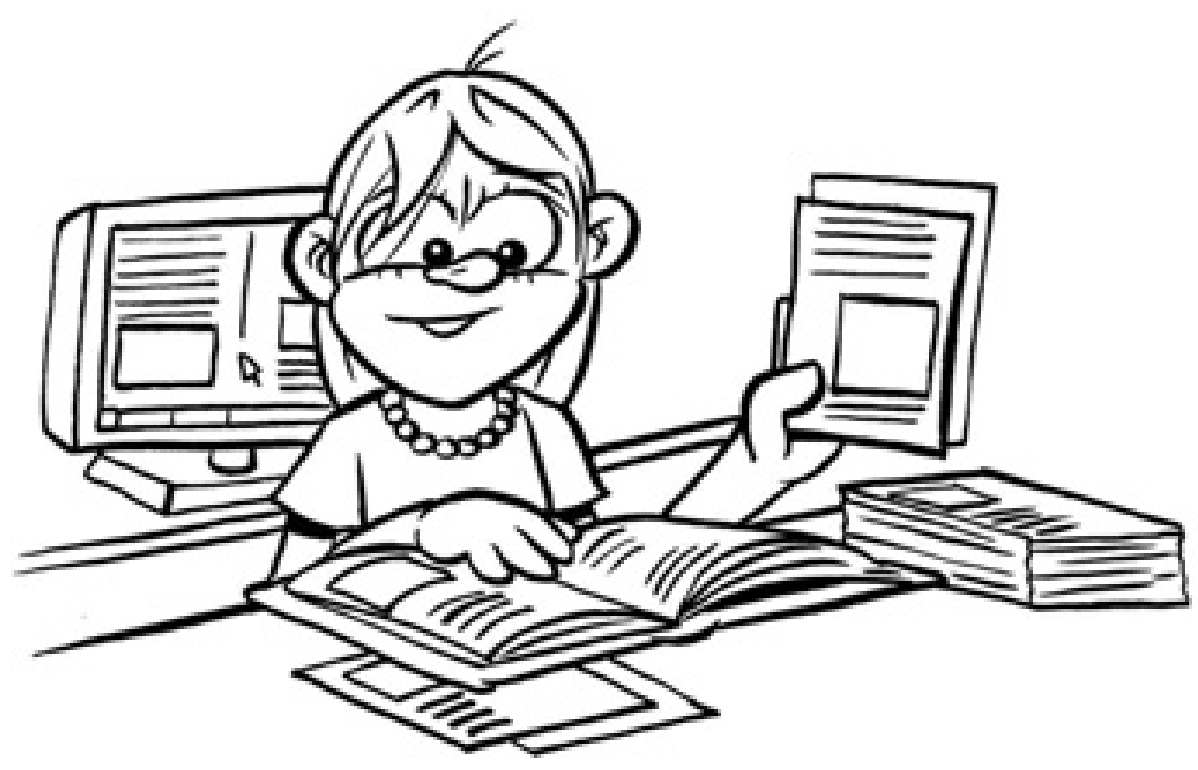




\section{Wat wilden wij te weten komen?}

We willen weten hoe we goede seksuele voorlichting kunnen maken.

\section{Wat hebben wij gedaan?}

We hebben gekeken naar onderzoeken die seksuele voorlichtingsmaterialen getest hebben.

\section{Wat zijn we te weten gekomen?}

- Sommige methoden worden in meerdere seksuele voorlichtingsmaterialen gebruikt.

- Veel onderzoeken zijn niet goed opgeschreven. We weten dan ook niet goed wat wel goed werkt. En wat niet goed werkt.

- We hebben niet heel veel geleerd van de onderzoeken. 
Hoofdstuk 6

Nadenken over wat we te weten zijn gekomen

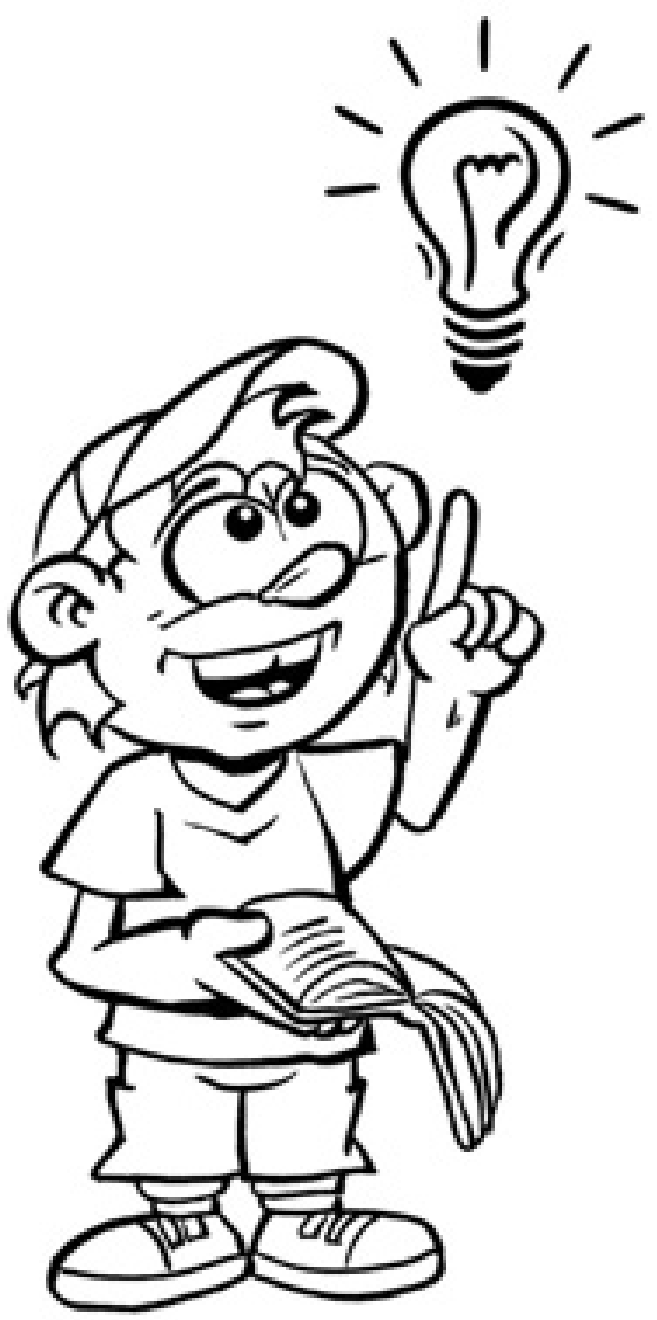




\section{Wat moeten we gaan doen?}

- Goed kijken naar hoe goed voorlichtingsmateriaal is.

- Altijd eerst vragen naar de behoeftes en wensen van de persoon die voorlichting krijgt.

- Voorlichting aanpassen op de wensen en behoeftes van de persoon die voorlichting krijgt.

- Bij voorlichting ook praten over relaties, sociale media en kinderwens.

- Voorlichting moet op tijd gegeven worden. Negatieve ervaringen en seksueel misbruik kunnen dan voorkomen worden.

- Mensen die voorlichting geven goed opleiden.

- Organisaties moeten beleid goed invoeren.

- Er moet seksueel voorlichtingsmateriaal ontwikkeld worden dat goed werkt.

- Mensen, zoals mensen met een verstandelijke beperking en begeleiders, betrekken.

- Programma's evalueren: kijken wat gewerkt heeft en wat niet. 



\section{Dankwoord}




\section{Dankwoord}

Ik wil van deze ruimte gebruik maken om mensen te bedanken die, in welke hoedanigheid dan ook, een bijdrage hebben geleverd aan de succesvolle afronding van mijn promotietraject.

Allereerst mijn paranimfen. Joke, mijn onderzoekspartner en congres/ presentatie/ shop/ reismaatje. Ik hoop dat we nog lang gaan optreden als (komisch) duo. Anne, mijn Halestorm- partner en EHPS-congres-buddie. “Don't do as we do, but do as we say!" Wat fijn dat jullie mijn paranimfjes willen zijn!!

Mijn promotieteam, Leopold en Gerjo. Wat zijn jullie toch een fijn team samen! Ik heb erg genoten en veel geleerd van onze bijeenkomsten. Ook kon ik altijd rekenen op goede raad wanneer ik die nodig had (niet dat ik die vaak nodig had natuurlijk).

Mijn (oud)kamergenootjes: Saar, wat hebben we samen leuke jaren beleefd. Jammer dat ons contact nu vooral via mail, Whatsapp en Facebook verloopt. Wie weet kom ik ooit nog eens jouw kant op! Birthe en Sanne, Saar mag dan weg zijn, maar ik heb er gelukkig wel twee superfijne/ leuke/ gezellige kamergenoten voor in de plaats gekregen!

Mijn lieve/ leuke/ behulpzame/ soms-ietwat-té-gezellige collega's bij W\&SP: Loes, Karlijn, Fraukje, Alicia, Gerda, Mariella, Philippe en Stefan.

Onze capgroepvoorzitter, mijn voormalige Bachelor- en Masterthesebegeleider en ex-voetbaltrainer: Rob.

Mijn collega's die zich (helaas) elders in het land bevinden: Marjolein, Lisette en Irene.

Mijn (helaas) oud-collega's: Gjalt-Jorn, Alvin, Hans, Siu-Hing, Sarah, Arjan en Marieke.

Mijn studie- en mede-onderzoeker-buddies: Joyce, Joep, Sil, Matthijs en Florence.

De dames van de Nederlandse les op Maasveld, die mij absoluut een betere onderzoeker hebben gemaakt: Ine, Henny, Truus, Charlotte, Nettie, Annie, Marjo, Trees, Gertruda, Lies, Gemma en Kea.

De dames van de schilderclub voor het maken van de prachtige schilderwerken, die voor een gedeelte terug te vinden zijn in dit proefschrift: : Jo, Marlies, Ria, Jet, Isabel, Romij, Mia, Vivian and WS. 
Lunet zorg, voor hun inzet op het gebied van seksuele gezondheid voor mensen met een verstandelijke beperking en het mogelijk maken van dit project.

Alle personen die meegedaan hebben aan mijn onderzoek. Zonder hun deelname zou dit proefschrift er nu niet liggen.

Remko, voor het maken van de illustraties.

Jornie, voor het maken van de prachtige omslag. Maar natuurlijk ook omdat je er altijd voor me bent.

Mijn (schoon)familie: Mam (Anita), Pap (Frits), Oma (Marie), Margo, Willem, Michael, Anneke en Pierre.

En iedereen die ik per ongeluk vergeten ben (waar ik natuurlijk achter kom zodra het boekje al gedrukt is). 



\section{Curriculum Vitae}




\section{Curriculum Vitae}

Dilana Schaafsma was born in Leeuwarden, the Netherlands on the 22nd of August 1985. After completing her secondary school education at the o.s.g. Piter Jelles Gymnasium in 2003 she studied Psychology at Maastricht University. In 2006 she started the Master Experimental Health Psychology, during which she worked as a project assistant for Prof. dr. Reinout Wiers and Dr. Katrijn Houben. In 2008 she obtained her Master's degree under the supervision of Prof. dr. Rob Ruiter en Dr. Loes Kessels. She started her Phd project, of which the results are presented in this dissertation, in March 2009 under the guidance of Prof. dr. Leopold Curfs and Prof. dr. Gerjo Kok. During her PhD project she started doing volunteer work; helping elderly women with intellectual disabilities enhance their reading and writing skills. In 2011 she got involved in the Dutch Healthy Athletes program, which is part of the Special Olympics. 